Portland State University

PDXScholar

1991

\title{
A Comparison of Socio-Political Attitudes of Older Urban Women: The 1910-1924 Cohorts
}

Elizabeth Slack Ikehara
Portland State University

Follow this and additional works at: https://pdxscholar.library.pdx.edu/open_access_etds Let us know how access to this document benefits you.

\section{Recommended Citation}

Ikehara, Elizabeth Slack, "A Comparison of Socio-Political Attitudes of Older Urban Women: The 1910-1924 Cohorts" (1991). Dissertations and Theses. Paper 1342.

https://doi.org/10.15760/etd.1341

This Dissertation is brought to you for free and open access. It has been accepted for inclusion in Dissertations and Theses by an authorized administrator of PDXScholar. Please contact us if we can make this document more accessible: pdxscholar@pdx.edu. 


\title{
A COMPARISON OF SOCIO-POLITICAL ATTITUDES \\ OF OLDER URBAN WOMEN : \\ THE 1910-1924 COHORTS
}

\author{
by
}

ELIZABETH SLACK IKEHARA

A dissertation submitted in partial fulfillment of the requirements for the degree of

\author{
DOCTOR OF PHILOSOPHY \\ in \\ URBAN STUDIES
}

Portland State University 1991 
TO THE OFEICE OF GRADUATE STUDIES:

The members of the Committee approve the dissertation of Elizabeth Slack Ikehara presented April 30, 1991.
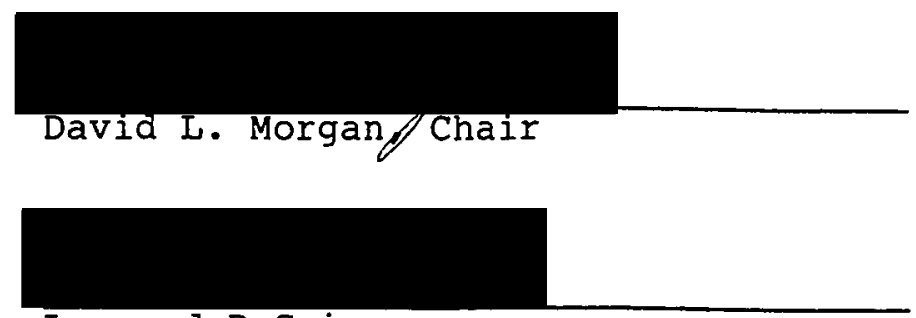

Leonard D Cain

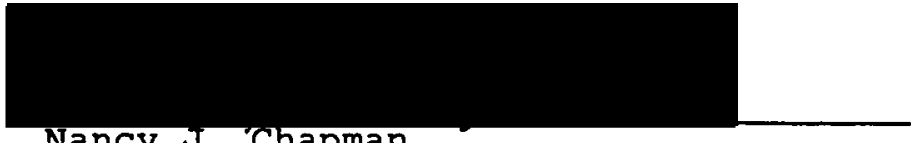

Nancy J. 'Chapman
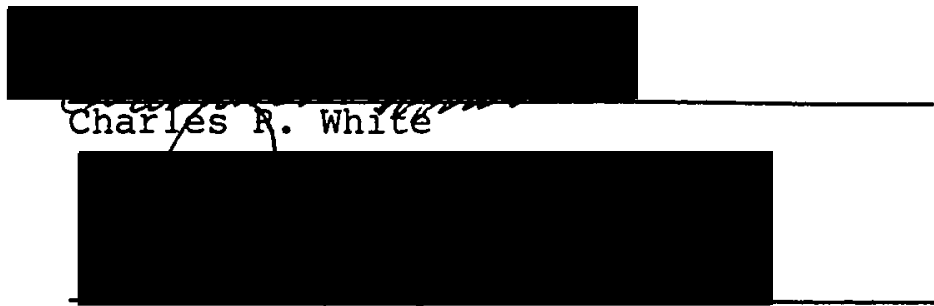

Robert W. Shotola

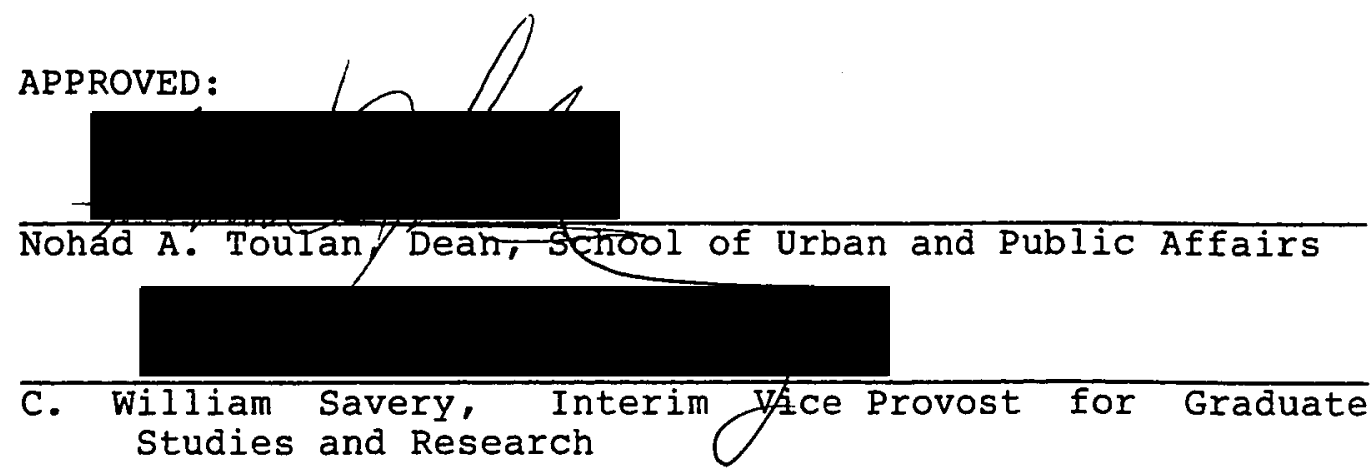


AN ABSTRACT OF THE DISSERTATION OF Elizabeth Slack Ikehara for the Doctor of Philosophy in Urban Studies presented April 30, 1991.

Title: A Comparison of Socio-Political Attitudes of Older Urban Women: the 1910-1924 Cohorts.

APPROVED BY THE MEMBERS OF THE DISSERTATION COMMITTEE:
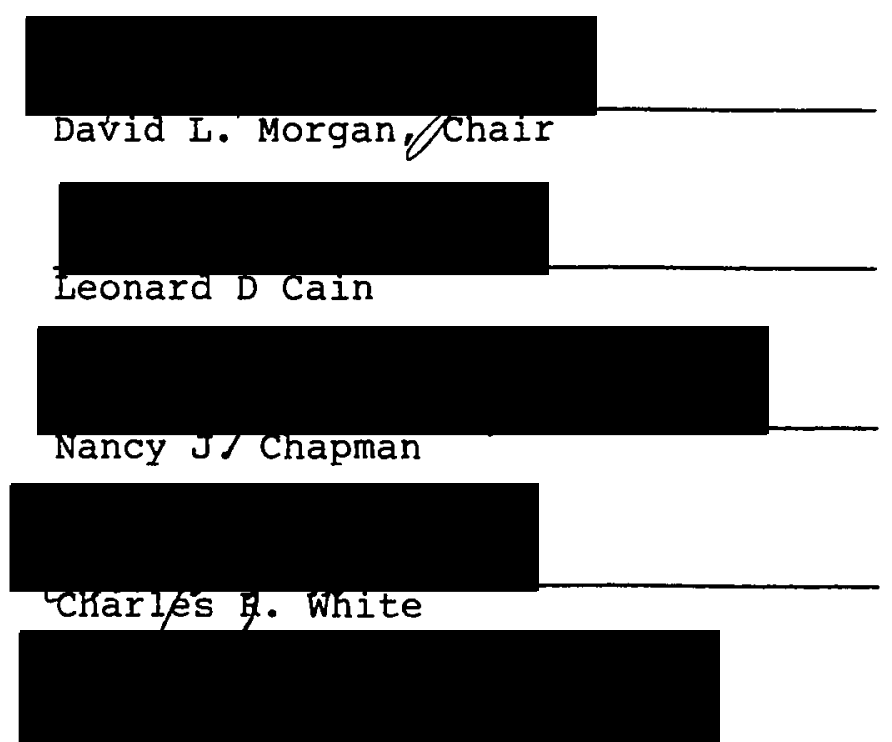

Robert w. Shotola

The central theme of this study is that because of the changing life styles and the macro-events which occurred after World War I these years were a watershed. The women born in the three five-year cohorts from 1910 through 1924 were at different stages of maturity and awareness as particular economic and political events occurred. The social 
and political climates were different for each of these cohorts of women. Therefore there would be discernible differences in attitudes and opinions among the cohorts.

A literature review indicated three models for the formation of social attitudes and political opinions. The "Personality Types" is based on the premise that attitudes formed early in life remain fixed. The "Aging/Conservative" model considers that attitudes become increasingly conservative as the person ages. This study, however, was based on the "Historical Change" model. Beliefs and attitudes may change in response to personal experiences throughout the life course.

Four research questions were developed.

1. How have macro-events affected the life experiences of women in these cohorts?

2. How have social pressures affected their experiencing of employment, matrimony, and motherhood?

3. How do the opinions of women in these three cohorts with regard to social and political issues differ and change?

4. Can differences of opinions among the women of the three cohorts be traced to dissimilarities in life experiences?

Census data literature was researched to provide background documentation on technological and demographic changes in the United States during the 20 th century.

Questions for cohort comparisons were selected from the National Opinion Research Council Surveys of 1972 through 1989. These considered individual and family demo- 
graphics, labor force participation, social attitudes, and political orientation. For the 2,814 respondents analysis was done by five-year cohorts to determine differences and by six-year periods to point out trends. Both ANOVA and Chi-square were used to verify statistical significance.

Focus group sessions, with 41 participants, met at senior centers and housing units in the Portland metropolitan area. A questionnaire completed by each participant confirmed that the focus group demographics corresponded to those of the national sample. Individual life experience time lines provided material for opening the discussion. Other discussion topics were based on differences noted among the three cohorts in the NORC data analysis. These were in the areas of education, work experience, family life patterns, political orientation, and attitudes toward societal changes.

A brief finding for each research question follows.

1. NORC data indicated that each successive cohort held increasingly liberal sociopolitical opinions, and that women of all three cohorts became less conservative over the years. The focus group participants related these changes to specific macro-events in their life experiences.

2. Focus group discussions disclosed that the 19101914 cohort realized later in life that societal pressure had limited their educational achievement. Women of the 1915-19 cohort came to understand that their acceptance of 
the homemaker role was somewhat based on societal expectations. The 1920-24 cohort were aware that discrimination in the work arena was based on societal norms of the time.

3. Analysis of both NORC data and opinions expressed in the focus groups indicated that each successive cohort was increasingly broadminded and tolerant.

4. The women participating in the focus groups exhibited an awareness of the differential effects of life experiences. They specified the effects of macro-events (chiefly the Great Depression), education, mobility, and workforce participation.

This research has tentatively confirmed that a generational watershed occurred for women born before World War I and those born after. As the women of the 1910 through 1924 cohorts matured they experienced differing social and political climates. This resulted in cohort differences. Further investigation may reveal more precise cohort boundaries for the 1910 through 1924 years. It should be remembered also that cohort boundaries for men may not coincide with those of women. 


\section{ACKNOWLEDGEMENTS}

Thanks first to the members of my committee, Dr. Leonard Cain, Dr. Nancy Chapman, Dr. Robert Shotola, Dr. Charles White, and especially to the chairman, Dr. David Morgan, for their guidance, suggestions, and patience.

A second thank you goes to the administrators of the sites of the focus group meetings for their cooperation in arranging meeting times and rooms, and also for their assistance in recruiting participants.

Finally, special thanks go to the women who so cheerfully shared their experiences and opinions during the focus group sessions. In addition to providing qualitative data, the meetings have contributed to my store of happy memories. 
TABLE OF CONTENTS

PAGE

ACKNOWLEDGEMENTS. . . . . . . . . . . . . . . . . iii LIST OF TABLES. . . . . . . . . . . . . . . . . . vi vi LIST OF FIGURES • • • • • • • • • • • • • • • • • viii CHAPTER

I INTRODUCTION TO THE PROBLEM. . . . . . . . . . 1 Watershed Hypothesis. . . . . . . . . 1 Cohort and Period............. 4 Research Questions. . . . . . . . . 6

II REVIEW OF IITERATURE • . • . . • • . • . . • . 11 Introduction. . . . . . . . . . . . 11 Personality Types . . . . . . . . . 12 Aging and Conservatism. . . . . . . . . 14 Historical Change . . . . . . . . 18 Additional Historical Background. . . . . 26

II METHODOLOGY AND NORC DATA ANALYSIS . . . . . . 28 Organization of the Report. . . . . . 28 Collection and Analysis of Quantitative Data. 29 Conclusion. . . . . . . . . . . 81 
IV FOCUS GROUP DATA ANALYSIS. . . . . . . . . 85

Purpose of Focus Groups . . . . . . . 85

Recruitment and Procedure . . . . . 86

Focus Group Sessions. . . . . . . . . 88

Differences in Focus Group Meetings . . . 126

$\mathrm{V}$ CONCLUSIONS AND IMPIICATIONS . . . . . . . 128

Introduction. . . . . . . . . . . 128

Conclusions . . . . . . . . . . 129

Implications. . ... . . . . . . . 138

Future Research . . . . . . . . 139

REFERENCES. . . . . . . . . . . . . . . 143 APPENDICES

A HISTORICAL DEVELOPMENTS. . . . . . . . . 150

B SAMPLE OF MEETING NOTICE . . . . . . . . . 162

C INFORMED CONSENT . . . . . . . . . . . . . 164

D FOCUS GROUP QUESTIONNAIRE. . . . . . . . 166

E TIME LINE FORM . . . . . . . . . . . 168

F THANK YOU NOTE ................ 170

G FOCUS GROUP DEMOGRAPHICS . . . . . . . . . 172

H TALLY OF TIME LINE EVENTS. . . . . . . . . . 175

I JOB DISCRIMINATION REPORTS . . . . . . . 178 
I Female NORC Respondents by Cohort and Period . 30

II Age Range of Cohorts by Periods. . . . . 30

III Type of Place Lived in when 16 Years old . . 34

IV Family Background Variables Showing Statistically Significant Differences by Cohort and/or Interaction. . . . . 37

V Marital Status by Cohort Mean Percentages 1972-1989....... 40

VI Occupations of Respondents . . . . . . . . 44

VII Analysis of Membership in Organizations. . . 51

VII Adult Life Variables Showing Statistically Significant Differences by Cohort and/or Interaction. . . . . 55

IX Social Attitude Variables Showing Statistically Significant Differences by Cohort and/or Interaction. . . . . 67

$\mathrm{X}$ Attitude Toward Three Activities of Four Selected Groups . . . . . . . . 73

XI Attitude Toward Four Selected Groups for Three Activities. ............ 73

XII Political Opinion Variables Showing Statistically Significant Differences by Cohort and/or Interaction. . . . 80

XIII Focus Group Participants by Site and Cohort. - 87

XIV Summary of Two Events Selected From the Time Iine.............. 89 
XV Labor Force Participation Rates by Marital Status, Sex, Age........... 158

XVI Percent Distribution of Ever-Married Women

by Number of Children Ever Born . . . 160 


\section{IIST OF FIGURES}

1. Conceptual model guiding the selection

of variables............. . 3

2. Labor force status by period and cohort . . 46

3. Family income in 1989 constant dollars. . . 47

4. Perception of health status.... . . . 54

5. Summary of means of opinions on permitting abortion in seven different circumstances 59

6. Summary of opinions about three types of sexual activity.......... . 62

7. Opinions on whether police permits should be required to purchase a gun. . . . . . 74

8. Opinions on spending for defense. . . . . 77

9. Conceptual model with important variables . . 136 
CHAPTER I

INTRODUCTION TO THE PROBLEM

\section{WATERSHED HYPOTHESIS}

All societies experience slow incremental changes in the mood and attitudes of the people. Cohort analysis, however, attempts to emphasize when changes take place and to highlight dramatic shifts (Cain, 1967; Kammen, 197980). Thus, the purpose of this study of urbar. women of the 1910-24 birth cohorts is to explore the watershed, or hinge, theory that major historical events and rapid technological changes can be the basis for significant differences in cohort experiences and attitudes.

The hypothesis is that, because of historical events and technological developments which occurrec roughly from World War I through world War II, the women of each of the three Eive-year cohorts from 1910 through 1924 differ markedly in life experiences. These women vere at different stages of maturity and awareness as particular economic and political events occurred. Hence they may differ in socio-political attitudes. Briefly, the hypothesis is that a generational watershed occurred between women born before World war I and those born after. 
In the conceptual model for this study (Figure 1) historic events may be considered as independent variables while opinions and attitudes are dependent variables. How ever, life experiences would serve as intervening variables. The influence of historic events on the development or modification of social and political attitudes will vary because of the individual woman's life situation at the time the historic event was occurring. This might be defined as a "how" and "why" study, generalizable to theoretical propositions rather than to populations.

The emphasis on studying women born around the World War I years is because of speculation that key historic events following these years have resulted in many changes in life experiences for women. For centuries males have gone to daily work as breadwinners, participated in armed conflicts, and traveled the world on crusades, searching for new lands, or seeking fame and fortune. It has been since World War I that women have participated in these activities to a greater degree and in increasing numbers.

Also, there is, on the popular level, a stereotype of each generation of old people as persons with conservative opinions. That is, they tend to favor the preservation of the existing order and to regard proposals for change with distrust. Liberals, on the other hand, express social or political views or policies that favor non-revolutionary progress and reform. 


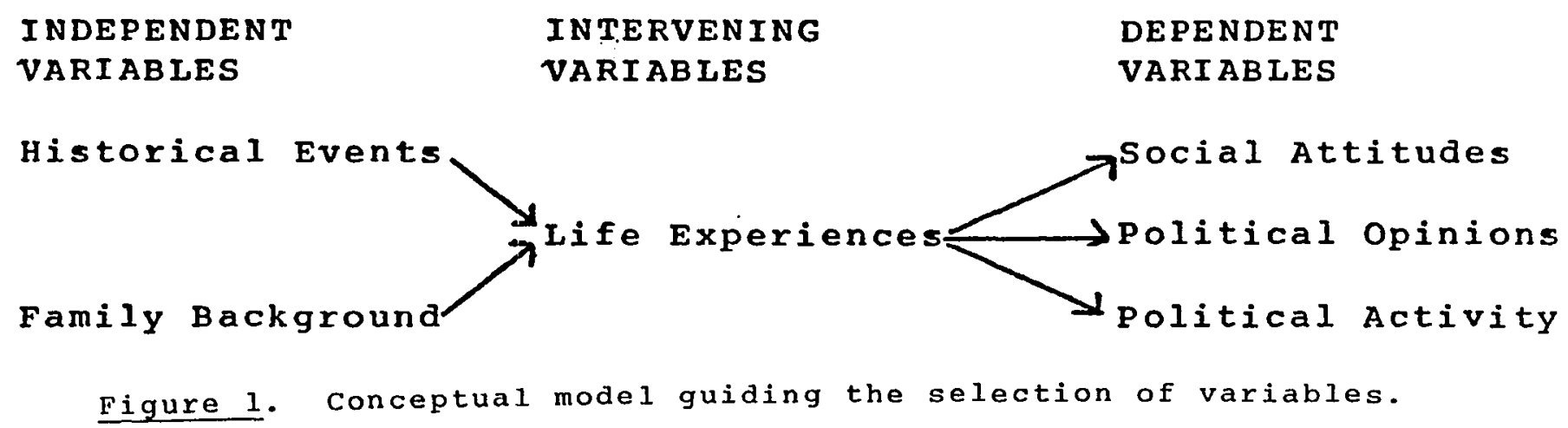


Researchers have attempted to ascertain whether the elderly become more dogmatic, rigid, and conservative with the passage of time per se or whether life experience factors influence attitudes and opinions. If life experience factors do influence attitudes and opinions, older persons would not necessarily become more conservative in their outlooks but could even become more diverse.

\section{COHORT AND PERIOD}

Quite often study reports group together all persons over the age of 60 or 65 . While means are reported, often there is no indication of the range. However, with increasing longevity and a drop in the retirement age there seems to be appearing a division between the young-old, aged 55-75, and the old-old, 75 and over (Neugarten, 1974). Younger persons are divided into many groups such as infant, pre-school, and up through young adult to adult. While these divisions are based on developmental stages there are also cohort effects. With older persons it would seem possible that life experiences would make for more heterogeneity than is encountered in younger cohorts.

Maddox (1979) gives an explanation of the terms age, period, and cohort used in research dealing with the life course. Age has at least three connotations: biological, psychological, and sociological. Period, the year(s) of 
the research measurement usually has political events as the referents. If variation is due to period effects there will be no variation by age at any period, and the variation from each period to the next will be the same at each age level and in each cohort.

Demographically the definition of cohort is straightforward: persons born at approximately the same time constitute a cohort whose size and composition can be described. Cohorts tend to be defined broadly and for convenience (e.g. persons born in five-year periods). Evolving attributes of successive cohorts may be traced through successive stages of the life course: childhood, adolescence, adulthood, and old age.

For this study arbitrary five-year cohorts have been established because census data and other statistical reports are usually based on five- or ten-year intervals which conform to the start of each century. It may be that a generational cohort could encompass seven or twelve years. Or a generational cohort might span from 1917-1924 rather than the statistically convenient 1915-19. Generally studies report that income, education, or marital status are variables which can be used to predict a particular attitude. There seems to be little probing of the individual's own assessment of the importance of these and other variables in the development of attitudes and opinions. 
Period effect studies concentrate on overall attitudinal changes but do not have much to say about the individual reaction to historical events. Either economic status or time of birth may cause events to be viewed from different perspectives.

From a consideration of these elements four research questions evolved. As explained in the following section, these research questions could be explored in three stages.

\section{RESEARCH QUESTIONS}

There will be four major questions to be compared and contrasted for women born in the three cohorts of these years (1910 through 1924). The process of seeking answers to these four questions divides roughly into three stages of investigation.

The first stage is to characterize the different life experiences of the three cohorts. Two of the research questions are utilized to reveal any notable differences.

1. How have macro-events differentially affected the life experiences of women in these cohorts?

Macro-events may include the depression of the 1930s, World War II, or the Vietnam conflict.

2. How have social pressures differentially affected their experiencing of employment, matrimony, and motherhood?

Examples of social pressures might be government propaganda to urge women in and out of the labor force, or commercial advertising for cosmetics, household appliances, 
or cigarettes. These two questions also give rise to a hypothesis that the women born in the later cohorts are more politically liberal and active than those women born in the years immediately preceding world War I.

stage two in the process is to test this hypothesis and ascertain what differences have been produced by variations in life experiences. The third research question is designed to investigate this issue.

3. How do the opinions of women in these three cohorts with regard to social and political issues differ and change?

This analysis could include topics such as the role of women in the home and workplace, and funding for programs such as Social Security and Medicare/Medicaid.

The final stage in the investigation is to gain an understanding of why any differences in attitudes and opinions occurred among the three cohorts. This goal is stated in Research Question 4.

4. Can differences of opinions among the women of the three cohorts be traced to dissimilarities in life experiences?

More details regarding the methods used in the exploration of Research Questions 3 and 4 will be presented in the Research Data section of this chapter.

Chapter II presents a review of the literature related to three models of the formation of political beliefs and social attitudes. Of particular interest are several 
studies which discuss cohort effects as a result of the intersection of personal and national history.

Appendix A includes a summary of demographic changes and historical events occurring in the United States during the 20th century. An indication of the approximate age of each cohort at the time of the event is noted.

\section{$\underline{\text { Research Data }}$}

Research data will be presented in Chapters III and IV. Quantitative data from the National Opinion Research Council (NORC) surveys from 1972-1989 will be analyzed by Cohort and by Interaction of Cohort and Period in Chapter III. Qualitative data obtained by focus group sessions will then be discussed in Chapter IV.

NORC data from the surveys from 1972-1989 were used to obtain a large sample: 2814 female respondents born between 1910 and 1924. This also provided a standardized survey format for all sections of the United States, with continuity across the years.

Information from the NORC questions was recoded by Cohorts of 1910-14, 1915-19, and 1920-24; and by Periods of 1972-77, 1978-83, and 1984-89. Variables were selected to provide for comparison of early background and adult life demographic information. Other variables selected related to attitudes on social issues and opinions on political questions as well as political activity. Analysis was made by frequencies, chi-square, and Anova. 
The first intent of this analysis was to ascertain if there were statistically significant differences among the cohorts. A second purpose was to formulate discussion topics and questions for use in focus groups: to uncover why these differences existed--what had been the basis for attitude/opinion formation.

As will be reported in Chapter IV, the goal of the focus group discussions was to find out why differences existed among the three cohorts. That is, what were the women's differential perceptions of the influence of historical and personal life events on their activities and opinion development.

To accomplish this goal three focus groups of 5-6 women were set up for each of the three cohorts; nine sessions in all. Pilot testing was done with interviews and a mixed-cohort focus group session. Recruitment was through senior housing complexes, senior centers, and other senior organizations. At each session the women were asked to complete a one-page demographic questionnaire, fill in a time line of personal and national events of significance in their lives and discuss some of these events. Further discussion centered on issues which showed statistically significant differences when the NORC data were analyzed. Information from the tapes of these sessions was then categorized and comparisons made among the cohorts. 
Chapter IV concludes with a summary interrelating the findings from the NORC quantitative data and the focus group qualitative data. This is a summary not only of the differences or similarities among the cohorts, but also of the interrelationship of these differences with the women's perception of the comparative impact of macro-events and personal life experiences.

Findings and Conclusions

Chapter $\mathrm{V}$ summarizes the research findings and presents conclusions regarding the hypothesis that a generational watershed occurred between women born before world War I and those born later. The events which occurred after World War I and the technological developments which had the greatest differential impact on the lives and outlook of these cohorts of women are noted.

Finally, suggestions are made regarding possibilities for further research in the area of short-span cohort (i.e. 5-year intervall variability. 
CHAPTER II

REVIEW OF LITERATURE

INTRODUCTION

There has been much scholarly research which relates to the social attitudes and political orientation of the "senior citizen." This literature indicates that there are three major models which attempt to explain the development of political beliefs and social attitudes.

One model is that attitudes are formed during adolescence and early adulthood and stay largely fixed thereafter. This model might be called "Personality Types."

A second model considers that attitudes become increasingly conservative as people become older. This might be labeled the "Aging/Conservative" model.

The third model of the formation of political beliefs and social attitudes is based on the premise that attitudes change in response to personal experiences throughout the life course. The time of birth may cause events to be viewed from different perspectives, thus forming differential cohort attitudes. "Historical Change" might be a suitable label. This model is the one upon which this comparative study of women in the 1910-24 cohorts was based. 
PERSONALITY TYPES

During the 1950 s and 1960 s research on the development of social attitudes and political opinions suggested that these were a result of personality types. Three personality traits often suggested as typical of the older person were authoritarianism, dogmatism, and rigidity. A brief discussion of these three personality types follows.

\section{Authoritarianism}

Janowitz and Marvick (1953) found that younger people and those with more education tended to be low authoritarians. T. W. Adorno had previously noted (1950) that the authoritarianism syndrome had only a moderately close relation to political economic conservatism. Authoritarian pre-dispositions seemed to be more closely linked with reactionary and radical positions than with a continuum from conservatism to liberalism.

\section{Dogmatism}

Milton Rokeach (1956) suggested that political and religious dogmatism is an alternative to the authoritarian personality. Dogmatism is defined as a relatively closed cognitive organization of beliefs and disbeliefs about reality, organized around a central set of beliefs about absolute authority. This set of beliefs provides a framework for patterns of intolerance toward others. Dogmatism 
has a further reference to the intolerant manner in which ideas and beliefs are communicated to others.

A later study (Hanson, 1968) supports Rokeach's conclusion that dogmatism taps general authoritarianism but authoritarianism measures only rightist authoritarianism. Zagona and zurcher (1965) in working with the dogmatism scale noted that the dogmatic individual is leader oriented and prefers structured, routine situations.

\section{Rigidity}

Rigidity refers to the resistance to change of single beliefs or habits. Rigid thinking should be expected to lead to difficulties in thinking analytically (Rokeach, 1956, 1960) . Conventional stereotypes of rigid behavior include people of low intelligence acting in a rigid manner because they see only certain aspects of a situation, and the elderly being unwilling to change long-established patterns of behavior. However, some people of all ages display an orderly, detail-loving nature (Chown, 1960, 1961).

In discussing attitude change, especially among the elderly, Sears (1981) points out that attitudes acquired during the impressionable years of childhood through late adolescence and early adulthood are apt to persist because an affective "mass" is built up over time. Sears also indicates that little is known about how private life situations cause changes in political attitudes. 
The literature related to "Personality Types" indicates that attitudes are developed based on intelligence, economic class, or personal habits and become firmly fixed during adolescence and early adulthood. The implication for this model is that analyses of attitude and opinion variables would show no significant effects by age, cohort, period, or interaction.

\section{AGING AND CONSERVATISM}

The second model which attempts to explain the development of sociopolitical attitudes assumes that attitudos become increasingly conservative as a person ages. This model will be considered next.

One of the stereotypes about aging has been the belief that older people tend toward conservatism in political and social attitudes. A comparison of sociopolitical attitudes of high school students and adults (Lorge and Helfant, 1953) led to the conclusion that a person's age, in and of itself, is of no value in estimating sociopolitical verbal attitudes. This conclusion is in agreement with an earlier study by Pollak (1943).

Generational Differences

Researchers no longer seize upon the rigidity of opinion or "fogyism" apparent among some old people as a causal explanation for differences between the young and old. Generational differences might be the effect of being 
at different points in the life cycle or of the impact of being socialized at different times--life course timing differences. Cohort differences may reflect changes in cultural norms (Achenbaum, 1978; Stewart and Healy, 1989).

In The American Voter (Campbell, et al, 1964) the point is made that party choice depends primarily upon social transmission from the family or early reference groups. It is pointed out that movement to a different region, change in occupational status, and additional education can all have effects on the strength of party identification.

In general, when a large variety of social characteristics are taken into account there are no residual differences in partisanship between men and women. However, in the 1950s the husband usually sifted the information and the wife abided by his ultimate decision. A sense of some political competency in the political world was less adequately transmitted to women. Decades after passage of the 19th Amendment many wives wished to refer interviews to their husbands. "I don't know anything about politics--I thought that business was for men, anyway." (Campbell, 1964,2311 .

A more recent (1945-1969) and comprehensive study (Glenn and Hefner, 1972) concluded rather that Republican identification did not decline as much in the aging cohorts as it did in the total adult population. The high per- 
centage of Republicans in the older cohorts, who received their socialization prior to the Great Depression, was apparently a cohort rather than an age effect.

\section{Historical Trends}

Lipset and Ladd (1971) state that the elderly do not become more conservative. As persons mature they usually become more moderate, as against an earlier position closer to the extreme. However, because political attitudes among American college generations tend toward a more liberal position over time, older cohorts, in comparison, appear to be more conservative.

National surveys conducted from 1950-1970 (when the 1910-1924 women were of voting age) studied changes in political attitudes, beliefs, and behavior among American voters (Nie, et al, 1979). The pattern of changes between conservative and liberal attitudes on questions of economic welfare, size of government, black welfare, school integration, and foreign policy were further analyzed by various categories. The white south and border south became more conservative during this twenty-year period while Blacks and Jews became more liberal. Catholics became less liberal. Among white Protestants (not in the south) the lower middle class became more conservative while the affluent educated became more liberal. There was no breakdown indicating trends for the elderly or for women. 
More recently Kenney (1988) reported on two studies conducted in Vermont in which respondents identified with a political party. When the Independent option was announced, a much higher percentage of younger than older respondents chose the option. When the Independent option was not voiced, across four age categories the percent of Vermonters claiming independence increased gradually from 34.4 percent among those 18 to 30 to 41.0 percent among those over 60 .

Two possibilities are pointed out by the literature on the "Aging and Conservatism" model. One is that, possibly because of the physiological and psychological aging process, older persons' opinions shift toward the conservative end of a continuum. Therefore, in analyzing data "age" would show the greatest statistical significance.

The second possibility is that the elderly do not become more conservative but retain the attitudes of their early adult years. If society becomes more liberal over time each cohort would appear to become conservative. In this case, analysis of data would show statistical significance only by cohort with no effects by age or period. Also, the cohort mean, on any given variable, would remain the same across periods.

It is interesting to note that most of the research reports, from the 1940 s through the 1980s, which discuss the relationship of aging to conservatism actually seem to 
dispute the popular Aging/Conservative stereotype and yet this myth often prevails in the public mind.

\section{HISTORICAL CHANGE}

This section reviews literature related to the third, Historical Change, model of the formation of social attitudes and political opinions. This model, which started to supersede the Personality Types model in the 1970s, postulates that attitudes may change in response to personal experience throughout the life course.

Lipset and Ladd (1971) consider the impact of historical events such as the Great Depression, the Munich appeasement of Hitler, and World War II. Obviously the rich and poor, factory workers and professionals, blacks and whites, males and females, for example, do not experience events in the same way. For example, a fifteen year old and a twenty-five year old may experience a war quite differently. Only in a demographic sense do people in the same age group constitute a homogeneous unit.

This point of view is substantiated in a study of older women (Sedney, 1985-86). The women felt they had become more flexible over the years because of education, increased maturity, getting to know men more closely, social change, dissatisfaction with the traditional female role, and demands at work. 
Because this model is the one on which this study is based, the review of literature in this Historic Change section is further divided into four sub-topics: Openness to Experience, Political and Social Attitudes, Influence of Personal Concerns, and Cohort Effects.

Openness to Experience

The domain of openness to experience has been identified as a third major dimension to supplement the established personality dimensions of anxiety-adjustment and introversion-extroversion (Costa and McCrae, 1978). It was suggested that this open-closed system of thought, values, and ideology might be part of the liberal thinking domain of personality analysis. A domain of openness to experience could be of importance to the field of gerontology. Adjustment to aging and to a rapidly changing culture might be easiest for open individuals.

A discussion of life-span developmental psychology (Dannefer, 1984) points out that when cohort demarcation is treated as deriving from historical variations each cohort will have a "normative" pattern. Historical variation is seen as important, but variations in the individual experience may not be considered. This can result in intracohort diversity being treated as error variation.

It is interesting that a literature search located only one study on conservative/liberal attitudes of women. This study (Glamser, 1974) was based on 118 faculty wives 
aged 20 to 65 . The conclusion was that there was no marked conservatism on the part of older women lages 20-29, 68; 50-65, 108) but there was a high proportion of liberal attitudes on the part of the younger women lages 20-29, 55\%; 50-65, 218). There was no analysis of the social and political attitudes of women older than 65 .

Political and Social Attitudes

At least thirty years ago it was noted that the growing population proportion of older people, their high voting record, and their higher motivation toward political participation underscored the real as well as potential influence older persons could have in American politics (Schmidhauser, 1958). The assumption was that the majority of persons over the age of 65 hold the same political opinions and will vote as a bloc.

That attitudinal differences between age groups were less impressive than those within age groups was noted by Angus Campbell (1971). He stated that there was little evidence of systematic movement toward conservatism as people move through the life course. People of all ages respond to political issues and events in terms of their early socialization and their immediate social and economic circumstances. Age groups may be mobilized in support of specific social action they see to be in their own personal or family interest, but age is not likely to become the basis of other political movements. 
As society changes, those attitudes which are becoming less prevalent may be considered conservative and those which are becoming more prevalent are considered liberal. Which specific attitude is considered conservative is relative to time and place; yesterday's liberalism may tend to be today's conservatism (Glenn, 1974).

In their longitudinal study of the political/economic attitudes of women who attended Bennington College (Vermont) during the 1930s and 1940s, Alwin, Cohen, and Newcomb (1990) concluded that the women acquired their basic sociopolitical orientations during late adolescence and early adulthood. Attitudes developed by the women while in college differed from those of their parents.

An interdependent relationship between attitudes and supportive social networks, including spouses, was noted. The most attitude change occurred when the post-collegiate social environment was less congruent with college attitudes. Apparently the reference group is important in mediating the impact of historical events and social change.

When the Bennington study considered children as an important source of potential attitude persistence and change they found that attitude change was greatest among those women most exposed to children of the 1960 s generation. Considerably more attitude persistence was found among those with least exposure to children born between 1940 and 1954. Although these results were not judged to 
be statistically significant, Alwin, et al, suggested that the experiences of children may have a substantial influence on parental attitudes.

\section{Influence of Personal Concerns}

An analysis of political surveys conducted in the period from 1940 to 1970 (Douglass, Cleveland, and Maddox, $1974)$ found that only at the most immediate political level, the family level, did age enter at all as a significant determinant of political attitudes. For example, the older cohorts, and adult children who might be responsible for their parents, would view measures related to Social Security and Medicare from the point of view of how they would be affected financially by any changes. Age probably would not be a significant factor in shaping attitudes on issues such as spending for national defense. The results indicated that time of testing and the political/economic/ social climate of the time are much more important determinants of political attitude than the age or generation membership of the individual.

A study by Cutler \& Kaufman (1975) agreed with Douglass in stating that the elderly cohorts were less conservative on certain issues than the younger cohorts, especially on issues directly affecting themselves such as health care, housing, and income. Thus one should not conclude that the conservatism of elderly cohorts on such 
issues as the federal government's involvement in the economy and society is a consequence of the aging process. In some instances it may be to the specific advantage of older persons to favor such federal activity (Birren, 1983). This self-interest may be mistaken as liberalism.

However, in an analysis of national surveys from 197386 it was found that responses to a series of vignettes depicting low-income families with young children and elderly women living alone showed the elderly respondents slightly more supportive than average of transfers to low-income families with children and less supportive than average of transfers to low-income members of their own cohort. Elderly respondents appear more generous once their frugal notions of what it takes to "get along" are taken into account. There were more income-based than age-based differences in supportiveness (Ponza, et al, 1988).

The possible influence of personal concerns on interest in politics is reinforced by a study carried out in the late 1960s (Glenn, 1980). Age differences in reported interest in politics had virtually disappeared by the late 1960s. The data indicated that from 1960 to 1968 reported interest in politics declined in all the cohorts (the largest changes occurred in the two oldest cohorts: ages 61-68 and 69-76) possibly due to period influences. Yet reported interest did not decline at the youngest adult level (ages 21-28) which would be expected if there had 
been general period influences toward less interest in politics.

There is no evidence to support the hypothesis that the aging are less likely to hold and express opinions (Glenn, 1969). When "education" is controlled, older persons are less prone to "no opinion" responses than are younger persons. Cohort analysis revealed increased willingness to express opinions with aging and also no decline in voting behavior until physical disabilities developed. Related to this is the finding (Turner and Kahn, 1974) that older persons may be less biased by candidate preference in evaluating campaign issues as favoring their candidate. That is, the younger persons surveyed tended to perceive their preferred candidate favorably on most issues, whereas the older respondents distributed favorable ratings between candidates with apparent objectivity.

\section{Cohort Effect}

In this context it should be noted that in the studies previously cited Lipset, page 18; Dannefer, page 19; and Campbel1, page 20; are referring to what have been termed "generation-units" and "Late Adulthood" (Age 60+). References to intra-cohort differences being greater than intercohort differences are not in terms of five-year cohorts. However, a point to consider is that while different cohorts may appear to hold similar opinions or consider the same national or world events as important the reasons 
prompting the choices may vary greatly. Stewart and Healy (1989) found that the impact of the expanded work role for women in World War II and the impact of the contracted one in the postwar period were quite different depending on the age of the woman at the time. Pro-family pressures after World War II, to produce families for returning soldiers, were strongest for the women born after World War I. These post-World War II anti-work, pro-family pressures created a period in adulthood during which vocational and family roles were experienced as contradictory. However, in later adulthood these women had a high level of employment.

According to a study done by Schuman and scott (1989), in general different cohorts recall different events or changes. These memories come especially from adolescence and early adulthood. However, reasons for mentioning various events and changes differ across cohorts in ways that indicate that cohort effects are the result of the intersection of personal and national history.

Perhaps the most significant study of the influence of social changes on individual lives is Elder's (1974) study of children of the Great Depression. Elder showed that the Oakland Growth Study, generally thought of as a longitudinal study of child development, is also a study of the impact of the Depression. By comparing children in families hard-hit with those in families relatively less affected by the Depression, he was able to examine how individual 
differences in the experience of the Depression affected children both at the time and in their later lives.

Elder did a further comparison of children who were young adolescents at the time of the Depression with those who were young children at the time. With this cohort comparison he was able to show that the stage of development of the child at the time of a major social experience was an important factor in determining the effects of that experience.

Based on this "Historical Change" model an analysis of data of cohort differences should show significant effects by cohort, and some period effects. Assuming that adults can and do modify their attitudes and opinions because of the influence of personal experience and changing societal mores, data analysis should show significant effects by cohort and by interaction of cohort and period.

ADDITIONAL HISTORICAL BACKGROUND

As stated at the beginning of this chapter, this study is based on the Historical Change model of the formation of political beliefs and social attitudes. That is, attitudes are developed and changed in response to personal experiences throughout the life course. Therefore, Appendix A presents some of the social and technological developments and historical events which occurred in the United States from about 1910. The approximate age of the women in the three cohorts (1910-14, 1915-19, and 1920-24) at the time 
of the event will also be indicated. This should provide some background for the analysis of differing effects of seemingly common experiences.

The next chapter will describe the research methods used to analyze the NORC surveys from 1972 through 1989 and a summary of the findings as they related to the three cohorts. 
CHAPTER III

METHODOLOGY AND NORC DATA ANALYSIS

ORGANIZATION OF THE REPORT

The presentation of data in this report is organized in two major chapters, followed by a short concluding chapter. This chapter is composed of comparative quantitative data about the women of the three cohorts (1910-14, 1915-19, 1920-24). There are four sections: how the data were obtained and analyzed; the demographics of the three cohorts; a quantitative analysis of their social attitudes; and a quantitative analysis of their political viewpoints and opinions.

This chapter is intended to accomplish two objectives. It seeks to ascertain if there are differences among the three cohorts which could be attributed to the events and social changes which occurred during and immediately after world war I. The study was conducted using National Opinion Research Council (NORC) data in order to give the quantitative data analysis national significance. The data presented nay have interest for sociologists and practitioners in the field of gerontology.

The second purpose of the presentation of the quantitative data is to provide a background for the analysis of 
the qualitative data carried out in the second part of the study. The next chapter describes the use of focus groups to obtain qualitative data. Details of the focus group procedure and method of analysis will be discussed in that chapter.

\section{COLLECTION AND ANALYSIS OF QUANTITATIVE DATA}

NORC survey data from 1972 through 1989 were utilized. There were no NORC surveys in 1979 and 1981. From the total of 24,893 respondents 2,814 were selected based on sex (female) and age (born between 1910 and 1924). Table I indicates the number and percentage of respondents by cohorts (1910-14, 1915-19, 1920-24) and periods (1972-77, 1978-83, 1984-89). Table II shows the age range of the cohorts by periods.

Because not all questions were asked in each survey, data are not available on a year-to-year basis. Therefore six-year periods were used for the analysis procedure. The combination of five-year cohorts and six-year periods made possible the development of $3 \times 3$ tables to indicate changes within a cohort over time and the relationship of each cohort to the other two.

Approximately 120 variables were studied. Variables were chosen from NORC questions to provide comparisons on family background, education, work experience, marital status, organization memberships, and political party affilia- 
TABLE I

FEMALE NORC RESPONDENTS

BY COHORT AND PERIOD

\begin{tabular}{|c|c|c|c|c|}
\hline Cohort & $\begin{array}{l}\text { Period } \\
1972-77 \\
\end{array}$ & $1978-83$ & $1984-89$ & $\begin{array}{l}\text { Row } \\
\text { Total }\end{array}$ \\
\hline $1910-14$ & 319 & 227 & 264 & $\begin{array}{l}810 \\
28.88\end{array}$ \\
\hline $1915-19$ & 372 & 227 & 319 & $\begin{array}{l}918 \\
32.68\end{array}$ \\
\hline $1920-24$ & 429 & 274 & 383 & $\begin{array}{l}1086 \\
38.68\end{array}$ \\
\hline $\begin{array}{l}\text { Column } \\
\text { Total }\end{array}$ & $\begin{array}{l}1120 \\
39.88\end{array}$ & $\begin{array}{l}728 \\
25.98\end{array}$ & $\begin{array}{l}966 \\
34.38\end{array}$ & $\begin{array}{l}2814 \\
100.08\end{array}$ \\
\hline
\end{tabular}

TABLE II

AGE RANGE OF COHORTS BY PERIODS

\begin{tabular}{|c|c|c|c|}
\hline Period & $1910-14$ & $\begin{array}{l}\text { Cohort } \\
1915-19 \\
\end{array}$ & $1920-24$ \\
\hline $1972-77$ & $58-67$ & $53-62$ & $48-57$ \\
\hline $1978-83$ & $64-73$ & $59-68$ & $54-63$ \\
\hline $1984-89$ & $70-79$ & $65-74$ & $60-69$ \\
\hline
\end{tabular}


tion. Other variables selected pertained to social and political issues such as abortion, right to die, sexual permissiveness, crime, the role of the United States in international affairs, and government assistance for the elderly. Statistically significant effects as low as $p<.10$ were considered because the purpose was to assess patterns across the NORC data for qualitative analysis by the focus groups.

Variables to provide demographic information about the women have been grouped as Family Background and Adult Life. An analysis of variance by cohort and period was done on interval variables to determine if there were statistically significant effects by cohort, period, or interaction. Period effects were not the major focus of the research. Because the NORC surveys were conducted from 1972 through 1989, it was considered important to control for period across this time span. Frequencies were also run for each variable to determine numbers, percentages, mean, and mode. For those variables with categorical, rather than interval, data a chi-square test was run to ascertain if there was a statistically significant relationship between cohort and period and the dependent variable.

Some variables with a wide range of values, such as occupation, were recoded into fewer, but larger, categories. 
Those variables considered as Social Attitudes or Political Opinions were analyzed by frequencies as well as by analysis of variance or chi-square by Cohort, Period, and Interaction. Some recoding was done to ensure consistency in scoring of conservative/liberal viewpoints.

A Pearson's correlation was run for questions which had been grouped together in the NORC questionnaire in order to juage the degree of relationship. cronbach's alpha was also figured to ascertain whether a scale built from these variables would have internal reliability. Basically, Cronbach's alpha multiplies the number of items in a scale by the average of all the correlations. When the alpha was high enough (.65 or better) a scale was built. Otherwise subscales were developed or each item was considered separately.

\section{Family Background}

Geographic. With regard to their own origin locations (reported as of age 16) 31.5 percent were from the North Central states and 18.9 percent from the South Central area. The Middle Atlantic states were listed by 16.3 percent, while 17.1 percent were from the South Atlantic states. Mountain and Pacific states accounted for 3.1 percent and 4.6 percent, while 5 percent were from New England. Only 3.5 percent reported a foreign origin.

A chi-square cohort analysis showed a significant effect of different origin locations by cohort $(p<.05)$ but 
no significant Period or Interaction effects. There was some over representation of New Englanders and foreign born in the 1920-24 cohort and an under representation in the 1910-14 and 1915-19 cohorts of women from the South Atlantic and East South Central states.

The type of place lived in when 16 years old was summarized as shown in Table III. A chi-square analysis showed statistical significance by cohort $p<.05$, by Period $\mathrm{p}<.01$, but Interaction. was not significant. In the 1920-24 cohort there were fewer women who lived on farms at age 16 than expected (25.7 vs 29.6 percent) and more from cities greater than 250,000 (18.0 vs 15.6 percent). It is not clear why there were differences by Period.

For the responses to a question regarding residential mobility a chi-square analysis showed no significant differences by Cohort, Period, or Interaction. Overall, 35.4 percent of the women were living in a different state from the one they were living in at age 16 . The same state was given by 25.6 percent, and 39 percent were still living in the same city.

Ethnic. The countries of origin were recoded into six ethnically based categories. The group tallies were: Africa/West Indies, 6.9 percent; Europe/Canada, 82.7 percent; Hispanic, 2.8 percent; American Indian, 3.0 percent; America, 3.5 percent; and Other, 1.0 percent. A chi-square analysis showed only one statistically significant dif- 
TABLE III

TYPE OF PLACE LIVED IN WHEN 16 YEARS OLD

\begin{tabular}{|c|c|c|c|c|}
\hline Residence 16 & $\begin{array}{l}\text { Cohort } \\
1910-14 \\
\end{array}$ & $1915-19$ & $1920-24$ & $\begin{array}{l}\text { Row } \\
\text { Total } \\
\end{array}$ \\
\hline Farm & 32.3 & 32.0 & 25.7 & $(29.68)$ \\
\hline Country, Nonfarm & 7.3 & 8.0 & 7.8 & $(7.78)$ \\
\hline Town LT 50,000 & 31.4 & 29.3 & 32.5 & $(31.18)$ \\
\hline 50,000 to 250,000 & 11.2 & $12 \cdot 3$ & 11.7 & $(11.88)$ \\
\hline Big-city suburb & 4.1 & 4.1 & 4.2 & $(4.28)$ \\
\hline city GT 250,000 & 13.7 & 14.3 & 18.0 & $(15.68)$ \\
\hline Column Total & $\begin{array}{l}810 \\
28.8\end{array}$ & $\begin{array}{l}917 \\
32.6\end{array}$ & $\begin{array}{r}1083 \\
38.5\end{array}$ & $\begin{array}{l}(2810) \\
(100.08)\end{array}$ \\
\hline
\end{tabular}


ference, by Period, among the categories. Statistically it was expected that Hispanic women would represent 2.8 percent of the total sample. However, the actual percentages vary by period: 3.6 percent in $1972-77 ; 1.3$ percent in 1978-83; and 3.0 percent in 1984-89.

Parental Occupation. Respondents were asked what kind of work the father (or father substitute) did while they were growing up. The work mentioned was then categorized according to the 1970 U.S. Census occupational codes. The percentage of fathers employed in each of five large categories was: Professional, technical, and managers/department heads, 15.7 percent; Sales and clerical workers, 6.2 percent; Craftsmen, operatives, and laborers, 41.5 percent; Farmers and laborers, 32.8 percent; Service workers, 3.8 percent. The occupational mode was farmer owners and tenants with 718 responses, 29.8 percent.

A chi-square analysis of these percentages showed a statistically significant difference by cohort $p<.05$. There were no significant effects by Period or Interaction. The difference occurred between the 1915-19 and 1920-24 cohorts. Instead of the 32.8 percent expected to be farmers, 36.9 percent of the 1915-19 cohort parents were farmers, while only 27.9 percent of the 1920-21 fathers were in this category.

This may be indicative of a general decline in the number of family farms in the united states during the 
1920s. It may also be that the fathers of the 1920-24 cohort left the farm as young men to serve in world war I and did not return to that occupation. This shift also corroborates the findings of the variable regarding type of place lived in at age 16 in which fewer women of the 192024 cohort than expected (as indicated by chi-square analysis) lived on farms.

The prestige scores assigned to occupations in the NORC surveys were taken from a rating system developed at NORC during 1963-65. An analysis of variance of the father's occupational prestige scores showed an Interaction statistical significance of $p<.10$. Cohort and Period effects were not statistically significant. Across the three periods, for the 1910-14 cohort the father's occupational prestige mean declined. For the two younger cohorts the means showed a net increase. It is not clear what caused this pattern.

Siblings. With regard to the number of brothers and sisters a woman had there were no statistically significant effects by Cohort, Period, or Interaction. The population mean was 4.82 , the median 4 , and the mode was 2 siblings. The number of siblings and the percentage of women indicating each number were: None, 5.2 percent; one, 11.1 percent; two, 12.6 percent; three, 12.0 percent; four, 11.4 percent, five, 10.2 percent; six, 8.4 percent; seven, 9.5 percent; eight, 5.5 percent; and nine, 5.0 percent. All 
other categories were mentioned by less than 5 percent of the women.

Education. Survey data on education showed that of the women in the three cohorts 47.3 percent had less than a high school education. High school graduates constituted 33.0 percent, while 17.0 percent had attended college, and 2.6 percent had done post-graduate work. An analysis of variance of years of schooling indicated that cohort was significant at $\mathrm{p}<.001$. Period and Interaction effects were not significant.

The oldest cohort (1910-14) had a mean of 10.46 years of schooling. The 1915-19 cohort mean rose to 10.78 , and the mean was 11.08 for the youngest cohort.

Summary. Table IV shows the Family Background areas in which there were statistically significant differences between the cohorts and by cohort/period interaction.

TABLE IV

FAMILY BACKGROUND VARIABLES SHOWING STATISTICALLY SIGNIFICANT DIFFERENCES BY COHORT AND/OR INTERACTION

Variable Cohort Interaction

Demographics--Family Background

Region of Residence age 16 Type of Residence Area age 16 Parent's Occupation

Parent's Occupational Prestige Education

$$
\begin{gathered}
p<.05 \\
.05 \\
.05 \\
\text { None } \\
.001
\end{gathered}
$$

None

None

None

$p<.10$

None

Briefly, the 1910-14 and 1915-19 cohorts had an under representation of women who grew up in the southern states 
east of the Mississippi River. The 1920-24 cohort had more from New England and of foreign origin than expected as indicated by chi-square analysis.

Cohort differences in the type of place lived in at age 16 seemed to tie in with differences in the father's occupation. That is, fewer women of the 1920-24 cohort than expected, according to the chi-square analysis, lived on farms and more lived in cities over 250,000 population. For this cohort only 27.9 percent of the fathers were farmers, contrasted to the expectation of 32.8 percent. Conversely, the 1915-19 cohort reported 36.9 percent of the fathers as farmers.

The interaction effects of cohort and period on the parent's occupational prestige score may also be related to this shift from farm to urban living. Each younger cohort had a higher mean for prestige of the parent's occupation. The decline in means across the three periods may have been caused by additions to the U.S. Occupational Index of more highly rated positions in white collar occupations.

The most significant difference in the early background of these women was in the area of years of schooling. These figures were 10.46, 10.78, and 11.08 years of schooling, increasing for each younger cohort. These figures give no indication whether these differences were caused by economic conditions, changes in school age 
leaving laws, or social changes pointing up the desirability of more education for women.

\section{Adult Life}

Marital. Table $\mathrm{V}$ summarizes the marital status of the three cohorts. Married and widowed status differences among the cohorts may be an aging effect. Divorced or Separated status shows some differences between the 1910-14 cohort and the two younger cohorts. The Never Married status shows a steady decrease from the oldest to youngest cohort.

In answer to a Yes/No question 15.9 percent of the women indicated they had been divorced or separated. An analysis of variance showed a significant Period effect of $\mathrm{p}<$ 10. There were no significant effects by cohort or Interaction.

Children. The scale for the ideal number of children for a family ranged from zero to seven or more or as many as you want. Zero was selected by 1.3 percent of the women, one by 1.0 percent, two by 42.7 percent, three by 25.8 percent and four by 18.8 percent. An analysis of variance showed no significant effects by cohort, Period, or Interaction.

However, an analysis of variance of the number of children a woman actually had indicated a significance by Cohort of $p<.001$. The cohort means were 2.31 for the 


\section{TABLE V \\ MARITAL STATUS BY COHORT \\ MEAN PERCENTAGES 1972-1989}

\begin{tabular}{|c|c|c|c|c|}
\hline arital status & $\begin{array}{l}\text { Cohort } \\
1910-14 \\
\end{array}$ & 1915-19 & $1920-24$ & $\begin{array}{l}\text { Row } \\
\text { Total }\end{array}$ \\
\hline Married & 46.0 & 53.8 & 64.8 & $(55.88)$ \\
\hline widowed & 39.5 & 31.6 & 21.8 & $(30.18)$ \\
\hline Divorced & 5.7 & 7.1 & 7.7 & $(6.98)$ \\
\hline Separated & 2.0 & 2.9 & 2.9 & $(2.78)$ \\
\hline Never married & 6.8 & 4.6 & 2.7 & $(4.58)$ \\
\hline Column Total & $\begin{array}{l}810 \\
28.8\end{array}$ & $\begin{array}{l}918 \\
32.6\end{array}$ & $\begin{array}{r}1086 \\
38.6\end{array}$ & $\begin{array}{l}(2814) \\
(100.08)\end{array}$ \\
\hline
\end{tabular}


1910-14 cohort, 2.50 for 1915-19, and 3.01 for the 1920-24 cohort.

A chi-square analysis pointed out the differences among the cohorts. More women in the 1910-14 cohort had no children or only one child than might have been expected (22.5 vs 16.53 percent and 19.4 vs 15.1 percent respective1y). On the other hand fewer of the women of the 1920-24 cohort had no children or only one child but more had five children (9.6 vs 6.7 percent) than statistically expected from the chi-square analysis. Although other category differences were not as large, the 1910-14 cohort consistently had fewer children from 2 through 8 or more, whereas the 1920-24 cohort women consistently had more children in these categories.

A Pearson's correlation between the variables of ideal number of children and actual number of children was only .15.

\section{Economic Status}

Spouse's Occupation. Respondents were asked what type of work their spouses did (or had done). Categories of the U.S. Census occupational codes were grouped. Percentagés employed in each large group were: Professional, technical, managers/department heads, 28.6 percent; Sales and clerical workers, 11.1 percent; Craftsmen, operatives, and laborers, 46.7 percent; Farmers and laborers, 6.5 percent; Service workers, 7.2 percent. The mode was in the mana- 
gers, administrators n.e.c. category with 199 workers, 12.8 percent of the spouses.

A chi-square analysis of the spouse's occupation showed no statistically significant effects by cohort, Period, or Interaction.

An analysis of variance of the occupational prestige scores of the women's spouses showed a statistically significant effect by Period of $p<.10$. Cohort and Interaction effects were not statistically significant. The mean for the total population was 39.41. The median was 40 and the mode was 50 . By periods the means were 38.62, 1972-77; $40.14,1978-83$; and $40.29,1984-89$.

Prestige of the spouses' occupations at a mean of 39.41 ranked higher than that of fathers (or father substitute) with a mean of 38.03 .

Respondent's Occupational status. In response to the question, "Did you ever work for as long as one year?", 84.3 percent of the women indicated that they had. An analysis of variance showed a statistically significant effect by Period $p<.001$. There were no significant effects by Cohort or Interaction.

Period means were 80 percent, 1972-77; 85 percent, 1978-83, and 87 percent, 1984-89. The trend toward Yes was for each cohort period by period.

A summary analysis of the occupational classifications of women in the 1910-24 cohorts is presented in 
Table VI. To determine the predominant occupation in each classification some grouping was done. These are occupations in which the women were employed at the time of each survey, or in which they had been employed before retirement. This summary does not account for 316 women of the 2814 surveyed. These women may have categorized themselves "Full-time Homemaker," which is not a labor force occupational classification.

A chi-square analysis showed no statistically significant effects by cohort or Interaction. The Period effect was significant $p<.01$. During the $1972-77$ period 16.6 percent of the women were in the Professional category. The expected figure was 19.7 percent. Sales and Clerical workers were 37.1 percent during 1972-77 and 28.6 percent during 1978-83. The expected figure was 33.0 percent.

An analysis of variance of the prestige scores of the respondents' occupations showed no statistical significance by Cohort, Period, or Interaction. Based on a range of 10 through 89 the total population mean was 36.34. The median and mode were both 36 .

The population mean of 36.34 for the women's prestige score was lower than that of the fathers, 38.03; and of the spouses, 39.40 .

Labor Force Status. Responses to labor force status, recoded into four categories: working, retired, keeping house, and other. A chi-square analysis indicated statis- 
TABLE VI

\section{OCCUPATIONS OF RESPONDENTS}

\begin{tabular}{|c|c|c|c|}
\hline $\begin{array}{l}\text { Occupational } \\
\text { classification }\end{array}$ & $\begin{array}{l}8 \text { of } \\
\text { Total }\end{array}$ & $\begin{array}{l}\text { Predominant* } \\
\text { Occupations }\end{array}$ & $\begin{array}{l}8 \text { of } \\
\text { Total } \\
\end{array}$ \\
\hline $\begin{array}{l}\text { Professional, } \\
\text { Technical, } \\
\text { Managers, and } \\
\text { Dept. Heads }\end{array}$ & 19.7 & $\begin{array}{l}\text { Manager } \\
\text { Teacher } \\
\text { Registered } \\
\text { Nurse }\end{array}$ & $\begin{array}{l}8.3 \\
4.8 \\
2.7\end{array}$ \\
\hline $\begin{array}{l}\text { Sales and } \\
\text { Clerical } \\
\text { Workers }\end{array}$ & 32.8 & $\begin{array}{l}\text { Secretaries } \\
\text { Clerks } \\
\text { Sales Clerks } \\
\text { Bookkeepers }\end{array}$ & $\begin{array}{l}8.9 \\
6.3 \\
4.7 \\
3.4\end{array}$ \\
\hline $\begin{array}{l}\text { Craftsmen, } \\
\text { Operatives, } \\
\text { and Laborers }\end{array}$ & 21.1 & $\begin{array}{l}\text { Clothing and } \\
\text { Textiles } \\
\text { Assemblers, } \\
\text { Packers }\end{array}$ & $\begin{array}{l}7.1 \\
3.1\end{array}$ \\
\hline $\begin{array}{l}\text { Farmers and } \\
\text { Laborers }\end{array}$ & 0.7 & Laborer & 0.4 \\
\hline $\begin{array}{l}\text { Service } \\
\text { Workers and } \\
\text { Private } \\
\text { Household } \\
\text { Workers }\end{array}$ & 25.6 & $\begin{array}{l}\text { Food Service } \\
\text { Private House, } \\
\text { Maids } \\
\text { LPN/Nursing } \\
\text { Aide } \\
\text { Cook }\end{array}$ & $\begin{array}{l}4.8 \\
4.3 \\
3.6 \\
2.7\end{array}$ \\
\hline $\begin{array}{l}\text { Total } \\
\text { Responses }\end{array}$ & $\begin{array}{l}2498 \\
100.0\end{array}$ & & \\
\hline Mode $=$ Secreta & & & \\
\hline
\end{tabular}


tically significant differences by Cohort, Period, and Interaction $\mathrm{p}<.001$.

Figure 2 presents a period by period comparison of the labor force status of the three cohorts. The 1920-24 cohort had a larger proportion of its members remaining in the work force than did the two older cohorts. Noticeable also is the increase in retirees for all cohorts during the 1984-89 period. Possibly the younger women did not indicate "Keeping house" but chose "Retired" because their lives have been more labor market oriented. It may also be that the removal of mandatory retirement regulations, and rising costs, influenced the 1920-24 cohort to remain in the labor market.

Family Income. The data on family income was recoded into six groups with intervals of $\$ 5,000$, ranging from zero to $\$ 25,000$ or over. It was felt a $\$ 25,000$ ceiling would be adequate in considering the family income of these older cohorts. The analysis of variance showed statistically significant effects by Cohort, Period, and Interaction $\mathrm{p}<.001$.

Figure 3, page 47, in which income is shown in constant 1989 dollars, presents the picture. The sharp decline in family income may have been caused by double digit inflation between 1978-83. It is also likely that the two older cohorts, 1910-14 and 1915-19, chose retirement at some time during the first two periods, 1972-77 and 


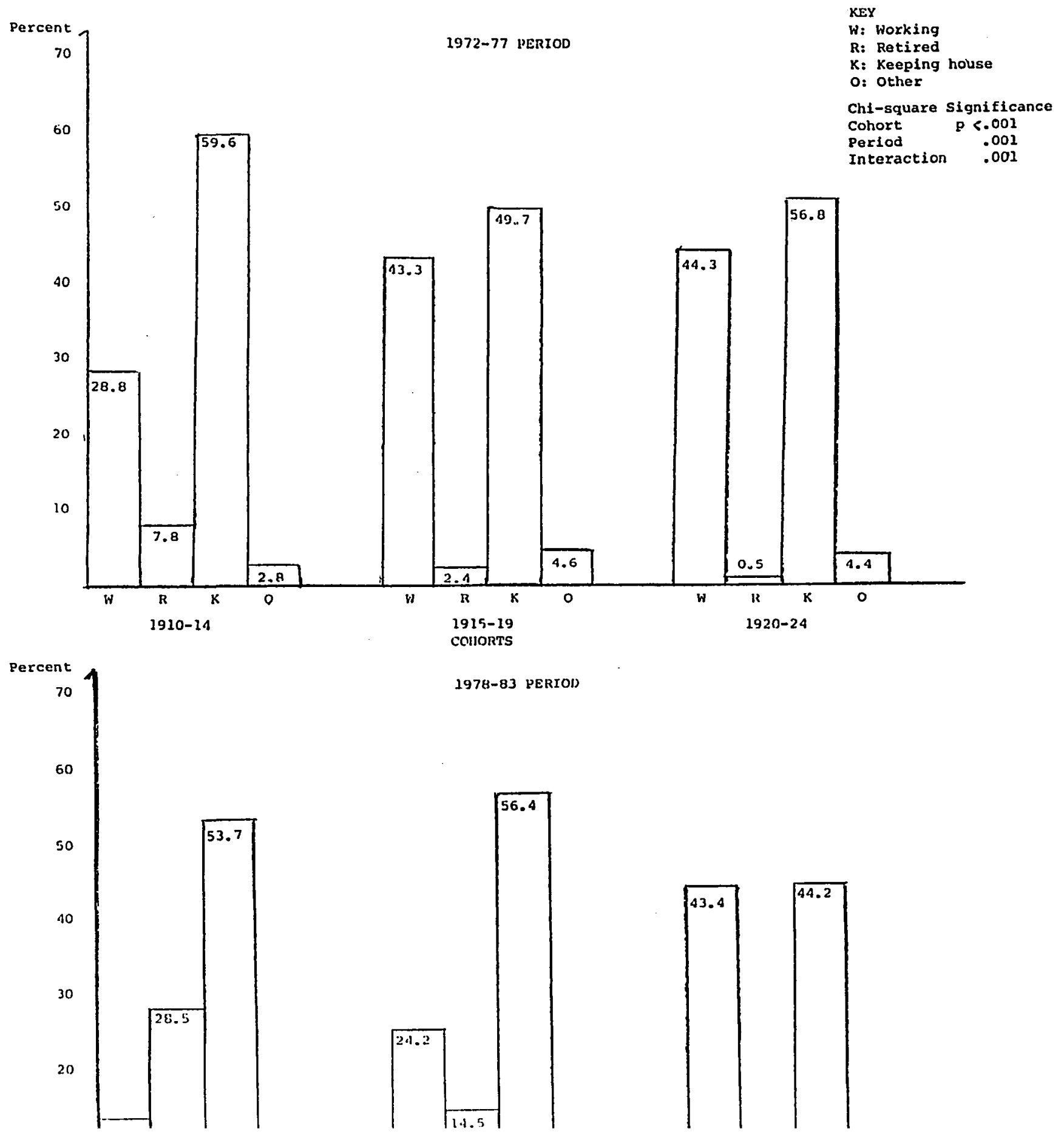


. 

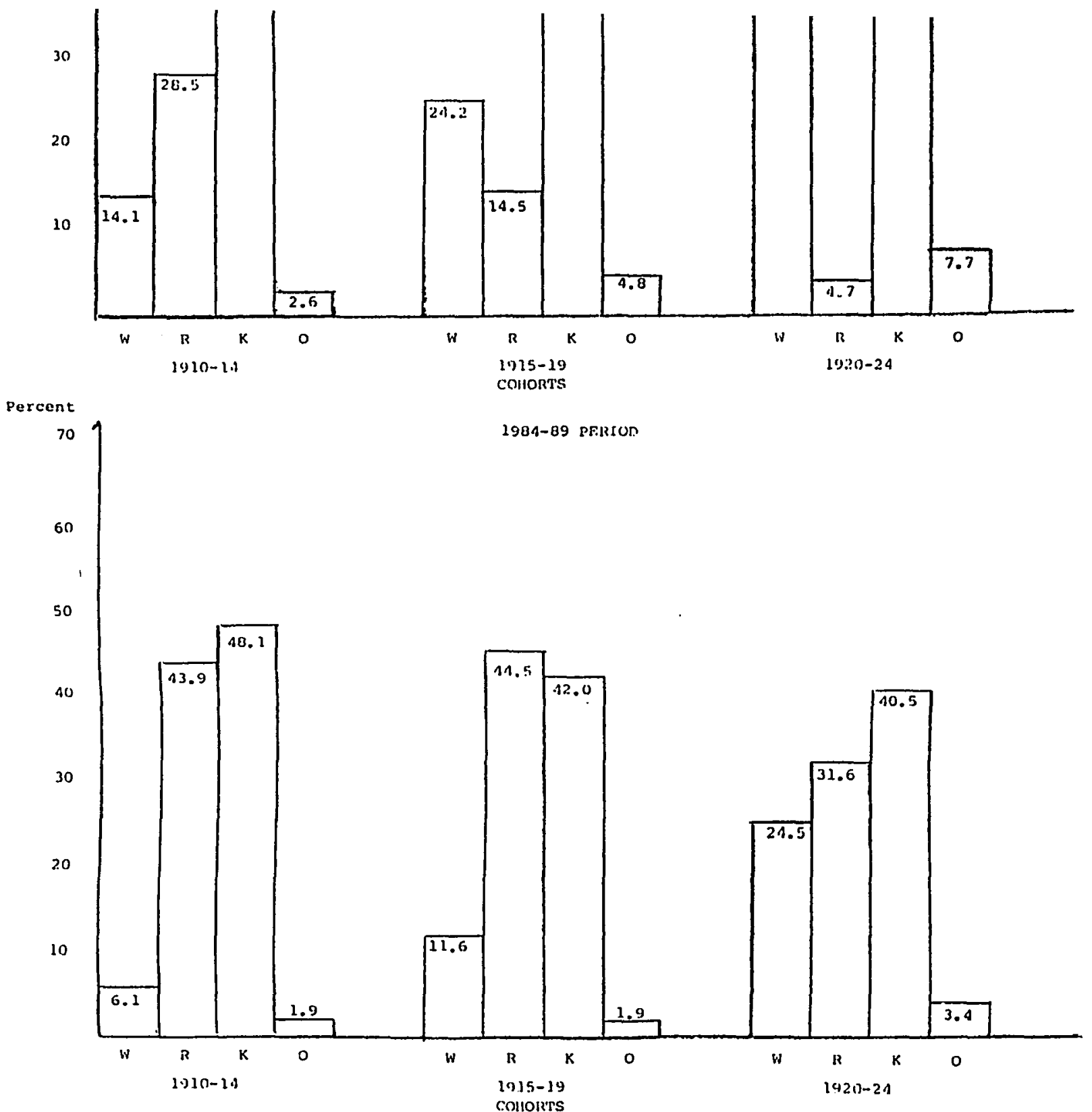

Eigure 2. Labor force status by period and cohort. 



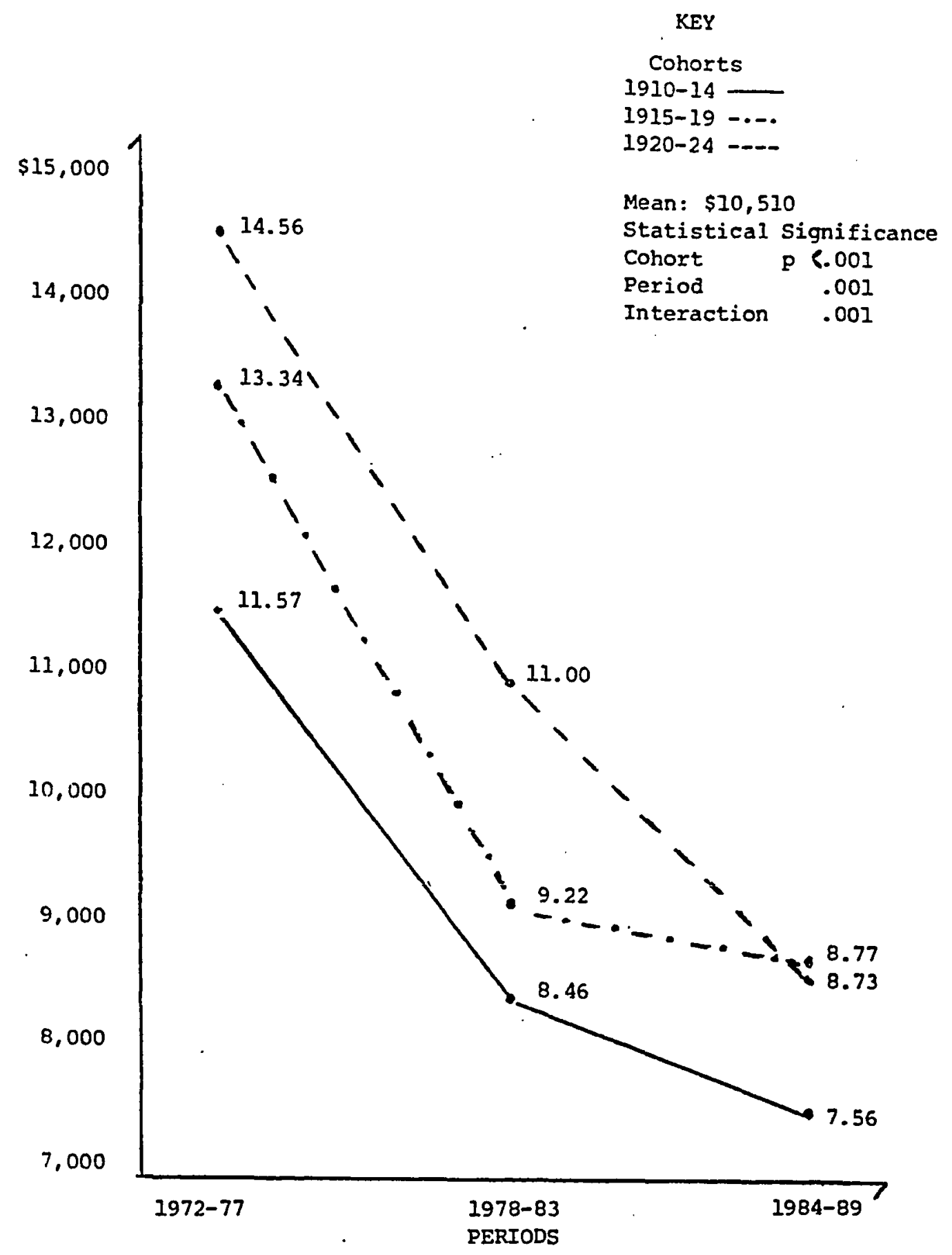

Figure 3. Family income in 1989 constant dollars. 
1978-83. The income of these two cohorts levels off during 1984-89, whereas that of the 1920-24 cohort, who could be retiring during this period, continues to decline.

Class Identification. An analysis of variance showed Subject Class Identification main effects of Cohort $p<.05$ and Period $p<.001$. Interaction effects were not statistically significant.

On a scale of 1 to 4 (lower class, working class, middle class, and upper class) the mean for the 1910-14 cohort was 2.58. The middle cohort mean was 2.53 and the 1920-24 cohort mean was 2.48. By period the mean rose from 2.47 during $1972-77$ to 2.52 for $1978-83$, and then to 2.58 for the third period.

Because subjective class identifications might be considered categorical rather than interval level, a chisquare analysis was run. This analysis confirmed the statistical significance, and also served to pinpoint differences. The chief shifts were between working class and middle class status during the 1972-77 and 1984-89 periods. The 1910-14 cohort selected middle and upper class more often than might have been expected. Lower and working class status was chosen by the 1920-24 cohort more often than expected.

The respondents were asked their opinion of the family income. The categories were: 1. Far below average, 2. Below average, 3. Average, 4. Above average, and 5. Far 
above average. Average was selected by 55.7 percent. Below average and above average were chosen by 27.6 percent and 11.1 percent respectively. Only 4.6 percent selected far below average, and 0.9 percent far above average.

An analysis of variance showed statistically significant effects by Cohort $\mathrm{p}<.01$ and Period $\mathrm{p}<.05$. There were no significant Interaction effects. Means by cohorts were 3.18 for $1910-14 ; 3.50,1915-19 ;$ and $4.05,1920-24$. These figures were confirmed by a chi-square analysis. The Cohort effect was the result of more members of the 1920-24 cohort than expected indicating that they felt the family income was Above average--13.4 percent vs 11.1 percent expected. And by 6.5 percent of the 1910-14 cohort selecting Far below average, whereas the expected rate was 4.6 percent. There is the possibility that there may also be an aging effect. Families of the 1910-14 cohort may have reached retirement status and experienced an income reduction.

Personal Activities. A tabulation of organization memberships of the three cohorts showed that 46.5 percent held membership in a church. There were no significant effects by Cohort or Interaction, but Period was significant $\mathrm{p}<.10$. Means were based on Yes $=1$, No $=0$. Over the three periods the mean shifted from .50 during 1972-77 to .45 in the middle period, and remained at .45 during 1984-89. 
A further analysis by religious preference indicated Protestant, 70.6 percent; Catholic, 23.7 percent; Jewish, 2.8 percent; None, 2.0 percent; and Other, 0.9 percent. The chi-square analysis showed Period effects significant $\mathrm{p}<.10$. The largest single source of this difference was during the 1984-89 period when 1.4 percent of the respondents indicated Jewish as their religious preference. The expected figure was 2.8 percent.

The question on strength of religious affiliation was statistically significant only by Period $p<.01$. A strong religious affiliation was indicated by 55.6 percent of the women.

A tally of organization memberships showed that 33.7 percent of these women did not belong to any organization. Another 30.6 percent were members of one organization, while 16.0 percent belong to two groups. Three and four memberships were listed by 8.4 percent and 4.6 percent of the respondents. An analysis of variance showed a significant effect by Cohort $p<.01$ and by Period of $p<.05$. Interaction effects were not significant. The mean for the oldest cohort was 1.35. The 1915-19 cohort mean was 1.66 , and the 1920-24 cohort mean was 1.44 .

Table VII gives a summary of group memberships ranked by the percentage of women indicating membership. The first four organizations were mentioned by 5 percent or fewer of the women. The 1910-14 cohort had fewer members 
TABLE VII

ANALYSIS OF MEMBERSHIP IN ORGANIZATIONS

\begin{tabular}{|c|c|c|c|c|}
\hline \multirow{3}{*}{$\frac{\text { Organization }}{\text { Youth group }}$} & \multirow{2}{*}{$\begin{array}{l}\text { Percent } \\
\text { Belonging }\end{array}$} & \multicolumn{3}{|c|}{ Chi-square significance } \\
\hline & & Cohort & Period & Interaction \\
\hline & 5.0 & None & $p<.10$ & None \\
\hline Nationality club & 5.0 & $\mathrm{p}<.10$ & None & None \\
\hline School sorority & 5.0 & .05 & None & None \\
\hline Farm organization & 5.0 & None & None & None \\
\hline School service & 5.5 & .10 & .001 & None \\
\hline Veteran's group & 5.7 & .01 & None & $\mathrm{p}<. .10$ \\
\hline Labor union & 7.3 & None & .001 & None \\
\hline Professional club & 7.4 & None & .10 & None \\
\hline Sports club & 7.7 & .001 & .05 & None \\
\hline Fraternal group & 9.6 & None & None & None \\
\hline Service group & 9.7 & None & None & .05 \\
\hline Literary/art club & 10.6 & None & .01 & None \\
\hline Hobby club & 10.9 & None & None & None \\
\hline Other & 14.0 & .05 & .001 & None \\
\hline
\end{tabular}


in nationality clubs and school sororities than did the two younger cohorts. The increased sorority membership in the younger cohorts may be tied to college attendance.

An analysis also showed that for school service organizations the means for all three cohorts and across periods shifted steadily toward "No," apparently as children finished school.

Veteran's group membership means for the two older cohorts were 3 percent and 4 percent. The 1920-24 cohort mean was 7 percent. These figures do not indicate whether the women were members of a veteran's group in their own right or were members of auxiliaries. Labor union membership dropped across the periods as indicated by means of 11,7 , and 5 percent.

The means for sports club membership were 4 percent for the 1910-14 cohort; 8 percent, 1915-19; and 10 percent for the youngest cohort. There is no indication whether the women were participating in sports or were members of an organization sponsoring sports. In service groups the 1915-19 cohort showed a membership increase across the three periods. The older and younger cohorts showed decreases.

The membership means for "Other" organizations were 16 percent for the 1910-14 and 1915-19 cohorts and 11 percent for the 1920-24 cohort. 
For all these membership percentages and fluctuations it should be noted that membership is not necessarily an indicator of activity.

Health and Happiness. An analysis of variance of the condition of health showed significant effects by Cohort of $p<.001$, and Period and Interaction $p<.01$. (See Figure 4.)

A chi-square analysis indicated that the cohort difference significant during the $1972-77$ period was because more of the 1910-14 cohort indicated fair or poor health and more of the 1920-24 cohort indicated excellent health than might have been expected $(\mathrm{F}<.001)$. This same pattern was noted to a lesser degree during 1984-89 ( $p<.05$ ).

An analysis of variance of estimates of General Happiness showed no significant effects by Cohort, Period, or Interaction. Very happy was indicated by 36.6 percent of the women, pretty happy by 50.9 percent, while only 12.5 percent felt they were not too happy.

Summary. Table VIII, on page 55, lists the Adult Life variables which showed statistically significant differences by cohort and/or Interaction. 


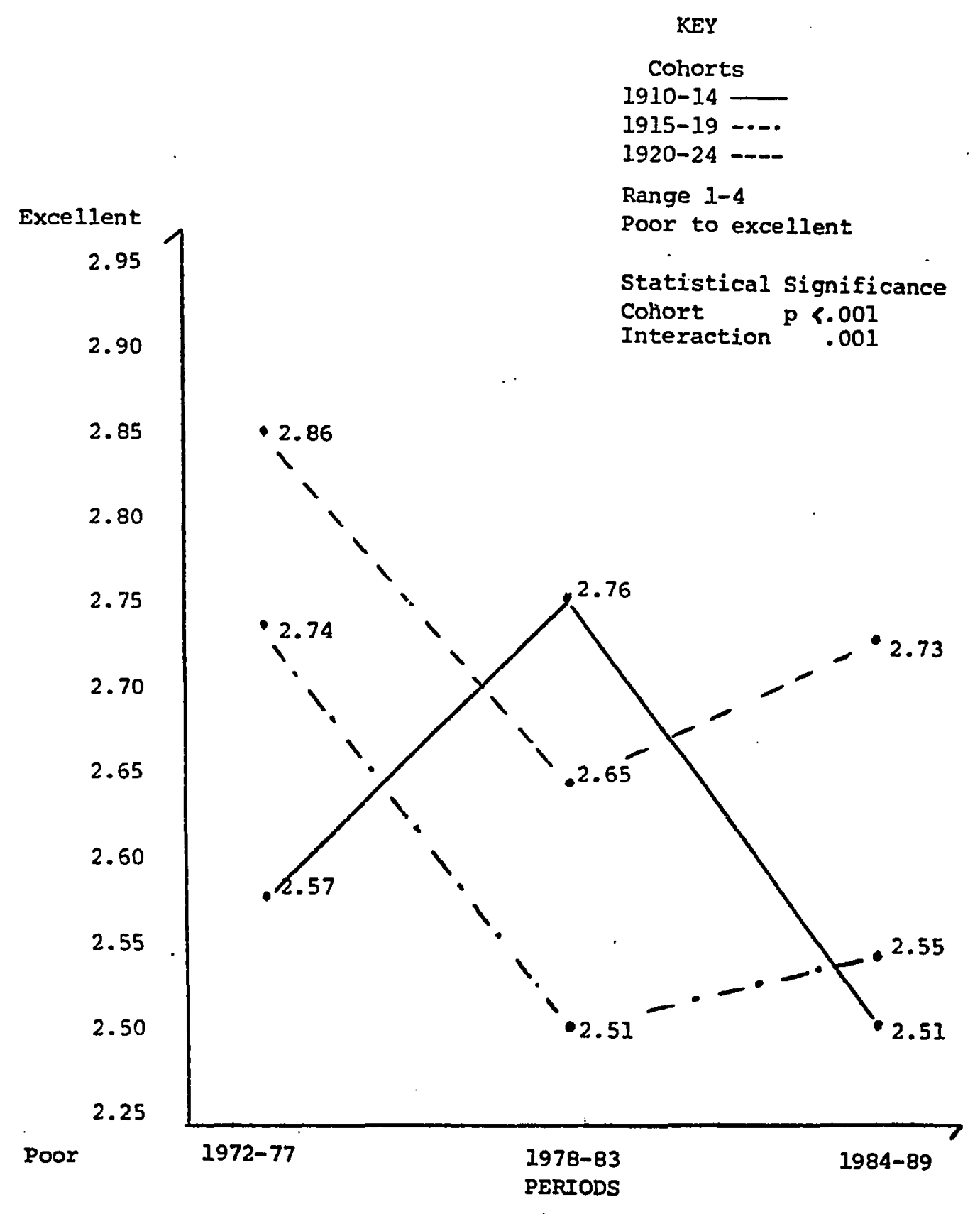

Figure 4. Perception of health status. 
TABLE VIII

ADULT LIFE VARIABLES SHOWING STATISTICALLY SIGNIFICANT

DIFFERENCES BY COHORT AND/OR INTERACTION

Variable

Demographics--Adult Iife

Cohort Interaction

$\mathrm{p}<.001$
.001
.001
.001
.05
.05
.01
.05
.001
None
.01
.10
.05
.05
.001

$\mathrm{p}<.10$

None .001

None

None

None

None

None

None

.10

.10

None

None

None

.01

Considering the Marital status variable llisted in Table VIII) it is possible that increases by cohort $(46.0$, $53.8,64.8$ percent) in the number of married women resulted because there were fewer widows among the younger women, but also fewer younger women in the Never Married category. The increase in the number of children borne by the women of these cohorts $(2.31,2.50$, and 3.01$)$ may have been the result of several factors. The increase in marriages and, following world War II, the desire for stability, improved economic conditions, and government propaganda to get women out of the labor force may have played a part.

However, women in the younger cohorts apparently continued to work after establishing families. The percentages working, from the oldest to youngest cohort, were 
17.3, 27.6, and 37.1. This is further reflected across periods. During $1972-77$ only 3.2 percent were retired and 52.9 percent were keeping house. In the 1984-89 period 39.2 percent designated themselves as retired and only 43.1 percent were keeping house.

As stated previously, Family Income of all cohorts increased across periods, but the increase did not change the relative position of the cohorts. The 1910-14 cohort had the lowest, 1915-19 was in the middle, and 1920-24 was highest. This pattern may reflect rising economic conditions, but, as suggested by the labor status figures, may also be indicative of the two-earner family.

Class identification differences were between the oldest and youngest cohorts. The 1910-14 cohort indicated they were of middle class status, whereas the 1920-24 cohort felt they were of the working class. This choice by the 1920-24 cohort may have been influenced by their growing up during the Depression years. It does not seem to match with the evaluation of family income. As was noted previously, the 1910-14 and 1915-19 cohort means were somewhat above "average." The 1920-24 cohort mean was slightly over "above average."

Although there were fluctuations in membership in various organizations, the women of each older cohort showed a steady decrease in rates of membership. The figures do not indicate whether dropping of membership in an organization 
was because the woman's family responsibilities changed, whether she no longer enjoyed participating, or whether illness prevented her continued participation.

During the 1978-83 period the oldest cohort reported themselves in better health and the younger cohorts reported poorer health than in the previous period. By 198489 the younger cohorts reported themselves in better health. However, all cohorts reported poorer health than they did for the 1972-77 period. It is not certain whether these shifts in perceived health were caused by actual changes in physical health. The shift towards poor health during 1978-83 of the two younger cohorts may have been the result of psychological adjustment to retirement of themselves or of their spouses (see Figure 4). In the 1984-89 period they seem to be following the pattern of the 1910-14 cohort of feeling better again. It would be necessary to have comparative figures pre-1972 and post-1989 to explore this pattern.

\section{Social Attitudes}

Variables were grouped into the topics of Abortion, Right-to-Die, Sexual Permissiveness, and Children.

Abortion Opinions. Seven items were used to build an Abortion Opinions scale. The reasons for permitting an abortion included a strong chance of serious defect, wants no more children, woman's health endangered, low income, rape, does not want to marry, and any reason. Cronbach's 
alpha rank for internal reliability was .869 . An analysis of variance showed that the period effect was significant at $\mathrm{p}<.01$. Cohort and Interaction effects were not significant.

The scale showed a non-significant drop in acceptance of abortion across the three cohorts. The 1910-14 cohort had a mean of 10.95. The middle cohort (1915-19) mean was 10.95, and the 1920-24 cohort mean was 10.89. Across periods there was a significant drop from the 1972-77 mean of 11.38 to the 1978-83 mean of 11.02, and the 1984-89 mean of 10.69 .

Figure 5 shows that the three cohorts did not consistently follow a falling pattern. The youngest cohort ranked as the most conservative during the first two survey periods but were comparatively the most liberal during the 1984-89 period. The range on the Abortion Opinions scale was from 7 to 14, non-acceptability to acceptance for any reason. However, the cohort medians ranged from 10.51 to 11.48. Therefore, the vertical scale on Figure 5 is somewhat expanded so that cohort and period differences can be discerned.

A Pearson's correlation showed strong correlations $(.5767, .5949, .6268)$ among the questions about abortion in cases involving possible birth defects, the woman's health, and rape. There were even stronger correlations 


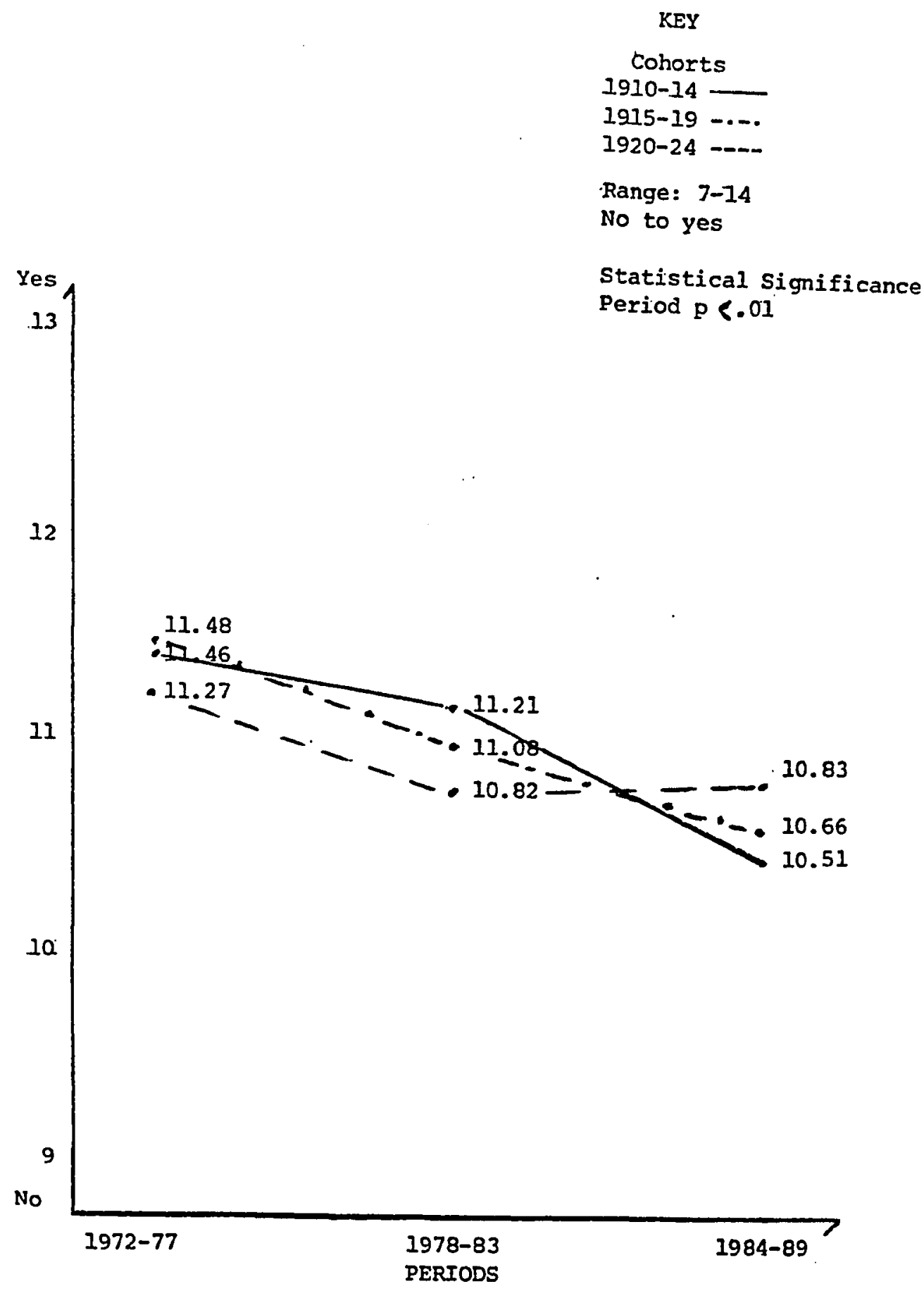

Figure 5. Summary of means of opinions on permitting abortion in seven different circumstances. 
among the other four items $(.65$ to .75$)$. Correlations between items in the two groups were noticeably lower.

Two sub-scales, of three items each, were set up and designated as "Hardship Reasons for Abortion" and "Prochoice Attitude" (social reasons). Cronbach's alpha of internal reliability of the scales was .82 for hardship reasons and .90 for the pro-choice scale. The two subscales largely repeated the pattern of the overall scale.

The seventh variable of the original scale, abortion if the woman wants it for any reason, had no significant effects of Cohort, Period, or Interaction.

Right-to-Die Opinions. The Right-to-Die was analyzed by considering three variables. Allowing incurable patients to die was accepted by 55 percent of the women. Suicide if the person had an incurable disease was accepted by 29.3 percent, but only 9.6 percent condoned suicide if a person was tired of living.

An analysis of variance did not show any significant main effects for any of the three variables.

Sexual Permissiveness. A scale to analyze opinions about Sexual Permissiveness was built by summing three variables. The questions asked whether premarital sex, extramarital sex, and homosexual relations were always, almost always, or sometimes wrong, or not wrong at all. Internal reliability of the scale was validated by a cronbach's alpha of .65. An analysis of variance indicated 
that Period was not significant, but that cohort and Interaction of Cohort and Period were both significant at $\mathrm{p}<.05$.

As shown by Figure 6 , although all cohorts are at the conservative end of the scale, the oldest cohort steadily became more conservative over time. The 1915-1919 cohort moved from most conservative to most liberal, but then dropped from a mean of 5.02 to 4.27 in the third period. The youngest cohort means were 4.79, 4.85, and 4.79. In both the 1972-77 and 1984-89 periods they were the most liberal cohort.

Because the Cronbach's alpha was marginal the three items were examined separately. One difference was that the 1910-14 cohort became more tolerant of pre-marital sex during 1978-83 but during 1984-89 became least tolerant. The three means for this cohort were 2.02, 2.13, and 1.73. Also, the 1915-19 cohort pattern on homosexual relations showed a small but steady conservative trend across the three periods with means of $1.42,1.39$, and 1.34 .

These cohort differences on the items of tolerance of pre-marital sex and homosexual relations are in contrast to the overall pattern of attitudes toward sexual permissiveness indicated in Figure 6. However, changing attitudes toward extra-marital sexual relations followed the cohort patterns of Figure 6. 
KEY

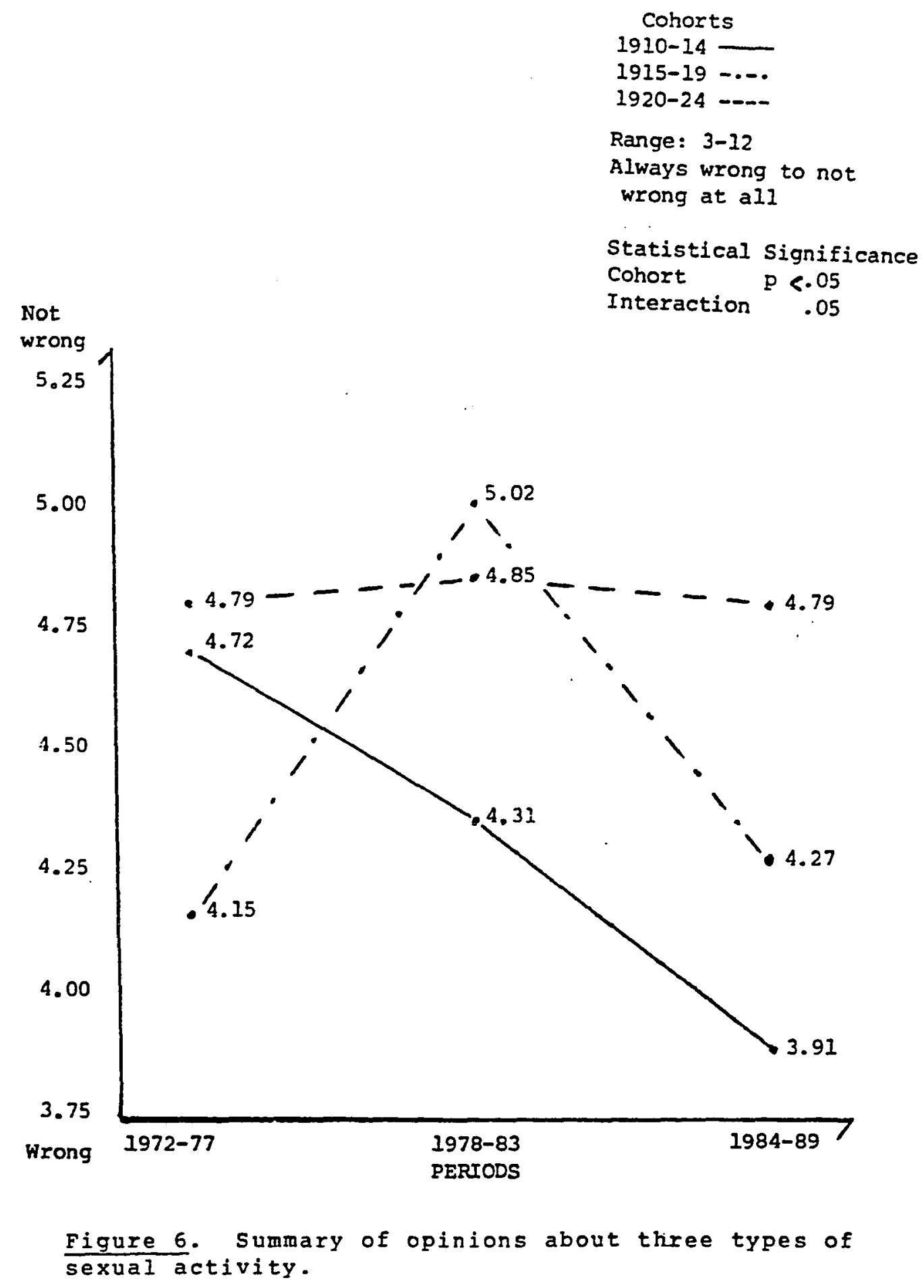


An analysis of a related variable which asked whether divorce laws should be made more difficult, stay as they were, or become easier showed a Period effect significant at $p<.01$. Cohort effects were not significant, but Interaction effects were significant at $p<.10$. Across the three six-year periods the mean dropped from 1.60 in 197277 to 1.45 in the 1984-89 period. On this variable all three cohorts showed patterns across periods similar to their opinions on sexual permissiveness.

Children. The national survey asked respondents to rate the desirability of thirteen qualities for children. Qualities listed were good manners, tries hard to succeed, honesty, neatness and cleanliness, good sense and sound judgment, self-control, acts like a boy/girl, gets along well with other children, obeys parents, responsibility, considerate of others, interested in how and why things happen, and is a good student.

The respondents were asked to select three qualities they considered most desirable. From the remaining ten characteristics they were asked to select three of lesser importance. Responses were recoded on a three-point scale: most desirable traits $=3$, not mentioned $=2$, and least important traits $=1$. An analysis of variance was done on each of the thirteen character traits.

The variable that a child tries hard to succeed was statistically significant by Cohort $p<.10$ and Period 
$\mathrm{p}<.05$. There were no significant Interaction effects. This character trait was not mentioned by 61.9 percent of the women and considered one of the least important traits by 25.6 percent. The mean was 1.90 for the 1910-14 cohort, 1.81 for the middle cohort, and 1.89 for the 1920-24 cohort, i.e., it decreased in importance.

The variable regarding the importance of the child acting like a boy/girl was statistically significant by Period and Interaction $\mathrm{p}<.05$. Cohort did not show any significant effects. The population mean was 1.397. This was considered to be one of the least important traits by 63.9 percent of the women. Across periods the mean for the 1910-14 cohort dropped from 1.48 to 1.43 and for the middle cohort from 1.36 to 1.30 . The 1920-24 cohort showed the greatest decline, from 1.45 to 1.25 .

Four of the characteristics: that a child show interest in how and why things happen, be neat and clean, be a good student, and be honest were statistically significant by period. Cohort and interaction effects were not significant. Population means for these variables were: shows interest in how and why things happen, 1.70 ; be neat and clean, 1.72; be a good student, 1.75; and be honest, 2.68 .

The remaining seven characteristics showed no statistically significant effects by Cohort, Period, or Interaction. Population means for these variables were: good manners, 1.982; gets along well with other children, 2.018; 
self-control, 2.084; considerate of others, 2.176; good sense and sound judgment, 2.26; responsibility, 2.263; and obeys parents, 2.32 .

Three other items related to children and education were analyzed.

1. Would you be for or against sex education in the public schools?

Although 75.3 percent of the women favored sex education in the public schools, the difference by cohort was significant at $p<.001$. Variations by Period and Interaction were not significant. Among the oldest cohort (1910-14) 70 percent were in favor, while for the 1915-19 cohort 73 percent favored sex education in the public schools. The 1920-24 cohort had 80 percent of the women favoring this type of instruction.

2. Do you disapprove/approve of the U.S. Supreme court ruling that no state or local government may require reading of the Lord's Prayer or Bible verses in public schools?

An analysis of variance did not show any significant effects by Cohort, Period, or Interaction. The disapproval rating was 72.9 percent.

3. An analysis of variance on the item of spending to improve the nation's education system showed a cohort effect significant at $p<.10$ and a Period effect significant at $\mathrm{p}<.001$. The Interaction effect was not significant. A scale of 1 = too little spending, 2 = about right, and $3=$ too much spending was used. The mean for the 1910-14 
cohort was 1.66, that for the 1915-19 cohort was 1.61 , and the mean for the 1920-24 cohort was 1.58. Across periods there was a trend toward "too little spending." In the 1972-77 period the mean was 1.68 . This dropped to 1.60 for 1978-83, and dropped again, to 1.49 , for the third period.

Other Social Issues. Three additional questions were on the legalization of marijuana use, national spending for dealing with drug addiction, and the distribution of pornographic material.

The question of whether marijuana use should be made legal had 88.4 percent of the women in opposition. An analysis of variance showed a statistically significant effect by Period of $p<.10$. Cohort and Interaction effects were not significant. For 1972-77 the period mean was 1.13, 1.14 in the middle period, and 1.10 during the 198489 period. That is, during the third period opinion was moving closer to "Should not be legal."

An analysis of variance showed no significant effects by Cohort, Period, or Interaction on the question of national spending for dealing with drug addiction. Too little was being spent in the opinion of 65.1 percent of the women, while 27 percent felt the amount was about right. only 7.9 percent indicated that too much was being spent. With regard to the distribution of pornography 95 percent of the women felt this should be illegal. A chisquare analysis showed that the Cohort effect was signifi- 
cant $\mathrm{p}<.10$ and the Period effect at $\mathrm{p}<.05$. Interaction effects were not significant. Across the three periods the mean moved closer to "Illegal"; from 1.07 in 1972-77 to 1.06 for 1978-83 and down to 1.03 during the third period. Summary. Table IX summarizes the differences in social attitudes by cohort and interaction of cohort and period.

TABLE IX

SOCIAL ATTITUDE VARIABLES SHOWING STATISTICALLY SIGNIFICANT DIFFERENCES BY COHORT AND/OR INTERACTION

Variable

Social Attitudes

Pro-Choice Scale

Sexual Permissiveness Scale

Sex Education in Schools

Pornography Law

Child's Role Adaptation

Child's Success Attitude

Spending for Education

\section{Cohort Interaction}

$\begin{array}{cc}\text { None } & \mathrm{p}<.10 \\ \mathrm{p}<.05 & .05 \\ .001 & \text { None } \\ .10 & \text { None } \\ \text { None } & .05 \\ .10 & \text { None } \\ .10 & \text { None }\end{array}$

In regard to abortion the cohorts ranked as more liberal from oldest to youngest. Across periods, though, while maintaining their relative positions, all cohorts became more conservative.

Across periods the 1910-14 cohort became less tolerant of pre-marital, extra-marital, and homosexual relations. The 1915-19 cohort had increased tolerance for pre-marital and extra-marital relations during 1978-83. During 1984-89 their tolerance of all three relationships dropped again. With the 1920-24 cohort tolerance for pre-marital sexual 
relations incrased by 1984-89 but declined for the other relationships.

These attitudes toward sexual activity may be reflected in the opinions about including sex education in the public schools. This was favored by 70 percent of the 1910-14 cohort, 73 percent of the 1915-19 cohort, and 80 percent of the youngest cohort.

Attitudes towards the distribution of pornography are probably related to sexual mores. Each younger cohort was more liberal, but 95 percent of the women felt this should be illegal. Across periods each cohort became more conservative.

The fact that 63.9 percent of the women felt it was not important whether a child acts like a boy/girl may also be an indicator of changing social mores. There was a shift toward least important across periods and from the oldest to youngest cohort.

Another indicator of differing attitudes may be the 1915-19 cohort responses regarding the importance of a child trying hard to succeed. They ranked this lower than did the other cohorts. This trait was considered least important by 25.6 percent of the women, and not mentioned by 61.9 percent of the total sample.

The women may not have felt that striving for success was important for children, but they did indicate that there should be more Federal funding to improve the na- 
tion's education system. From oldest cohort to youngest and from 1972-1989 the means shifted toward too little being spent.

Political opinions

Political party identification and political views (conservative/liberal) of the three cohorts were analyzed first. Second, variables regarding civil rights, crime control, federal international activity, and federal spending for elderly assistance were studied. Summary scales and analytic sub-scales were developed. Finally, an analysis of opinions about the role of women in government, as differentiated from the voting process, was made.

Political Identification. A question about memberships in organizations revealed that 3.6 percent of the women belong to a political club. A chi-square analysis showed no significant effects by Cohort, Period, or Interaction.

In spite of lack of membership in a political club the women did identify with political parties and conservative/ liberal viewpoints.

Party identification showed 11.3 percent as strong Republican and 16.7 percent as not very strong Republican. There were 23.3 percent who identified as strong Democrat and 24.9 percent as not very strong Democrat. Another 23.9 percent considered themselves as independent. The 
item range was from 1 to 7 , strong Republican to strong Democrat.

With regard to political viewpoint the percentages were: extremely conservative, 3.5 percent; conservative, 14.7 percent; slightly conservative, 16.1 percent; and moderate, 46.6 percent. At the liberal end of the scale there were 10.2 percent slightly liberal; liberal, 7.3 percent; and extremely liberal, 1.5 percent. The item range was 1 to 7 (conservative to liberal), with a population mean of 3.736 .

An analysis of variance of political viewpoint showed no statistically significant effects by Cohort, Period, or Interaction. However, the 1910-14 cohort began as the most liberal and became the most conservative. The youngest cohort remained in the mid position. Starting as the most conservative the 1915-19 cohort became the most liberal.

International Issues. An analysis of variance of the question as to whether the United states should remain in the United Nations showed no significant effects by Cohort, Period, or Interaction. The question regarding United States participation in international affairs showed no significant effects by Cohort or Period, but the Interaction effect was significant $p<.10$.

Based on a scoring of 1 = Take an Active Part in World Affairs and 2 = Stay Out, the cohort means by periods were as follows. The 1910-14 mean was $1.40,1972-77$; 1.50, 
1978-83; and 1.46, 1984-89. For the same periods the 191519 cohort means were $1.42,1.45$, and 1.34 . The youngest cohort (1920-24) had means of $1.46,1.39$, and 1.40. That is, although there were periodic shifts in opinions, overall the 1910-14 cohort women became more isolationist in their viewpoint. Women of the two younger cohorts became somewhat more participation oriented.

An analysis of variance on spending on foreign aid gave no significant effects by Cohort, Period, or Interaction.

Civil Rights, A scale to analyze opinions on Civil Rights issues was built by summing twelve variables. These variables were based on three actions of allowing persons to make a public speech, teach in a college, and have their books in a public library, for four groups of people. The groups were anti-religionists, racists, homosexuals, and communists. Internal reliability of the scale was validated by a Cronbach's alpha of .88. Higher scores mean that more toleration was shown by the respondents for the activity and for the group of people to whom it applied. An analysis of variance indicated that Cohort was significant at $\mathrm{p}<.01$. Period and Interaction effects were not significant.

The 1910-14 cohort was the most conservative with a mean of 16.37. The mean of the 1915-19 cohort was 16.98. The youngest cohort $(1920-24)$ was the most liberal with a 
mean of 17.41. The population mean was 16.97. Although non-significant, across the three six-year periods there was a shift toward conservative attitudes. In the first period (1972-77) the mean was 17.16. The mean dropped to 17.02 in the second period and dropped again, to 16.83 , in the 1983-89 period.

Sub-scale analyses, Tables $\mathrm{X}$ and $\mathrm{XI}$, also indicate that each younger cohort showed greater acceptance of the activities of the four groups. All the cohorts apparently felt that activities of Communists should be more restricted than those of the three other groups.

Crime Control. Opinions on how to control crime were examined by checking responses to three questions.

1. Would you favor a law which would require a person to obtain a police permit to purchase a gun?

2. Do you favor the death penalty for persons convicted of murder?

3. Is the federal government spending too litte or too much in trying to halt the rising crime rate?

Analyses of variance of the responses to the three questions indicated that only the question referring to permits for guns was significant; by Period at $p<.001$, and for Interaction of Cohort and Period at $p<.05$. Figure 7 shows the changes of the three cohorts across periods. During the 1978-83 period the oldest and youngest cohorts shifted toward not requiring gun permits while the 1915-19 cohort remained stable. During 1984-89 the 1920-24 cohort returned to its 1972-77 position. During 1984-89 the mid- 
TABLE $X$
ATTITUDE TOWARD THREE ACTIVITIES
OF FOUR SELECTED GROUPS

Cohort Means*

Significance 1910-14 1915-19 1920-24

\begin{tabular}{|c|c|c|c|c|}
\hline Allowed to Speak & $\begin{array}{l}\text { Cohort } \\
p<.001\end{array}$ & 5.76 & 5.90 & 6.17 \\
\hline Teach in College & None & 5.13 & 5.19 & 5.28 \\
\hline Have book in Library & $\begin{array}{l}\text { Cohort } \\
p<.01\end{array}$ & 5.62 & 5.95 & 6.00 \\
\hline
\end{tabular}

TABLE XI

ATTITUDE TOWARD FOUR SELECTED GROUPS

FOR THREE ACTIVITIES

Cohort Means*

Significance $1910-14$ 1915-19 1920-24

Atheists

Cohort

Racists

$p<.001$

4.01

4.10

4.31

$\mathrm{p}<.10$

4.19

4.29

4.36

Communists

$p<.001$

3.95

4.08

4.21

Homosexuals

$\mathrm{p}<.001$

4.20

4.43

4.52

$\star 1=$ No, $2=$ Yes Range 1-6

Activities: Allowed to speak, Teach in college, Have book in library 


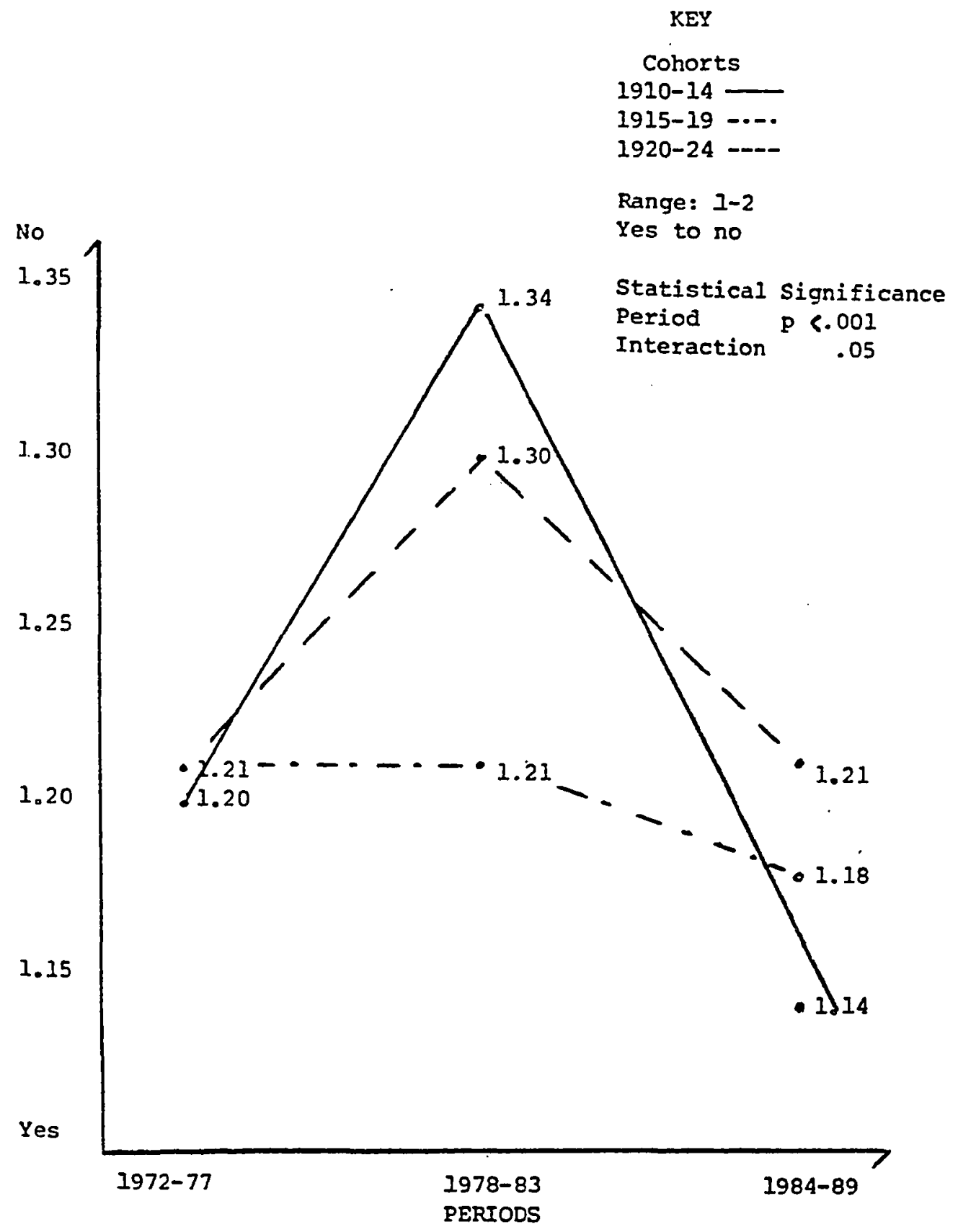

Figure 7. Opinions on whether police permits should be required to purchase a gun. 
dle cohort shifted slightly toward requiring gun permits. The 1910-14 cohort became most strongly in favor of this regulation. Overall 78.8 percent favored requiring gun permits.

The analysis of variance for the second question, regarding the death penalty, showed no statistical significance by Cohort, Period, or Interaction. Cohort means were 1.30 for the 1910-14 cohort; 1.31, 1915-19; and 1.28 for the youngest cohort. Capital punishment was favored by 70.6 percent of the women.

For the third question, regarding Federal government spending to halt the rising crime rate, an analysis of variance showed no statistically significant effects by Cohort, Period, or Interaction. on a scale of 1 - 3, from too little to too much being spent to halt the rising crime rate, the 1910-14 cohort mean was 1.30 . The mean was 1.33 for the middle cohort, and 1.34 for the 1920-24 cohort.

Federal spending $=$ General Welfare. Three items, spending on the space exploration program, for defense, and for improving and protecting the environment were considered. Pearson's correlations among these items were low so each variable was analyzed separately. In each case the range was from 1--spending too little, to 3--spending too much.

Analysis of variance on spending for the space exploration program showed a significant effect by period 
$p<.001$. There were no significant cohort or interaction effects. The period means were 2.67 for $1972-77 ; 2.53$, 1978-83; and 2.55 for $1984-89$.

The question of spending for defense analysis of variance showed a significant effect by Period of $p<.001$ and Interaction of $p<.05$. There was no significant effect by Cohort. As shown by Figure 8 , the means for all three cohorts fell toward "too little spent" during 1978-83 and rose during the third period, above the 1972-77 levels.

Spending for improving and protecting the environment showed a significant effect by Period p <.001. There were no statistically significant effects by Cohort or Interaction. Period means were 1.64, 1972-77; 1.75, 1978-83; and $1.53,1984-89$.

Federal Spending--Elderly Assistance. Four variables were selected to analyze opinions about the adequacy of federal spending on programs which benefit older people: social security, health, welfare, and mass transportation.

The question regarding social security funding was only included in surveys since 1984 so an across periods analysis was not possible. The Cohort effect was not statistically significant. The mean for the oldest cohort (1910-14) was 1.54. Both the middle and youngest cohorts edged toward the "too little" spent with means of 1.52 and 1.46 respectively. 


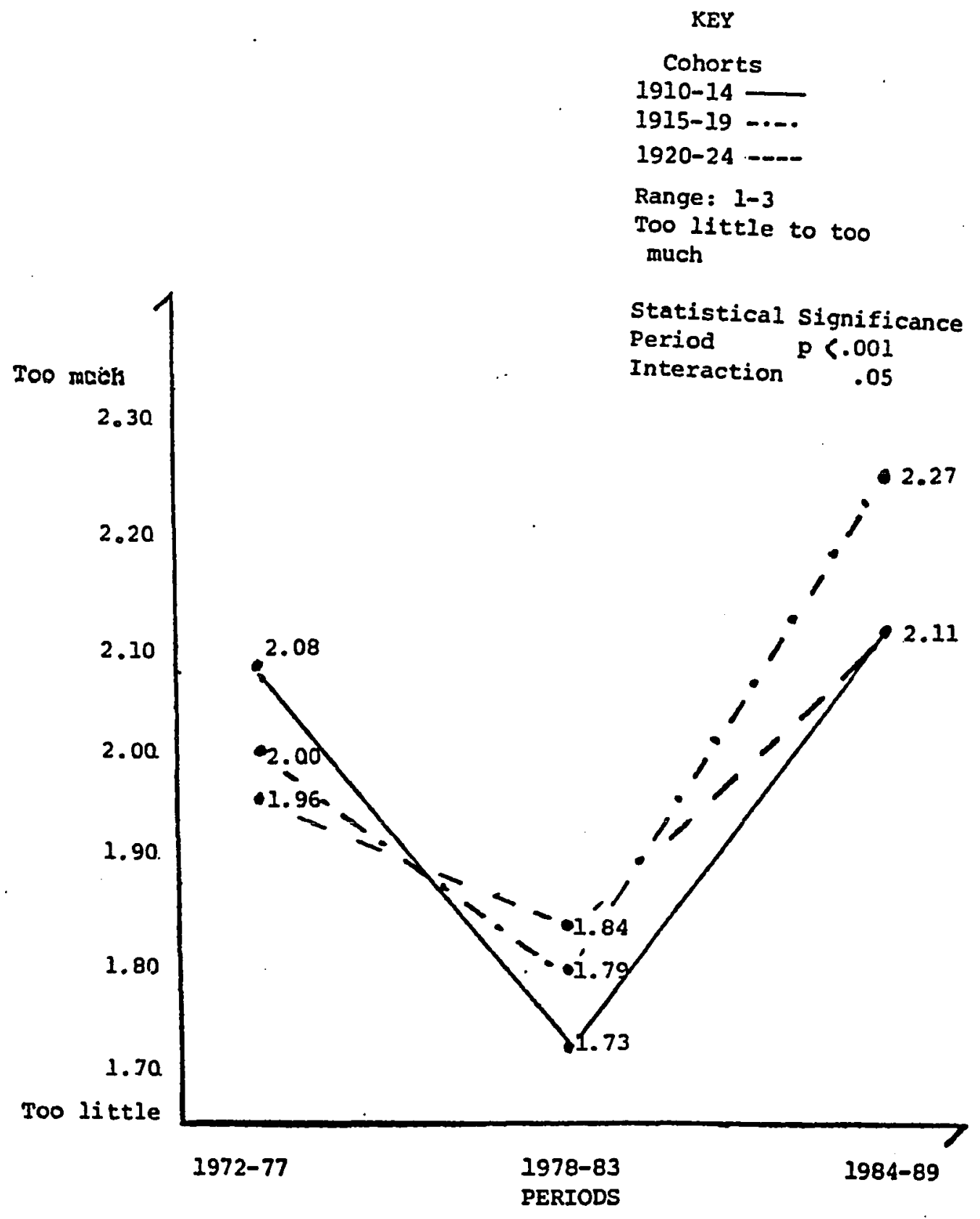

Figure 8. Opinions on spending for defense. 
Opinions on mass transportation funding were also surveyed only during the 1984-89 period. It is a more recent federal program with benefits restricted to urban areas. Federal regulations mandate that a transit system which receives federal funding must provide reduced fares and accessibility for the handicapped and elderly. The cohort effect was not statistically significant. Cohort means on the adequacy of funding were 1.80 for the 1910-14 cohort and somewhat toward "too little" for the 1915-19 cohort, 1.73 ; and 1920-24 cohort, 1.75 .

There was a statistically significant effect by Period, $\mathrm{p}<.10$, for the question regarding spending on health care. There were no significant effects by cohort or Interaction. Across periods the mean shifted from 1.44 during $1972-77$ to $1.49,1978-83$; then to $1.41,1984-89$.

For the variable about funding for welfare there was a statistically significant effect by Period $p<.001$. Cohort and Interaction effects were not significant. By period the trend was toward "too little" spent federally on welfare. There was a drop from 2.41 during 1972-77 to 2.39 during 1978-83. The mean dropped again, to 2.22 for the 1984-89 period.

Women's Role in Politics. A Women's Role in Politics scale was built summing three variables based on the three items: Women should take care of running their homes and leave running the country up to men; Most men are better 
suited emotionally for politics than are most women; and If your party nominated a woman for president, would you vote for her if she were qualified for the job? Internal reliability of the scale was validated by a Cronbach's alpha of .70. An analysis of variance indicated that each of the two main effects were significant: Cohort, $p<.01$ and Period, $p<.10$. There was no significant Interaction effect.

The scale showed a rise in feminist attitude across the three cohorts. The oldest (1910-14) had a mean of 4.63, the 1915-19 cohort ranked at 4.72, while the mean of the youngest cohort was 4.90 .

Changes in population means by periods showed the first six-year span (1972-77) with a mean of 4.68. During 1978-83 the mean rose to 4.87. The mean dropped to 4.75 during the 1984-89 period. These period changes may be a result of the rise of the Women's Lib movement, and its political defeats.

Summary. Table XII presents a summary of the variables which showed statistically significant differences by Cohort or by Interaction in this section on political Issues. 
TABLE XII

POLITICAL OPINION VARIABLES SHOWING STATISTICALLY

SIGNIFICANT DIFFERENCES BY COHORT AND/OR INTERACTION

Variable

Political Opinions

Civil Rights Scale

Gun Permit Law

Spending for Defense

Women's Role in Politics Scale
Cohort Interaction

$\begin{array}{cc}\mathrm{p}<.01 & \text { None } \\ \text { None } & \mathrm{p}<.05 \\ \text { None } & .05 \\ .01 & \text { None }\end{array}$

In regard to civil rights the 1910-14 cohort was the most conservative and the 1920-24 cohort was the most liberal. This was true in regard to the three activities and toward the four groups. Attitudes toward freedom to speak were the most liberal, followed by allowing books to remain in public libraries, and teaching in colleges. Tolerance for homosexuals was greatest, followed in descending order, toward racists, atheists, and Communists. As mentioned in the Review of Literature, education may have an influence on conservative/liberal attitudes. There may be other factors such as region of the country or type of residence during adolescence and early adulthood, or participation in the labor force.

From 1978-83 all three cohorts shifted toward not requiring gun permits. This shift was most marked for the 1910-14 cohort. By 1984-89 the two younger cohorts had shifted back to their original positions. The 1910-14 cohort had dropped from a mean of 1.34 to 1.14. Their 1972-77 mean had been 1.20. There is no indication as to 
whether these shifts were in relation to personal safety or to crime control measures in general.

National spending for defense also showed a marked change during 1978-83. All cohorts indicated that too little was being spent. The 1910-14 cohort showed the most marked shift. By the 1984-89 period the cohorts had shifted farther toward "too much spending" than had been their positions in 1972-77. These shifts may have been caused solely by world events, or there may be a connection with opinions such as not enough being spent to improve the nation's education system. This may also indicate that these women were aware of disclosures of cost overruns in defense spending contracts and of apparently exorbitant amounts paid for standard hardware items.

The rise in feminist attitude means across the cohorts from 1910-14 through 1920-24 (4.63, 4.72, 4.90), as indicated by the Women's Role in Politics scale, may stem from several factors. In addition to the women's Lib movement of the 1960s, the number of years of schooling, participation in the labor force, and increases in divorces/separations may have had their effects.

\section{CONCLUSION}

Throughout this chapter four section summaries, Family Background, page 36; Adult Life, page 54; Social Attitudes, page 66, and Political Opinions, page 79; have noted dif- 
ferences among the three cohorts. Possible reasons for these differences have been suggested. As the NORC data indicated there are demographic differences among the three cohorts. Each younger cohort has had more education and been more active in the labor market than the preceding cohort. This holds true even though more of the younger women married and had more children. Family income was higher for each younger cohort. It is not clear whether this is because of the husband's earning capacity or the two-income family.

On social and political issues the 1910-14 cohort was generally the most conservative, with the 1920-24 cohort as the most liberal. Possibly this difference correlates with more years of schooling. The 1915-19 cohort seemed to vacillate in their opinions. On several issues they shifted in a direction opposite of that of the other two cohorts. As was indicated at the beginning of the chapter the major focus of this research was on significant cohort differences and the effects of the interaction of cohort and period. However, some interesting period effects were noted. There were some issues that apparently affected all the women in a similar way regardless of their previous life experiences. Across the three periods the indication was that federal spending for education, health care, space exploration, and protecting the environment was inadequate. Although the younger cohorts retained their relatively more 
liberal opinions on the abortion issue, all three cohorts became more conservative across the three periods. The same effect is noted for the Woman's Role in Politics scale. These period changes may also actually be indicative that the Historical Change model of attitude and opinion development is valid for all age groups. Both the personal and public events which occurred from 1972 through 1989 apparently influenced the thinking of the women of the 1910 through 1924 cohorts.

The younger cohorts were comparatively more liberal on several social and political issues such as sex education in the schools, the legality of pornography distribution, sexual permissiveness, and civil rights issues. It is possible that these attitudes were developed from growing up in a more urban environment, more years of schooling, more work experience, higher incomes, and more contact with younger persons. These possibilities were suggested in some of the research studies reviewed in Chapter II. The study of older women by Sedney (1985-86) and the longitudinal study of Bennington College women (Alwin, Cohen, Newcomb, 1990) noted the influence of several of these variables. The expanded work role for women during World War I I as reported by Stewart and Healy (1989) may also have had a strong influence on the attitudes of the youngest cohort which would have been entering the labor market at that time. 
NORC quantitative data has been utilized to ascertain differences among the women of the three cohorts. It seems better at this point not to speculate about why there are cohort variations or on the differential influence of sociopolitical trends. In the focus group discussions the women explained the "why," based on their own experiences, in their own words. This qualitative data is the basis for the next chapter. 
CHAPTER IV

FOCUS GROUP DATA ANALYSIS

PURPOSE OF FOCUS GROUPS

As stated in the first chapter, focus groups were chosen as a means to clarify findings of the quantitative survey related to how the three cohorts differ. The focus group gives an opportunity to study attitudes and cognitions and produce insights that would be less accessible without the interaction found in a group. There is an opportunity to observe a large amount of interaction on a topic in a limited period of time. The purpose of these focus groups was to explore the perceptions of the women in the three cohorts of the influences of historical events and social pressures on their lives. That is, were the women aware of technological changes, labor force participation shifts, or changing marital and birth rates las mentioned in Appendix A) as influences on their personal life experiences? Likewise, could they suggest reasons for statistically significant differences in demographics or opinions indicated by the analysis (in Chapter III) of NORC survey data? 
RECRUITMENT AND PROCEDURE

Focus group data were obtained through a series of meetings held in Portland, Oregon, from June through November, 1990. Recruitment was through senior centers, senior housing complexes, and individual contacts. Initial contact was made by posted announcements similar to the bulletin notice shown in Appendix B. Telephone calls were then made to recruit individuals at each location. Pilot testing was done through interviews and a mixed cohort focus group session. Table XIII gives the number of participants by site and cohort.

At the start of each focus group meeting an informed consent form was distributed and explained (Appendix C). A demographic survey form (Appendix D) and a time line form (Appendix E) were also used. These forms were completed by each focus group participant. Where necessary the facilitator filled out the latter two forms as dictated by the participant. The author was the facilitator at all sessions. A note of thanks (Appendix F) was mailed to each participant and site administrator. Both the questionnaire and the time line forms used at the beginning of each focus group session provided valuable information. They also gave the participants confidence that they had a contribution to make.

A detailed summary of the information reported on the questionnaires can be found in Appendix G. This summary 
TABLE XIII

FOCUS GROUP PARTICIPANTS BY SITE AND COHORT

\section{Cohorts}

Site

Private Homes, SW

Senior Center, NW

(Combination Group)

Senior Center, NE*

Senior Residence, NW

Senior Residence, SW

Cohort Totals**
$1910-14$

$\underline{1915-19}$

2

2

2

4

4

5

3

4

3

3

3

3

13

14

14

* This senior center has members from both the northeast and southeast areas of Portland.

* Two of the women were in wheelchairs, three were visually impaired, and one was lacking her right hand. 
shows that, in general, the demographic data of the women participating in the focus groups match that of the larger sample of women who were surveyed in the NORC studies.

\section{FOCUS GROUP SESSIONS}

Time Iine Events

The women were asked to enter on a time line both public and personal events which they recalled as being important in their lives. These are summarized in a table in Appendix $\mathrm{H}$. There has been some grouping such as combining "Pearl Harbor" with World War II and designating some as "Local Events."

Next the women were asked to select only two events and tell the group why the events were chosen. In their responses the women also indicated how these events had affected their life situations or influenced their attitudes and opinions. These events have been summarized in Table XIV. The table also indicates which type of event, personal or public, was selected.

With public events such as World War II or the Depression there was usually a particular incident which was symbolic for that woman. Some of the women connected World War II with brothers or husbands in the service. However, one woman (1915-19 cohort) joined the WAVES and on the train trip to boot camp saw her first cow.

Perhaps less exciting, but no less important are the figures from Table XIV which indicate the emphasis placed 
TABLE XIV

SUMMARY OF TWO EVENTS SELECTED FROM THE TIME LINE

$\begin{array}{lccc} & \begin{array}{c}\text { Cohort } \\ 1910-14 \\ \mathrm{~N}=13\end{array} & \begin{array}{c}1915-19 \\ \mathrm{~N}=14\end{array} & \begin{array}{c}1920-24 \\ \mathrm{~N}=14\end{array} \\ \text { Number Selecting } & & & \\ \text { Personal Event } & 2 & 11 & 9 \\ \text { Public Event } & 6 & 1 & 0 \\ \text { Personal and Public Event } & 5 & 2 & 5\end{array}$

PUBLIC EVENTS

World War I

Flu Epidemic

Abdication of Edward VIII

Depression

World War II

Vanport Flood

Kennedy Assassination

Vietnam Conflict

Drug Scene of $1960 \mathrm{~s}$

Mt. St. Helens Eruption

1
1
1
5
6
1
2
2
0

$\begin{array}{ll}0 & 0 \\ 0 & 0 \\ 0 & 0 \\ 0 & 3 \\ 2 & 1 \\ 0 & 0 \\ 0 & 0 \\ 0 & 1 \\ 1 & 0 \\ 0 & 1\end{array}$

PERSONAL EVENTS

Schooling

First Radio at Home

Employment

Joined Navy

Volunteer Work

Marriage

Divorce

Birth of Children

Children Left Home

Death of Mother When Young

Care of Parents

Illness

Move to New Area

Death in Immediate Family

Travel

Retired

Public Garden Plot

1
1
1
5
6
1
2
2
0
0

0
0
0
3
1
0
0
1
0
1

$\begin{array}{lll}0 & 4 & 1 \\ 0 & 1 & 0 \\ 0 & 2 & 3 \\ 0 & 0 & 1 \\ 0 & 2 & 0 \\ 0 & 6 & 5 \\ 0 & 0 & 1 \\ 1 & 1 & 1 \\ 0 & 0 & 1 \\ 0 & 1 & 0 \\ 0 & 0 & 1 \\ 0 & 2 & 0 \\ 0 & 3 & 4 \\ 0 & 0 & 4 \\ 1 & 3 & 0 \\ 4 & 0 & 0 \\ 1 & 0 & 0\end{array}$


on personal events, particularly on marriage and family, by the 1915-19 and 1920-24 cohorts. This would seem to indicate an increased social pressure during the late 1940 s and 1950s on homemaking and "togetherness."

Rapid changes in the communication and transportation sectors in this century are noted in Appendix A. The fact that these changes were taking place during the lifetime of the women of the 1910-1924 cohorts does not in itself indicate that they had any effect on the women's Iives. However, responses on the brief survey and time line forms indicated that these women were aware of the effects in their lives of these developments. Some specific examples follow.

Transportation. A recollection of her first train ride was noted by a woman of the 1915-19 cohort. But one woman said that the importance of plane travel becoming common should not be overlooked. The travel experiences listed, particularly by the 1915-19 cohort, indicated that the travel was by plane. Women from the two younger cohorts stated that they did not learn to drive until they were adults.

Communication. Movies, particularly the weekly newsreels, were important to a woman of the 1915-19 cohort because her small town did not have a newspaper. Newsreels of some of the suffragette demonstrations were recalled by a woman of the 1910-14 cohort. Two other women of this 
cohort reported that their customary Sunday afternoon movie plans were disrupted on December 7,1941 , by a radio broadcast about the bombing of Pearl Harbor. At first they thought the announcement was another radio drama by orson Welles. A woman from the 1915-19 cohort said her family's first radio was battery operated with one set of headphones. She would rush home from school to listen to Orphan Annie or Jack Armstrong, the All-American Boy. Another woman from this cohort, a WAVE at the time, was in Times Square on VE day and was the first person to say "Hello" by radio to the troops in Europe.

As indicated on the focus group questionnaires, the effects of expanding telephone service were noticed in the job market area. The father of one woman (1910-14) owned a small telephone company. One woman of the 1915-19 cohort worked for a phone company, but four women of the youngest cohort had been employed at various job levels by phone companies.

Population Growth. Population expansion pressures were not experienced by these women as they were growing up. There were numerous references to "my small town" and oneroom or one-building schools. Thirty-six of them reported living, at age 16 , in the Central or Pacific states. Five were from New England or the Middle Atlantic states. A woman from the 1920-24 cohort thought that the development of suburbs was indeed an indicator of increasing population 
after World War II because, "There is a limit to the number of people who can be crowded into a city."

Education Patterns

In addition to indicating on the questionnaire the number of years of schooling, the women were asked to tell where they were living during the schooling period and what kinds of courses they studied. They also discussed how their lives might have been different if they had more, or less, education. The women's responses were revealing of societal attitudes and pressures.

For the 1910-14 cohort the educational pattern was business courses in high school or business school, or two years of nursing school at a hospital, or three or four years of teacher training. During the 1960s three of the women returned to college for a refresher course in teaching, a master's degree in social work, or classes in oriental art and literature.

The 1915-19 cohort women also mentioned teaching, nursing, and business courses. Rather than attending business schools the post-high school enrollments were at junior colleges. Four of the women mentioned that the depression made it impossible for them to continue their education beyond high school. Three of the women had gone on to do graduate work, one in the field of chemistry. 
However, five of the women had chosen to marry rather than complete their post-high school education.

There were three college degrees among the women of the 1920-24 cohort. Two women mentioned the depression and one mentioned marriage as limiting their education. Nursing and teaching were still vocational fields, and library work now required a degree. The area of business was also seen as a "career" rather than a stage between school and marriage. In addition to business college the women mentioned in-house courses in banking, industry supervision, and business psychology. These younger women also seemed to have fewer interruptions, more continuity to the educational process than did the two older cohorts. This may have been because of improving economic conditions in the late 1930s.

Effects of Education. Another question the women talked about was whether more or less education would have affected their Iives.

A woman in the 1910-14 cohort felt that more education couldn't but help in life. Another felt that additional education was necessary to remain in the labor market. Three of the women mentioned that with less education they would not have met their husbands.

One woman in the 1915-19 cohort concurred with these three women and added that her husband was a civil engineer. Therefore, with less education she probably would 
have worked more "because it seems sometimes women from lower income households do have to work more to help support the family."

Two of the women regretted not having completed college. One said:

"It would have been nice when the children were grown to use the education. At that time it seemed for women it wasn't important and after getting married they were just a homemaker."

One woman in the same cohort wished she could have gone beyond eighth grade because she wanted to be an artist, but has since taken painting courses. As another woman said:

"Personal enrichment whether in a school system or just on your own initiative is always good."

The connection between education and marriage was still somewhat evident among the women of the 1920-24 cohort. One woman would have liked more education but it took her husband seven years to get his advanced degree. A second was divorced after twenty years as a housewife and her life would have been much more difficult without government financed job training at that time. A correspondence course in business enabled one woman, when her children reached school age, to get a university library job.

A new element among the 1920-24 cohort women was the wish that they could have chosen different fields. One woman had wanted to be a dress designer, another wished she had not become a nurse, while a third had wanted a career 
in music rather than as a music teacher. Finally, the woman with a degree in library science had really wanted to become a geologist--but there were no jobs open to women.

Summary of Education Differences. As indicated by the NORC data each younger cohort averaged more years of education. Responses by the women of the 1920-24 cohort in the focus groups seem to indicate that the average schooling for these younger women may be more than the NORC data indicates. These women participated in on-the-job training programs which may not have been tallied as years of schooling in the national surveys. The shift in emphasis from nursing or teaching to the area of business presents another aspect of educational differences among the cohorts.

The 1915-19 cohort women were the most likely to marry rather than continue their education. This seems to tie in with the previous time line report in that this cohort is the one that chose most frequently to report on personal events. Another area of difference, as reported by the women, is that the 1920-24 cohort were aware at the time that their educational choices were being limited to the traditional fields of teaching, nursing, or clerical/sales training.

\section{Labor Force Participation}

Labor force participation for women, including married women and mothers, has risen quite steadily in the 20 th 
century as noted in Appendix $A$ and Chapter III. These figures show overall labor force participation. They do not give any indication of whether there was a pattern of women moving in and out of the labor force. Nor do they show the reasons why the women did or did not work outside the home nor their feelings about being homemakers or employees. Therefore in the focus group sessions the women were asked what types of jobs they had held, whether they worked before and after marriage and children, and what might have been the effect on the lives of more, or less, participation in the labor market.

Differing Work Patterns. From the 1910-14 cohort two women reported working while in school to help with expenses. Another, although married, worked all her life chiefIy as a secretary. Ten of the women worked until they were married and had children. Four went back into the labor market after divorce or the death of a spouse. One woman said that she had not gone back into the labor force because she was taking care of her mother at home. The one woman who had married shortly after graduating from high school did not enter the labor force until her husband died. The occupations mentioned were concession stand attendant, nursing, teaching, secretarial, cashier/sales clerk, and newspaper work.

The women had difficulty in visualizing a different work pattern in their lives. As one of the women remarked, 
"In those days housework took all the time." In contrast, hand, the women who returned to the work force felt it was an economic necessity. They were supporting small children or had chilaren of college age.

In the middle cohort (1915-19) there was one unmarried woman. She worked as a nurse until retirement. A second woman worked part-time in a drug store during high school, college, and while married until her children were born. Eleven other women worked after they were married until they had children. The fourteenth woman did not work after marriage, but after divorce had to return to department store work to support her daughter. Four of the women returned to work after divorce or husband's death. Five of the women, however, returned to work when their children were of school age.

These women also mentioned teaching and secretarial work, but also noted department store work, bookkeeping, bank teller, chemist, activities coordinator, Welcome Wagon visitor, and blueprint maker. Six women of this 1915-19 cohort emphasized the importance of the volunteer work they did during the years they were at home with young children. One woman reported when she realized how many hours were spent outside the house doing volunteer work she decided to get a job because the kids needed orthodontia.

This cohort also felt they could not imagine a different work pattern because of being responsible for up to 
seven children. However, as indicated by the women who returned to work after the children were in school, two incomes were becoming a necessity.

In the 1920-24 cohort one of the women remained at home after marriage until she was divorced, while two worked continuously even after marriage. Thus, eleven women remained in the labor force after marriage until the birth of children. Four returned to work after divorce or the husband's death, while six were at home until the children were at least in school. In addition to listing teaching, nursing, secretarial work, bank teller, the women mentioned library work, case worker, telephone company employee, waitress and cafeteria management, cooking at logging camps, photography, retail store experience, and electronics factory work. Two had experience running their own businesses, an antique shop and a small resort.

Two of the women joined the navy during World war II while others recalled working in a frozen food packing plant and Boeing because the men were away in the service. And the pay was up to 80 cents an hour and there were 12 hour shifts.

As far as a different pattern of labor force participation was concerned the 1920-24 cohort indicated it would have been humanly impossible to work more--one woman was holding down two jobs. Another went back to work as a 
nurse a few weeks after her fourth child was born at the age of 42 .

Likewise they felt that remaining at home would have been economically impossible. Four of the divorced women were raising several children with no help from the fathers. One said she had some help from her family, "but we were never on welfare." Two of the women found it necessary to continue working while their husbands completed courses for their degrees. There was also mention of paying for the children's education. One woman mentioned that she and her husband have an easier retirement because her pay helped build up their savings.

Several comments, in response to another question, indicated that the women felt that insisting on working outside the home would have jeopardized the marriage relationship.

The Homemaker Role. Judging by the women's work force participation patterns, the concept of "homenaker" as a lifetime career has disappeared, particularly among the younger women. The women were asked, though, for their opinions on being a "Homemaker" as a lifetime cミreer. The women made some comments on this question.

One woman (1910-14) said there was a period when she bitterly resented having to go to work but now she is glad for the retirement income. When her second husband insisted that she retire she realized she didn't want to retire 
very much. She liked the work (case worker) and is not particularly domestic.

Members of the 1915-19 cohort seemed ambivalent about the homemaker role, and sometimes a little defensive. A 1915 born woman said, "Who wants to be in business if they can have a lovely home and enjoy their home?" Another, born the same year, commented that her kids as teenagers liked to be able to come home and first thing they would do was yell for mother. She also noted that in some families the kids are just neglected. Another stated that her husband had worked swing shift while she worked days so the children were not without parental guidance. Still another was helping to take care of her parents as well as the children.

However, one woman went to work for a florist in Juneau because she felt so inept when so many women were working. Welcome wagon training came as a relief from three kids for another woman. Still another said:

"It's good experience to get out after being tied down with your children so many years. I enjoyed it."

A 1919 born woman: "I think it (homemaking) is very important. I think you can combine that with a career but it would be very difficult. Too many men don't want to do their part."

But to a later question on family size this same woman said:

"I don't know what I would have done with only one or two children rather than seven. I would have been young enough to get out and do some- 
thing. I certainly couldn't have just hung around. I would have gone back to work for sure. How long after the youngest I don't know."

Comments of the 1920-24 cohort women speak for themselves.

"I enjoyed 20 years at home but did not grow up until after the divorce."

"Financially impossible." (Not to work.)

"I never regret that I was at home with them for those years, but I was happy to go back to work after they were in school. I didn't have to."

"When the children were up a ways, I felt deprived so decided it was time to do something different, so I took office classes."

"I was never raised that way. Cooking at logging camps is not like that."

"I always wanted a career."

"I really enjoyed it at Boeing--four years--but he made me quit." When remarried and in her forties: "I was tired of it, I wanted something to do besides walk the street and look at pretty flowers."

"My husband was German and women stayed home you know."

"My husband felt very strongly since he was working I should stay home with the children. That's what we were expected to do and I did it."

Workplace Discrimination. A final question related to work experience was: Did you encounter any job discrimination because you were a woman?

Women in the 1910-14 cohort could recall no instances of discrimination as sales clerks, teachers, or nurses-with the unwitting qualifier, "There was no discrimination. Nursing was a woman's job." However, one woman said that 
as a married woman she received static from the single nurses about her husband not supporting her. In the accounting field women were advised not to bother to become CPAs as some employers would not let women touch the books. Women received one-half to one-third the pay of men. The woman reporter also was not paid as much as the men. While there were many demands on her she did not get the interesting assignments. Two women recognized later that "there were not all the choices in those days," and that they might have enjoyed other choices than the opportunities then offered.

Women of the 1915-19 cohort exhibited different outlooks on the discrimination issue, depending somewhat on their birth years. Several 1915 born women said they didn't think there were work limitations in the early years or they hadn't thought about it. One of them reported that she had never had any man discriminate against her in her whole entire life. She was one of the first two women on the Pacific coast to be offered a slot in a bank executive training program. Later she accepted an opportunity for executive training in a department store--"All these young men, all of them having graduated from the $U$ of $C$ and the $U$ of $W$ in merchandising, and I was the only woman."

Others noted that all the men were addressed as "Mr." but the women were called by their first names. They thought this might have been discrimination but had paid no 
attention to it. "I guess I wasn't liberated at that time." They also noted smaller wages.

"But you weren't in a position to know. You took what you could get and were thankful. In Massachusetts women could not work more than eight hours so they had to do split shifts."

One woman recalled that her mother in the $1930 \mathrm{~s}$ had great difficulty trying to get a job as a junior high school principal.

Those women born in 1919 were much more emphatic about workplace discrimination. For example:

"Boy I was sure limited in my choices because I was a woman. They were even going to fire me. I was doing scientific work, but during the war it was kind of routine work testing engine parts--no research or anything like that. It was only because of the war that they started thinking. When I went in there was one girl working in the whole department. She worked there a few months and they finally hired two girls--myself and another one. I worked up until six months before my child was born because at that time you had to leave work when you got pregnant--once you started to show you just weren't allowed to work. Just a few months previous to my leaving they needed an assistant in our division. Our boss had died, and the assistant was promoted and they finally agreed that I could be the assistant. Because they were not giving girls jobs like that - girls couldn't be given responsible positions because after all girls might get married and quit."

The 1920-24 cohort women enumerated specific examples of job discrimination against women. One woman realized

that she, too, had been prejudiced.

"I remember thinking as a kid going to look for work, and there were older women in the office, and I thought to myself 'Why aren't they home taking care of their kids?'--I don't know how I could be so arrogant thinking that way." 
These women realized they had been limited because of their education.

"The only choice was nursing or teaching. I realized later public relations was my interest."

"I wished for a different occupation, but we didn't know in those days."

"You were not given an educational chance because you were supposed to get married."

One woman had been advised that only men could be geologists, and another that only men could be math teachers because that position was combined with coaching. They also reported that in the $1940 \mathrm{~s}$ when a teacher became pregnant she had to quit. And even in library work there was a feeling that a man could be a better administrator. The women reported both pay and promotional discrimination in banks, telephone companies, a retail chain where no woman could become a department manager, and at a photography shop where the women never went out with the camera. One woman felt she had been swindled out of her sales commission by a national candy company; which they wouldn't have tried to do to a man. There were reports of discrimination against female civilian workers in the armed services and for civil service workers. One woman had been trained at government expense and had interned for six months as a county inventory control clerk. At this point she was told inventory clerk was a man's job and a man got the job. 
Summary of Labor Force Participation. Differences among the three cohorts show quite clearly in their attitudes toward labor force employment, as contrasted with homemaking as a full-time career, and in their perceptions of gender based workplace discrimination. In general the women left the labor force upon marriage or pregnancy. The younger women were quick to point out that this was because the regulations permitted no choice. Some noted that this was an example of workplace discrimination.

Most of the women did return to the workplace, either after the death of a spouse or as the children became older. However, women of the 1910-14 cohort were inclined to emphasize the economic necessity of their participation in the job market. The middle cohort, while mentioning the economic need for their earnings, placed more significance on the fact that by working they were in no way neglecting their homemaking role.

Several of the later born women of the 1915-19 cohort and women of the 1920-24 cohort, although mentioning finances, were guite outspoken about being happy to go back to work and wanting a career. Some also stated that it was only the husband's edict that kept them in the homemaker role.

As far as gender based workplace discrimination, some of the 1910-14 women still seemed unaware that being channeled into nursing, teaching, or sales work, with little 
chance of advancement to an administrative position, could be considered discrimination. The 1915-19 cohort women again split on an age basis. As noted, a 1915 born woman did not see the larger picture when she was the only woman in an executive training class. Those born in 1918 or 1919 had become aware that there had been discrimination, even in such details as to how people were addressed.

The youngest cohort (1920-24) was aware of workplace discrimination in pay scales, positions reserved for males, advancement opportunities, and pressures to limit their education or advanced training. To give a better sense of the range and intensity of the arguments of this youngest cohort, a segment of one of the focus group transcripts is included as Appendix I.

It seems to be somewhat evident that not only are there experience and attitudinal differences among the three cohorts but that the middle cohort tends to lean toward the 1910-14 or 1920-24 cohort based on birth year. In sum, the women born after world war I seem much more aware of overt and subtle discrimination in the workplace, and that the roots can be in educational options. They also feel that marriage and motherhood should not automatically disbar a woman from working. 
Political Participation

Following the discussions on educational and work experiences the focus was shifted to political views and the role of government.

Suffrage Amendment. Because it is the basis for women's participation in the electoral and governing process, a question was asked relative to the impact of the 19 th Suffrage Amendment which was ratified on August 26 , 1920 .

None of the women of the three cohorts felt that the ratification of the Suffrage Amendment had a specific impact on their lives because they were too young to vote at the time. By the time they were 21 and able to register as voters, in most cases, they did not realize that their mothers and grandmothers had not always been permitted to vote. However, there was agreement that it had made a big difference in women's lives. It opened up their interest in politics and in participation.

One woman from the 1910-14 cohort recalls hearing talk and men saying, "Oh, women don't know enough to vote!" Another who was only four years old in 1920, registered to vote as soon as she was eligible and has voted ever since. She felt that women in politics have made a difference. "Before that woman was a chattel, with no brains and no standing at all." 
From the 1920-24 cohort there was a report of stories that grandmother had picketed, but another grandmother never voted. Another woman recalled her mother having discussions with her father that she was entitled to her own opinions in voting.

The dissenting opinion was from a 1915 born woman who felt the Amendment was not that necessary. A family should vote together, and the men were taking care of women by enacting protective laws.

Political Identification. As far as their own political views were concerned most of the women of the 191014 cohort stated that they had not been much into politics, nor had their views changed much over the years. However, several of the women expressed the thought that today no one party is better than the other. "There is no statesmanship in the people who are running for public office." Four of the women felt that children and young adults are conservative, in that they follow parental or peer group trends. As these women got older and lived more and thought for themselves they became "conservative liberals."

One woman told of being changed from non-participation into a rabid Republican by her mother-in-law. She then insisted that her own mother register, which she did--as a Democrat. Later this woman became a social worker and when the Republicans cut funding for essential things like day care she angrily changed her party registration. 
The 1915-19 cohort also commented that as young women they were not much interested in politics and followed the family pattern. One woman noted that her family lived in Washington, DC, while she was growing up so she was never able to vote until she married and moved away. One "rockribbed Republican from Maine" changed her party affiliation because of "Tricky Dickie" (Nixon). They also indicated that in general they try to vote the candidate and the issue rather than a party line. Another felt that she became liberal because of her years of work at a neighborhood center. The Reagan administration strengthened the liberal views of several of the women.

Women of the 1920-24 cohort seem to have been more politically active than the older women. Because of the Hatch Act one woman, a civil service employee, was not permitted to campaign for candidates or issues. One woman of this cohort also grew up as a "Black Republican" but found her work in public welfare an eye-opening experience, although she is still not a flaming liberal. Another woman felt that she has calmed down a lot from her bleeding heart high school days. She is still a fairly liberal Democrat but has come to the conclusion that too much help is bad. The present welfare system has done much damage.

A "Flaming Democrat" also felt that people need to do for themselves, but need to be shown how. She became active after World War II and then in door-to-door civil 
rights campaigning in Georgia during the Kennedy era. Civil rights became the interest of another woman because she is Jewish and worked for a lawyer who was director of the Anti-defamation League of B'nai Brith. She mentioned also that her husband had become very supportive.

The One World concept of Wendell Willkie and the World Federation of Norman Cousins, of their college years, influenced two of the women. The husband of one of the woman was a conscientious objector during World war II.

Activities of the League of Women Voters were mentioned by several woman as helping them to consider issues and candidates. There were also comments from this cohort that the "fat cats" and "grabbers" in politics are not to be trusted.

Government Officials. Next the question was asked whether women should be elected to public office. The consensus was "Yes." Some comments from each cohort follow. $1910-14$

"Yes, if they do the right thing. Just because they are women doesn't mean they aren't as smart and can't manage things as well."

"I wonder about a woman president. It's the person, don't you think?"

"It balances our lives to have women in politics."

$1915-19$

"They do a better job many times. Usually they are more concerned about the ethical way."

"Other places have women as heads of government." 
"I'd be glad to see a woman president. They are more forthright with less wheeling and dealing. They are more sensitive to nuance."

"Yes, but there will never be a preponderance because men like the situation as it now is."

$1920-24$

"I don't feel as comfortable with a woman in pollitics as I do a man. And yet the other day I went just the complete opposite. (November, 1990, election)

"Women do pretty good. I voted for a lady this time--first time ever."

"Just as capable."

"Women have learned to live within a budget and I don't think our government has learned that yet."

A: "There's got to be a time for a woman to become president. Not because she's a woman, but is qualified."

B: "Why? We've had men that weren't."

Humor aside, supporting remarks of each younger cohort were more firm. The remarks of two of the 1920-24 women also indicate that the women do make considered judgments and change opinions even after age 65 .

Feminist Movement. The women were also asked their opinions about another political movement, the Feminist Movement of the 1960s. It is perhaps of interest that one woman (1920-24 cohort) equated this movement with the Civil Rights movement.

For the most part the women of the 1910-14 cohort linked the feminist movement with changes in family life and social interaction. They voiced disapproval of the perceived effects. Several women feared the movement be- 
cause it disrupted the home and was one of the reasons for delinquents and violence. "The young children they (women) bring into the world are one of their primary responsibilities." There is really no substitute for a mother. One woman stated that she had no respect for (Eleanor) Smeal because her activities in the National organization for Women had ruined her own family.

Another response was that feminists were "carrying things too far--it seems as if they do so many queer things. I get kind of disgusted with them." Getting into men's dressing rooms and clubs was thought to be stupid and going too far. Everybody has a right to a private spot. Women's clubs should not have to admit men.

However, the statement was made that, "If anybody wants a career I think it's wonderful." And business is done at lunch meetings at clubs. One woman who worked with younger women in her university studies thoroughly approved of the gains.

Women of the 1915-19 cohort also mentioned perceived losses in interaction with men. Some of the little niceties made them feel special. One woman thought that to some extent women had made themselves tools of men. She further stated that (without a marriage contract) women were exploited because men saved on living expenses and then got a free lunch as far as their personal lives. 
Another (b.1915) stated that the Equal Rights Amendment was not necessary--women had almost all those things.

Although they personally were not affected, some of the women (b.1919) had begun to understand the motivation for equality in pay and recognition, as well as the need for child care. The Feminine Mystique by Betty Friedan was mentioned. As for bra burning and other demonstrations several women felt that the press made fun and missed the real point. Also, "Some women do a better job out of the home than in the home."

Discussion of the feminist movement among the women of the 1920-24 cohort centered almost entirely on the job market. There was mention that some of the demonstrations and demands were a little extreme and beside the point. One woman said the movement made a big splash on the small college campus in Maine where she was living. There were talk sessions and book review clubs but not much action.

As far as types of jobs, a woman said women were making themselves macho by becoming linesmen, firemen, and policemen and "taking jobs away from men supporting families---of course, a lot of women are too."

Most felt that women should have equal rights if qualified for the job and the same pay for the same job. In certain capacities it is necessary to be able to join business clubs. As mentioned in the first paragraph of this section, one woman equated the feminist movement with 
the civil rights movement. She further indicated that women have had to deal with a lot more physically and psychologically; particularly the reactionary feelings toward women by men thinking in terms of the Dark Ages.

The Federal Government

Role of the Government. The basic question asked in the focus groups regarding government was what should be the role of the Federal government.

Women in the 1910-14 cohort tended to link the role of the Federal government with specific programs. However, one woman said that while there was too much Federal intervention, changing the present status might be like trying to put the toothpaste back in the tube. It was conceded that not all the toothpaste should go back in the tube because the people could have equalization of services from Federal jurisdiction which would be very unequal when left to local and state governments. The Federal government should not try to take on everything because local areas have different problems.

There were also indications that Federal officials should be statesmen. They tended to turn into politicians trying to remain in office for a lifetime. One woman stated that she could not answer the question intelligently. Some things about the government really frightened her because we are only told as much as is judged to be 
good for us. Locally we have only one newspaper so only one point of view is presented.

According to women of the 1915-19 cohort the Federal government should set the tenor for the whole country and set some standards (such as voting regulations) to make things fair and reasonable throughout the states. The states need some control over programs as situations are different in widely separated areas. However, when the airlines and Savings and Loan Associations, for example, were deregulated chaos resulted. The big, long-term plans (environmental concerns and the War on Poverty) should come from the Federal government and be augmented by state and local governments.

People as well as the government should decide just what we can afford to do. There is a need at all levels of government to cut back on a bunch of things to get the country back on a sound plane.

Another point raised was the government should not control family issues, one's personal life.

"Just because I think one way doesn't mean you should be forced by the Federal government to agree with me."

The role of the Federal government is to coordinate activities, but not mess with the states, according to women of the 1920-24 cohort. The Federal government should be an enabler. It depends on whether state finances can handle the programs needed to help their citizens become 
productive and normally healthy. Unfortunately, when the Federal government has the money it usually needs to be the leader in whatever program it is. But the bigger the organization the more the rules and restrictions are not geared to the local situation.

Lack of leadership was noted in that officials after being voted into office do not keep their campaign promises. Without Iimitation on terms of office they become interested only in protecting their own position. Similarly, commissions and committees are set up to investigate and study problems. The recommendations are not carried out and a few years later another study is funded.

One woman raised the question as to why the Federal government was subsidizing airlines and farmers. A business should be able to run without so much government assistance.

How to spend tax money. The women were next asked to give their opinions on the best, most useful ways to spend tax dollars. The three cohorts shared almost the same priorities as to programs which should be funded. There were differences in outlooks as to program goals and administrative practices.

Education, which should include job training, and health care education and good nutrition information, was a priority of the 1910-14 cohort. Health care and child care were mentioned. In the latter area western European coun- 
tries do better; anything for children is done grudgingly here. Social security and the welfare system need to continue, but inequities should be eliminated. Still, one woman felt that money should not go to drunkards, and at one time "every Indian in (city name) was getting great big welfare checks and that, having a good time."

Our own people should be helped rather than sending aid to foreign countries. Also, one woman stated, there are too many immigrants which require new schools and everything from the ground up.

Uncertainty about how to usefully allocate money to programs was voiced by the 1915-19 cohort. They questioned how to combat drugs, how to provide education for deprived kids, what is the reason for homelessness, and how to finance housing considering the S\&L scandal. They did, however, refer to practices in other countries and at other times. Canadian national health provisions were cited, as was housing for the elderly in Sweden. It was suggested that education did not require expensive buildings. NYA (National Youth Administration) and WPA (Works Progress Aaministration) type projects provided some job training and work experience and held down welfare costs.

Money should not be spent on aid to foreign countries before the problems of this country are solved. The United states should not try to be a big brother to the world. There was also mention of waste in the military and 
space projects. One woman who had been an army child and military wife questioned whether we can afford war, because it takes away from programs that could help the people. (This was in November, 1990, at the time of the Irag/Kuwait crisis.)

Funding for the National Endowment for the Arts should be deleted according to several women. The wealthy can support museums, operas, and ballets which are not of interest to most people. (Part of this reaction may have been caused by the Mapplethorpe pornography controversy.)

Women of the 1920-24 cohort thought that education programs and health issues, particularly insurance, were of major importance. Grants should be made to students but debts should be collected. As far as assistance to the homeless or other needy the emphasis was on training and work programs. Senior centers were considered as worthwhile as all elderly do not have children who can or will help them with day-to-day living. And, possibly more should be designated to study of alternative power sources.

On the opposite side, remarks were that less should be spent on other countries; particularly military aid. At the same time it was asserted that the united states does not need such big defense expenditures, particularly star Wars or $\$ 700$ hammers or screwdrivers. One woman stated that she felt, ever since she worked on any army base in 
World war II, that much money is wasted on spending which is not directly related to defense goals.

Summary of Political Opinions. Differences among the cohorts on political issues and the role of government seemed to be minimal in comparison to those related to education and labor force participation. It is of interest, though, that changes in political identification were toward the liberal end of the conservative/liberal continuum.

The women themselves recognized that their employment experiences and living in several sections of the country changed their outlook on issues. This was evident particularly in their concern for equitable financing such as for education. Apparently they also kept informed on world affairs as evidenced by the citing of national programs of other countries.

\section{Cohort Comparisons}

Comparisons between older and younger women was the last discussion topic. The focus group participants were asked whether they thought women who were somewhat older, or somewhat younger, than they were any healthier or happier, or whether their lifestyles were different. These are rather nebulous concepts. The women tended to make generational comparisons or to report their own experiences as being different. 
Health. Perceptions of women of the 1910-14 cohort were that older women endured illnesses more; they expected illness. Health care has made wonderful strides, but maybe it is not a good thing to be kept healthy if you are not mentally alert. One woman reported that she had all her own teeth because the family had lived in hard water country and couldn't afford candy.

For the 1915-19 cohort better health for themselves was equated with trying to eat right, cut down on cholesterol, and getting into exercise. Neither older nor younger groups (particularly grandchildren) are doing these things. However, they thought that older women lived simpler lives with less stress and strain. Health care improvement brought out the point that nursing home costs are incredibly high, but so are the premiums for such insurance.

The idea that older women accepted illness and death a little more easily was mentioned by the 1920-24 cohort also. They also pointed out that rural life was a cleaner life and less stressful. Medical advances and payments by Medicare and Medicaid were also noted as aids to better health. They felt they had become more nutrition conscious and that the food stamp program should be an aid to a better diet.

However, as one woman pointed out, it is hard to tell whether one cohort is healthier than another "unless a sample of a few hundred seniors can be seen and compared." 
Happiness. Three points about happiness were made by women of the 1910-14 cohort. Older women seemed to have enjoyed themselves more. They were more relaxed and serene with not so many activities. People were happier years ago; there were not so many broken homes.

The relationship between material possessions and the happiness of their own cohort as compared to younger women was brought out in statements that one might summarize as:

During the depression we had no money, but laughed and worked together.

Even if families didn't have so much they were happier.

On the farm there was a cellar and a spring to put the milk cans in. When a couple bought a refrigerator (not an ice box) after they had been married for several years it was a big event. It took more than a month's wages.

Younger people have to have everything right now. We were married ten years before we had a car.

Women of the 1915-19 cohort felt that life for older women was less complicated, there was less stress then (no drug problem to cope with), and they had lifetime friends living in the same town.

Possibly older women were happier because they were actively working with no time to sit about in life.

For themselves the women thought they did not have much peer pressure ("Whether or not to wear lipstick was 
our biggest worry."). They mentioned a simpler life where they did not expect a lot. They had to do more to entertain themselves with games, socials at school, and dances in the farmhouse kitchen.

Their current contacts with older women make women of the 1920-24 cohort think that the older women seem to have been happier. They are cheerful, talk about the good old days, and stayed married longer. They feel that younger people look for exterior things to make themselves happy, and there is no time to sit down and relax.

For themselves, as these paraphrases suggest, having a good time while growing up was more moral and did not cost as much. It was kind of an idyllic life as children; there was no war going on. We went to grandmother's house to play the wind-up victrola. Every Sunday people would come to visit and have a very quiet, nice time. Couples came over to play cards and make sandwiches; there was no money for shows. The boys from the CCC camp came to Epworth League meetings. One woman related that every saturday night there used to be house dances, but then people started bringing liquor (during the Prohibition years) so then she wasn't allowed to go and so she never learned to dance.

And as one woman recalled, it was fun working at Boeing even though the men weren't used to women around and were kind of crude speaking, but they did cool off after a while. 
One woman said there should be a distinction between "happiness" and "contentment." It was also mentioned that some personalities are always discontented while others find pleasure in many things.

Iife Style Comparisons. In discussing differing life styles of women somewhat older, or somewhat younger, than they the 1910-14 cohort noted that opportunities and education had become greater for younger women, though the women had become more materialistic. One reported that her older sister was very definitely a housewife with a very domineering husband but he was a good provider so it could not be said that he was a bad husband. Another said that at one time she had envied older women most of whom did not have to work, or didn't, and spent their time playing bridge or golf.

The mother of one woman was the oldest in a family of twelve and in those days it was not necessary to educate a girl so she was at home. Because of this the woman came into conflict with her mother about continuing her education.

That older women never had a chance for an education and that the value of women's work in the home was not recognized were mentioned as differences by women of the 1915-19 cohort. They also noted that older women looked down on women who worked outside the home and used to be too quick to judge a woman who did. 
These women also felt that they themselves had much more freedom and more opportunities. This was important because they knew older women who had been widowed and were unable to cope. One participant suggested that the $1930 \mathrm{~s}$ homemaker had more freedom than earlier $1920 \mathrm{~s}$ or later 1950s. By the 1930s the homemaker had labor saving devices such as the washing machine, refrigerator, electric iron, or toaster. She had the radio for companionship. Children walked or biked to school, church, scouts, beach, library, Saturday matinee, and could be sent to the grocer on errands. Children organized and played their own outdoor games. By the 1950s the homemaker became a chauffeur and shopper. Activities for chilaren became more group oriented and often were located out of the neighborhood.

The Great Depression was the focal point of the 192024 cohort in pointing out life style differences, as shown by these comments.

"We were children of the Depression and that
marks us. It was easier for the older and young-
er women."
"I have to save or I don't feel right. older wo-
men thought that social security would take care
of everything."
"You don't realize until you are an adult that
they (parents) were actually 'coping.' It was a
great thing for us to learn because it stands you
in good stead all your life."
changes in educational expectations, applicable to both boys and girls, were described by one woman. She said there was a span of 22 years in her family. The older 
brothers and cousins finished eighth grade and were not expected to go on to school. They were to become carpenters or mechanics, or whatever, but no more school. When the third brother came along, probably six years later, the father said if the boy must go he could go. So that brother went on to high school. By the time this woman came along the family was too poor for her to go to school, but she had fully intended to go into nursing because the family wanted her to have a career. By the time of the youngest brother it was a must to go to college. In the span of 22 years there was a change from "you can't go to school and, you must go to school."

Differences in attitudes from those of older women were mentioned. One woman said that in a camper group to which they used to belong most of the women were older and the majority never worked. They'd always been housewives and this was what they expected and a lot of them had never gone past high school and had no desire to. For these reasons they were finding it very hard sometimes to understand their chilaren's life style.

An exchange between several women pointed out differences in life experiences and attitudes.

A: "I find that absolutely, absolutely, I have very little in common with women that are older than I am. Consequently my friends tend to be women that are younger and in a lot of instances much younger. The women who are my age or older tend to have not had the extensive working experience that I have had and it does make a difference in 
your view of the world--it makes a great deal of difference if all you have ever done is stay home and raise children. You have a different point of view. My younger friends are I think, as I am, very aware of what is going on, educationally aware."

B: "A lot of these people, a lot of them retired from their jobs, they worked all their lives but they have also retired from life. They don't want to do anything, they don't want to go anywhere, and they never read a paper. Some of them don't have TVs or radios--they couldn't care less. They are into bingo, and pinochle--"

C: "--And talking about grandchildren!"

\section{DIFFERENCES IN FOCUS GROUP MEETINGS}

At this point it seems appropriate to draw one general conclusion regarding cohort differences which is based upon the ambience of the focus group meetings. First, the younger cohorts seem more inclined to resist, both mentally and physically, any indications of aging. They did not wish to adopt the attitude, "I'm too old for that," or to "retire from life."

Each younger cohort seemed to have given more thought to issues as they were occurring. The younger women seem to have had more awareness of the limitations on educational options and career possibilities imposed by societal standards of the time. Even though less accepting of these restrictions than the 1910-14 cohort they generally felt unable to initiate change.

In each group there was at least one woman who was quite outspoken, but the women of the 1920-24 cohort seemed 
more articulate and more forthright in their vocabulary. It may be that more education and a broader range of experience have led younger women to feel more empowered to develop their own opinions and express them.

One woman expressed this in a statement she made.

"I think you could look at it that maybe this group, because of the period of time in which we were born, because we're post World War $I$, we became adults during World War II, we're really a transitional group. We're changing from the old ways of living to the newer things where women are into far more things."

Although these words provide a most concise summary, the next, and final, chapter will be used to present broader conclusions and implications drawn from the NORC and focus group data. These conclusions will be linked with the four research questions set forth in Chapter I. 
CHAPTER V

\section{CONCLUSIONS AND IMPLICATIONS}

\section{INTRODUCTION}

The principal motive for this research was to test the hypothesis that because of historical events and technological developments which occurred roughly from world war I through World War II, the women of each of the three fiveyear cohorts from 1910 through 1924 differ markedly in life experiences. These differing experiences would thus result in variations in social attitudes and political opinions. The research was based on what was termed the "Historical Change" model of human development.

Background information which focused on statistical summaries of communication and transportation developments, labor market shifts, and changes in family life patterns was obtained. This is presented in Appendix A. Next an analysis was made of NORC survey data from 1972 through 1989 for the women born in the three five-year cohorts between 1910 and 1924. Finally focus group meetings were held to ascertain the women's perceptions of their life span experiences. 
Research findings as they related to the NORC data and focus group questions have been summarized to some extent in Chapter III and Chapter IV.

\section{CONCLUSIONS}

In this section the central findings of the research as related to each of the four questions posed in Chapter I will be presented.

1. How have macro-events differentially affected the life experiences of women in these cohorts?

As mentioned in Chapter IV on the focus groups, an opening activity was the completing of personal time lines. Based on the relating of anecdotes and mature perceptions of events noted on these time lines, the life experiences of these women have influenced them in two ways. Those events they encountered as adolescents are now perceived as character building in a beneficent sense. Events later in the life span, when the women were in their $40 \mathrm{~s}$ or $50 \mathrm{~s}$, resulted in action, usually political in nature.

The Great Depression of the 1930 s was one macro-event mentioned by 30 of the 41 focus group participants. In discussing this era the younger women now perceive that it was then that they learned values of saving and sharing, and to cope with disadvantageous circumstances.

Those women who had become more liberally oriented in their political identification and activities recollected events of the 1960s and early 1970s which had influenced 
them. In so doing they mentioned specific politicians or legislative action which had prompted the change.

2. How have social pressures differentially affected their experiencing of employment, matrimony, and motherhood?

The NORC data indicated one social pressure on these women in that each younger cohort had more years of schooling. The means were 10.46 years, 10.78 years, and 11.08 years. Also, according to the NORC data, participation in the labor force was for longer periods of time for the younger cohorts. There was a shift from designating labor force status as "Keeping House" to "Working" or "Retired" by each younger cohort. At the same time, for the marital status of "Never Married" the means shifted from 6.8 percent for the 1910-14 cohort to 4.6 percent for the 1915-19 cohort, and down to 2.7 percent for the 1920-24 cohort. Another change also shown by the NORC data was in the average number of children born to each married woman. This was 2.31 for the 1910-14 cohort, 2.50 for the 1915-19 cohort, and 3.01 for the 1920-24 cohort.

Awareness of these social pressures affecting their life experience was revealed in the focus group discussions by all three cohorts. In general the two older cohorts realized later in life that pressures had existed, whereas the 1920-24 cohort and some of the later born 191519 women were mindful at the time of existing constraints. 
Although education, employment, matrimony, and motherhood are intertwined in the life span, each cohort noted societal pressure iri a slightly different area. For the 1910-14 women it was understood that a girl did not need much education. Women of the 1915-19 cohort began to expand their educational goals. Nevertheless, the assumption was that they would drop out of school to get married, have children, and assume the homemaker role.

For the 1920-24 cohort societal pressure seemed most obvious in the employment arena. They were well aware that deliberate limitations were placec on their pay scales and upward mobility. Inceed, women were barred from some of the more prestigious professions.

3. How do the opinions of women in these three cohorts with regard to social and political issues ciffer and change?

Analysis of the NORC data on social issue questions for the larger sample of the three cohorts was reported in detail in Chapter III. Questions in this area were based on the topics of abortion, sexual permissiveness, sex education, and pornography.

In the main the 1910-14 cohort was the most conservative and the 1920-24 cohort the most broadminded. Nevertheless, durirg some periods the 1915-19 cohort assumed the most liberal position. As an across periods example, the NORC data shows that the 1910-14 cohort becan!e more conservative with regard to sexual permissiveness and 
divorce laws. The 1920-24 cohort remained relatively stable and liberal. During the 1972-77 period the 1915-19 cohort was the most conservative, from 1978-83 they were the most liberal, and during $1984-89$ assumed the midposition.

Opinions on political issues were also probed by the NORC surveys and detailed in chapter III. In addition to political identification, civil rights and women's role in politics were two important issues on which the cohorts showed statistically significant differences.

As far as civil liberties for atheists, racists, communists, and homosexuals (See Table X and Table XI) each younger cohort tended to be more tolerant than the previous cohort. On the second issue of women's role in politics, the three-item scale showed a rise in feminist attitude across the three cohorts. That is, the 1920-24 cohort women were the most feminist oriented.

As indicated also by focus group discussions the women of the 1915-19 and 1920-24 cohorts were more interested in political issues than were the 1910-14 cohort participants. In addition, over the years their political orientation tended to become more liberal. As they matured these younger women apparently became more independent thinkers, voting the person or the issue rather than a party line.

4. Can differences of opinions among the women of the three cohorts be traced to dissimilarities in life experiences? 
Specific dissimilarities (or similarities) in the life experiences of the women born between 1910 and 1924 cannot be used as predictors that a randomly selected woman will vote "Yes" (or "No") on a specific issue. Nevertheless participation in some broad categories of experiences does seem to be indicative of a more liberal outlook. Analysis of the NORC survey data indicated that the two younger cohorts usually had a more liberal attitude than did the 1910-14 cohort. These data also showed that each succeeding cohort had more years of schooling. This would seem to indicate that education is an important determinant in the formation of sociopolitical attitudes.

Another point to consider is at what point in the life span the experience occurred. For example, those women who gained or augmented their education later in life seemed to derive different values from the experience. Too, although all cohorts experienced the Great Depression, as mentioned previously, it was the 1920-24 cohort, who were adolescents at the time, who felt that their attitudes toward work and thrift had been molded during those years.

Mobility, either by moving to another geographic area or through travel, seems to have been another liberalizing agent. During the focus group meetings the women used terms such as "eye-opener" and "changed my way of thinking." 
The women also indicated quite strongly that participation in the workforce was influential in changing their opinions on several sociopolitical issues. These were, in the main, issues germane to the role of women in society.

Lastly, frequent contact with younger people in work or study situations was felt by some of the women to have been conducive to viewing issues from a different point of view. The contacts and circumstances motivated the woman involved to keep up with social and political trends.

While this study may not provide a definitive test of the watershed hypothesis, analysis of the NORC data and the focus group data through consideration of the research questions tentatively confirms that the world war I years were a watershed, which ultimately resulted in cohort differences. These differences were most marked between the 1910-14 and 1920-24 cohorts. The middle cohort, 1915-19, appears distinctive both in opinion changes revealed by the NORC data and in the mixture of points of view expressed in the focus groups. One possible interpretation, in line with the watershed hypothesis, is that these women are not a separate cohort but are similar to members of either the 1910-14 or 1920-24 cohort. That is, this study is actually of two distinctive groupings, not of three groupings.

A study of a longer time period might substantiate that differences among the women of the 1910-1924 cohorts are the result of events which occurred after the World war 
I years, and not part of a gradual continuum of social change. That is, the 1900 or 1905 cohorts might be compared with the 1910 cohort to ascertain if there were quantitative and qualitative differences, or whether this had been a plateau era. Likewise, if the 1925 cohort was not significantly different from the 1920 cohort this would further confirm that the world war I years (1915-19) were a watershed.

One further consideration is how effective is the conceptual model, Historical Change, (Figure 1) on which this study was based. In this conceptual model Historical Events and Family Background were independent variables, while Social Attitudes, Political Opinions, and Political Activity were dependent variables, and Life Experiences were intervening variables. It was suggested that this "how and why" study would be generalizable to theoretical propositions rather than to populations.

Based on quantitative data from the NORC surveys of 1972-1989 and the qualitative data of the focus groups, the original conceptual model has been augmented (see Figure 9) to indicate the most important variables in the lives of the women of the three cohorts of 1910 through 1924. In Figure 9 Attitude Toward Education is listed as a Family Background variable. For women of these cohorts the amount and type of education was usually decided upon by a parent. Education itself is given as a life experience variable for 


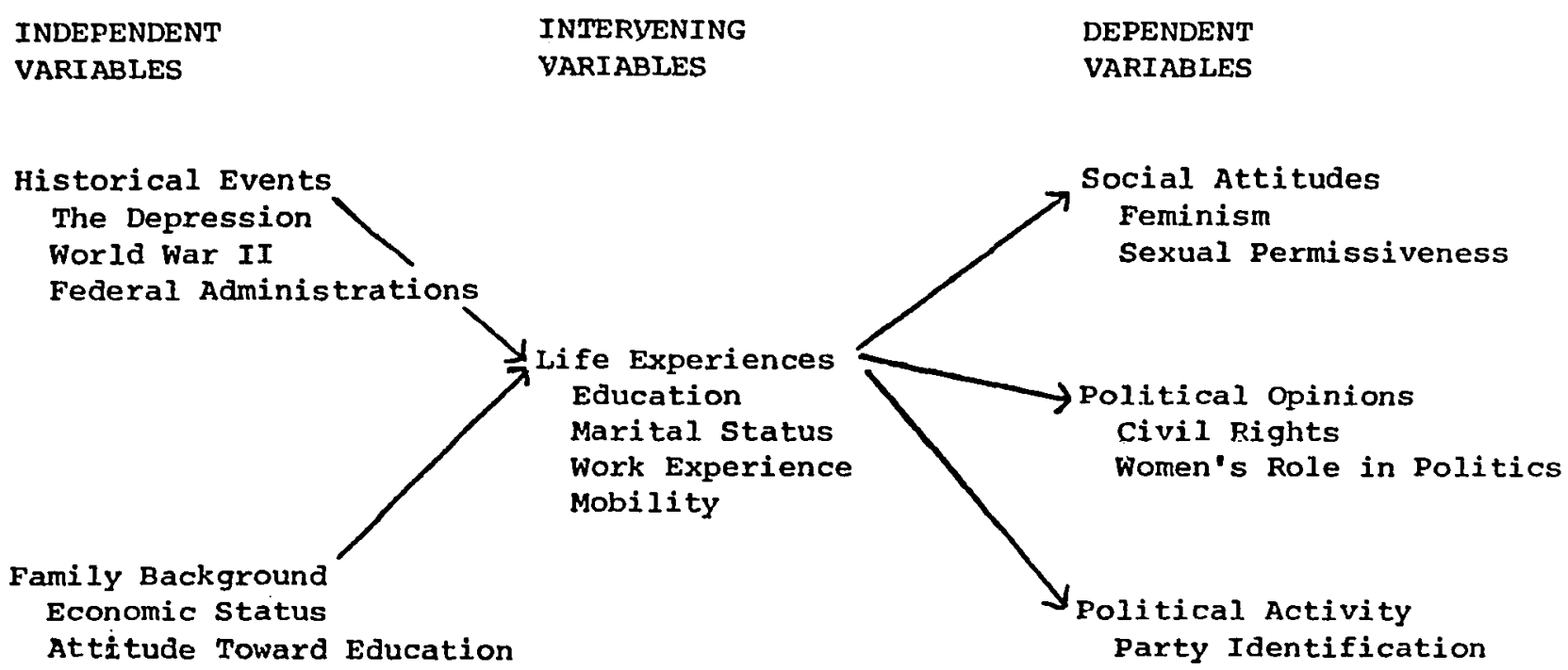

Figure 9. Conceptual model with important variables 
two reasons. Continuing on to advanced education often meant leaving home, and some women continued to further their education after marriage or while in the workforce.

"Federal Administrations" also needs explanation. The women mentioned that a particular president or policies of an administration influenced a decision to change their party identification.

The variables which the quantitative and qualitative data indicated as being of importance in attitude and opinion formation are those which were suggested in research studies reviewed in Chapter II. The Great Depression, World War II, and economic status are suggested by Iipset and Ladd (1971) as impacting on personal experiences. Education, marital status, and work experience were noted in Sedney's study (1985-86) of older women as factors in attitude changes. The Bennington study (Alwin, Cohen, and Newcomb, 1990) emphasized the influence of education and marital status on the political/economic attitudes of women. The meaning and influence of the Federal Administrations variable is suggested by Glenn (1969) and Turner and Kahn (1974). These studies indicated that older persons do hold and express political opinions and rate candidates with apparent objectivity.

The interrelationship and importance of the World war II and work experience variables were pointed out by stewart and Healy (1989) in their study of the expanding and 
contracting work role for women. Elder's (1974) study of the children of the Great Depression also relates the impact of the Depression to work experience, economic status, and education. Elder also found that the stage of development of children at the time of the experience was a major factor in how the children were affected both at the time and in their later lives.

This research has delineated and summarized quantitative differences among the cohorts through analysis of the NORC data (Chapter III). It is the focus group qualitative data as analyzed and summarized in Chapter IV, however, which indicate the positive linkage between the findings of previous research on the development of attitudes and opinions and the findings of this study.

\section{IMPLICATIONS}

In recent years there has been acknowledgement that all persons over age 60 are not alike. Three subgroups of the young-old from ages 60 to 75 , the old-old from age 75 on, and most recently the oldest-old have been delineated. The results of this study would indicate that consideration should be given to the idea that the needs and wants of the 1920-24 cohort upon reaching age 75 will not be the same as those of the 1910-14 women who are presently in that category. As suggested by Neugarten (1982) older persons are a heterogeneous group. Age is becoming in- 
creasingly irrelevant as a predictor of lifestyle. Future policies and programs related to income maintenance, health care, housing, transportation or other social services should perhaps be formulated more on the basis of relative physical or economic needs and personal preferences rather than on chronological age.

It may be expedient to define target populations for public programs on an age basis but it may not be meaningful. The women of the three cohorts studied, 1910-14, 1915-19, and 1920-24, have evidenced differences in demographic background and in sociopolitical attitudes. It should be noted also that the women continue to translate ongoing experiences into changes in attitudes and opinions. They are not settled into unchangeable attitudinal patterns which have been popularly ascribed as being typical of older persons. The women of the youngest cohort (1920-24), in particular, indicated that they did not wish to be segregated and stigmatized by the label "old."

\section{FUTURE RESEARCH}

In order to substantiate and make use of these findings and better understand their significance additional in-depth quantitative data might be developed at the national level. For example, the NORC data indicated more years of schooling for each younger cohort, but there is no indication what this meant to the women nationwide. Addi- 
tional questions might ask what course was followed, who influenced the choices, why did the woman leave school, or at what age did she complete her schooling. More information might also be obtained on post-school learning experiences. The focus group participants, from the 1920-24 cohort in particular, mentioned on-the-job training, conferences, workshops, and job-related or personal use classes. Similarly, there could be more depth to survey questions about workforce participation. Focus group participants from all three cohorts indicated that the question asking if they had ever worked for as long as one year was out of date. A more detailed picture of labor force participation might be gained by asking questions such as: Did you leave your job when you married? Did you leave your job when you had children? Approximately how long did you remain at home? Did you go back to the same job? About how many years have you accumulated towards Social Security or another pension?

The focus group sessions revealed that some of the women lived in the Portland area at age 16 and, obviously, were presently living there. However, several of the women had lived in other areas of the country for several years and this had influenced their attitudes. An additional NORC question might probe this mobility effect.

As mentioned previously, an unresolved issue is whether the 1915-19 cohort is a separate group. A year-by-year 
analysis of this cohort riight give a more precise date for the world war I watershed. fiditionally, no cohort boundaries have been established. The cut-off ciates of 1910 and 1924 were selected arbitrarily in order to utilize the available statistical data. These dates may not be the true boundaries for these cohorts. Further research might determine the correct boundaries. It is also possible to consider the analysis of these arbitrarily defined cohorts as a heuristic device to help identify generational boundaries or watersheds.

This research has analyzed ciata for women only. Another area for research might be the life patterns and attitudes of males born between 1910 and 1924. These may differ from those of women. It is also possible that cohort boundaries for females and males may not be precisely alike.

Another point to be noted is that for this study the focus groups were conducted only in the portland, Oregon, metropolitan area. Further research would be neeced to determine if the finaings are applicable to women in larger metropolitan areas, rural areas, and other geographical locations.

This study has noted both quantitative and qualitative differences among women born within a 15-year time span, roughly only half a generation. These differences do seem to have been basec on the experiential variables of the 
Historical Change model of the development of attitudes and opinions. Thus it seems probable that there will also be other watershed years which have resulted in diverse attitudes and opinions, and varying cohort boundaries among younger persons.

It should also be noted that macro-events may have different meanings for diverse ethnic groups. For example, the internment camps of World War II and the civil rights movement of the 1960s would be viewed from different perspectives by Japanese, Blacks, and Caucasians.

This model might be used to answer questions such as: What is a cohort? or what is a generation? A better understanding of attitudinal differences might be developed if, instead of arbitrary five- or ten-year groupings, natural breakpoints in life course experiences were studied as indicators of potential attitude shifts. This would necessitate much more research, but breakpoints can be ascertained. 
REFERENCES

Aaronson, Charles S. (Ed.). (1966). International Motion Picture Almanac. New York: Quigley Publishers.

Achenbaum, w. Andrew. (1978). Old Age in the New Land The American Experience Since 1790. Baltimore: Johns Hopkins University Press.

Adorno, T.W. (1950). Authoritarian Personality. New York: Norton.

Alwin, Duane F., Cohen, Ronald L., and Newcomb, Theodore M. (1990). Aging, Personality, and Social Change. Madison: University of Wisconsin.

American Experience \#105. (1988). The Life and Times of Rosie the Riveter. Boston: WGBH Educational Foundation.

Birren, James E. (1983). Relations of Development and Aging. Springfield, IL: Charles C. Thomas, Publisher.

Bogue, Donald J. (1985). Population of the United States Historical Trends and Future Projections. New York: Macmillan.

Botwinick, Jack. (1978) . Aging and Behavior. New York: Springer.

Brown, Coke, et al. (1978). "Community Standards, Conservatism, and Judgments of Pornography." Journal of Sex Research, 14:2, 81-95.

Cain, Leonard D., Jr. (1967). "Age Status and Generational Phenomena: The New old People in Contemporary America." Gerontologist, 7, 83-92.

Campbell, Angus. (1971). "Politics Through the Life Cycle." Gerontologist , 11, 112-117.

Campbell, Angus, Converse, Philip E., Miller, Warren E., Stokes, Donald E. (1964). The American Voter. An Abriagement. New York: John Wiley \& Sons.

Carson, Julia M. H. (1946). Home Away From Home. The Story of the USO. New York: Harper \& Brothers. 
Carmines, Edward G. and Zeller, Richard E. (1979). Reliability and validity Assessment, Sage University Paper Series on Quantitative Applications in the Social Sciences, Series No. 07-017. Beverly Hills and London: Sage Publications.

Chown, Sheila M. (1960). "The Wesley Rigidity Inventory: A Factor-Analytic Approach." Journal of Abnormal and Social Psychology, 61, 491-494.

- (1961). "Age and the Rigidities." Journal of Gerontology, 16, 353-362.

Costa, Paul T. and McCrae, Robert R. (1978). "Objective Personality Assessment." In Clinical Psychology of Aging. Edited by M. Storandt, I.C. Siegler, and M. F. Elias. New York: Plenum.

Crittenden, John. (1962). "Aging and Party Affiliation." Public Opinion Quarterly, 26, 648-657.

Cutler, Steven J., et al. (1971). "Aging and Conservatism: Cohort Changes in Attitudes About Legalized Abortion." Journal of Gerontology. 35, (1), 115-123.

Cutler, Steven J. and Kaufman, Robert L. (1975). "Cohort Changes in Political Attitudes: Tolerance of Ideological Non-Conformity." Public Opinion Quarterly, 39, (1), 69-81.

Dannefer, Dale. (1984). "Adult Developmental and Social Theory: A Paradigmatic Appraisal." American Sociological Review, 49, 110-116.

Davis, James Allan and Smith, Tom W. (1987). General Social Surveys, 1972-1987. Chicago: National opinion Research Center.

Douglass, Elizabeth B., Cleveland, William P., and Maddox, George L. (1974). "Political Attitudes, Age and Aging: A Cohort Analysis of Archival Data." Journal of Gerontology, 29, 666-675.

Elder, Glen H., Jr. (1974). Children of the Great Depression. Chicago: University of Chicago Press.

Ferree, Myra Marx. (1974). "A Woman for President? Changing Responses 1958-1972." Public Opinion Quarterly, 38 (3), 390-399.

Friedan, Betty. (1963). The Feminine Mystique. New York: W. W. Norton \& Co. 
Glamser, Francis D. (1974). "The Importance of Age to Conservative Opinions: A Multivariate Analysis." Journal of Gerontology, 29, 549-554.

Glenn, Norval D. (1969). "Aging, Disengagement, and Opinionation." Public Opinion Quarterly, 33, 17-33.

- (1974). "Aging and Conservatism." Annals of the American Academy of Political and Social Science, 415, 176 $-1 \overline{86 .}$

- (1980). "Values, Attitudes, and Beliefs." In Constancy and Change in Human Development. Edited by Orville G. Brim, Jr. and Jerome Kagan. Cambridge, MA: Harvard University Press.

Glenn, Norval D. and Hefner, Ted. (1972). "Further Evidence on Aging and Party Identification." Public Opinion Quarterly, 36, 31-47.

Greenbaum, Thomas L. (1988). The Practical Handbook and Guide to Focus Groups Research. Lexington, MA: D.C. Heath.

Hanson, D. J. (1968). "Dogmatism and Authoritarianism." Journal of Social Psychology, 76, 89-95.

Henige, David. (1982). Oral Historiography. New York: Longman.

Historical Statistics of the United States Colonial Times to 1970. (1975). Washington, $\overline{\text { DC: U.S. Department of }}$ Commerce, Bureau of the Census.

Janowitz, Morris, and Marvick, Dwaine. (1953). "Authoritarianism and Political Behavior." Public Opinion Quarterly, 17, 185-201.

Kammen, Michael. (1979-80). "Changing Perceptions of the Iife Cycle in American Thought and Culture." Massachusetts Historical Society Proceedings, $91,35-\overline{66}$.

Kenney, Patrick J. and Rice, Tom W. (1988). "The Evaporating Independents." Public Opinion Quarterly, 52 (2), 231-239.

Kirk, Jerome and Miller, Marc L. (1986). Reliability and Validity in Qualitative Research. (Sage University Paper Series on Qualitative Research Methods, Vol. 1). Beverly Hilis, CA: Sage. 
Kohn, Melvin L. and Schooler, Carmi. (1979). "The Reciprocal Effects of the Substantive Complexity of Work and Intellectual Flexibility." In Aging From Birth to Death: Interdisciplinary Perspectives, Volume i. Edited by Matilda White Riley. Boulder, co: Westview Press.

Lipset, Seymour Martin and Ladd, Everett Carl, Jr. (1971). "College Generations--From the 1930s to the 1960s." Public Interest, 25, 99-113.

Lorge, Irving and Helfant, Kenneth (1953). "The Independence of Chronological Age and Sociopolitical Attitudes." Journal of Abnormal and Social Psychology, 48 (4), 598 .

Louis Harris and Associates. (1981). Aging in the $80 \mathrm{~s}$. Washington, DC: National Council on Aging.

MacCann, Richard Dyer. (1987). The First Tycoons. Metuchen, NJ: Scarecrow Press, Inc.

Maddox, George. (1979). "The Sociology of Later Life." In Annual Review of Sociology, Volume 5. Edited by Alex Inkeles, James Coleman, and Ralph H. Turner. Palo Alto, CA: Annual Review.

Manchester, William. (1974). The Glory and the Dream A Narrative History of America $1932-\overline{1972}$. $(2$ vols.). Boston: Little, Brown and co.

Matthews, Sara H. (1979). The Social World of old Women-Management of Self-Identity. (Sage Library of Social Research, Vol. 78). Beverly Hills, CA: Sage.

McCracken, Grant. (1988). The Long Interview. (Sage University Paper Series on Qualitative Research, Vol. 13). Beverly Hills, CA: Sage.

Morgan, David L. (1988). Focus Groups as Qualitative Research. (Sage University Paper Series on Qualitative

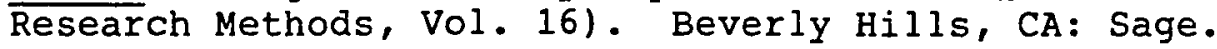

Morison, Samuel Eliot. (1965). Oxford History of the American People. New York: Oxford University Press.

Neugarten, Bernice L. (1974). "Age Groups in American Society and the Rise of the Young-0ld." Annals of the American Academy. September, 187-198. , ed. (1982). Age or Need. Sage: Beverly Hills. 
Nie, Norman H., Verba, Sidney, Petrock, John R. (1979). The Changing American Voter. Cambridge: Harvard University Press.

Nugent, Walter T. K. (1981). Structures of American Social History. Bloomington: Indiana University Press.

Olive, Kelsey, Visser, and Day, (1976). "Moving as Perceived by Executives and Their Families." Journal of Occupational Medicine, 18 (8), 546-550.

Persson, Goran. (1980). "Sexuality in a 70-year-old Urban Population." Journal of Psychosomatic Research, 24 $(6), 335-342$.

Pollack, Otto. (1943). "Conservatism in Later Maturity and Old Age." American Sociological Review, 8, 175-179.

Ponza, Michael, Duncan, Greg J., Corcoran, Mary, Groskind, Fred. (1988). "The Guns of Autumn?" Public Opinion Quarterly, 52 (4), 441-466.

Riegel, Klaus F. and Riegel, Ruth M. (1960). "A Study on Changes of Attitudes and Interests During Later Years of Life." Vita Humana, $\underline{3}, 177-206$.

Rogan, Helen. (1981). Mixed Company. New York: G. P. Putnam's Sons.

Rokeach, Milton. (1956). "Political and Religious Dogmatism: An Alternative to the Authoritarian Personality." Psychological Monographs: General and Applied. $70: 18$, Whole No. 425 .

ed. (1960). The Open and Closed Mind. New York: Basic Books.

Rudzitis, Gundars. (1982). Residential Location Determinants of the older Population. Chicago: University of Chicago, Department of Geography.

Rustad, Michael. (1982). Women in Khaki. New York: Praeger.

Ryder, Norman B. (1965). "The Cohort As A Concept In The Study of Social Change." American Sociological Review. $30,843-61$.

Sche11, Jonathan. (1987). "Paradise." Granta, 21, 202-218.

Schmidhauser, John R. (1958). "The Political Behavior of Older Persons: A Discussion of Some Frontiers in Research." Western Political Quarterly, 11, 113-124. 
Schuman, Howard and Scott, Jacqueline. (1989). "Generations and Collective Memories." American Sociological Review, 54, 359-381.

Sears, David O. (1981). "Life-stage Effects on Attitude Change, Especially Among the Elderly." In Aging: Social Change. Edited by Sara B. Kiesler, James N. Morgan, and Valerie Kincaid Oppenheimer. New York: Academic Press.

Sedney, Mary Ann. (1985-86). "Growing More Complex: Conceptions of Sex Roles Across Adulthood." International Journal of Aging and Human Development, 22 (1), 15-29.

Statistical Abstract of the United States 1988, 1989. Washington, DC: U.S. Department of Commerce, Bureau of the Census.

Stewart, Abigail J. and Healy, Joseph M., Jr. (1989). "Linking Individual Development and Social Changes." American Psychologist, 44 (1), 30-42.

Templeton, Jane Farley. (1987). Focus Groups. Chicago: Probus Publishing.

Terkel, Studs. (1984). "The Good War". New York: Pantheon Books.

Thomae, Hans. (1980). "Personality and Adjustment to Aging." In Handbook of Mental Health and Aging. Edited by James E. Birren and R. Bruce Sloan. Englewood Cliffs: Prentice-Hall.

Thornton, Arland, Alwin, Duane F., and Camburn, Donald. (1983). "Causes and Consequences of Sex Role Attitudes and Attitude Change." American Sociological Review. 48 (2), 211-227.

Turner, Barbara F. and Kahn, Robert L. (1974). "Age as a Political Issue." Journal of Gerontology, 29, 572-580.

United States Department of Labor, Bureau of Labor Statistics, Office of Prices and Living Conditions. (19721989). Consumer Price Index. Washington, DC: Superintendent of Documents.

West, Walter G. (1977). "Public Tolerance of Homosexual Behavior." Cornell Journal of Social Relations, 12 (1), 25-36. 
Wilderom, Celeste P.M. and Crynes, Arthur G. (1985). "Authoritarianism/Dogmatism as a Function of Age: A Relevant Yet Forgotten Area of Research." High School Journal, $68(4), 424-428$.

Willits, Fern K., Bealer, Robert C., and Crider, Donald M. (1977). "Changes in Individual Attitudes Toward Traditional Morality: A 24-year Follow-up Study." Journal of Gerontology, 32 $(6), 681-688$.

Zagona, Salvatore V. and zurcher, Louis A., Jr. (1965). "Notes on the Reliability and Validity of the Dogmatism Scale." Psychological Reports, 16 (3), (Pt. 2), 1234-1236. 
APPENDIX A

HISTORICAL DEVELOPMENTS 
The first section of this appendix provides background on population, communication, and transportation changes of the 20 th century.

Population Growth

From 1900 to 1910 the population of the United States increased by 21 percent, partially because of the immigration of about 1,000,000 persons each year. The depression years of 1930 to 1940 recorded the least gain with only a 7.2 percent increase. The 19 percent population increase in the $1950 \mathrm{~s}$ reflects the post-war baby boom.

It should be noted, too, that 1920 marked another turning point in that just over 50 percent of the population was then classified as urban. Related to this is the decreasing percent of the population living on farms. In 1910 this percent was 34.9 , decreasing to 27.0 by 1925 , and by 1978 was down to 3.0 percent. This meant an increasing density of persons per square mile from 25.6 in 1900 to 35.6 in 1920, and upward to 57.5 in 1970 (Historical Statistics, 1975; Nugent, 1981).

\section{Communication Changes}

Telephone. Beginning in 1876 with three telephones in the United States the number increased to $7,635,000$ by 1910 or 82 phones per thousand population. In 192035 percent of households were served. There was a further increase to 40.9 percent of households served by 1930 . The next five 
years showed an increase in phones per thousand, but a decrease of five percent in households served (Historical Statistics, 1975).

Radio. August 20, 1920, was the date of the first regular licensed radio broadcast. Two years later 60,000 households in the United States had a radio--probably battery operated and with earphones. Census figures for 1930 indicate about 40 percent of households with radios. By this time the radio could operate on house electric current and with a speaker. By 194082 percent of households had radios (Historical Statistics, 1975).

Motion Pictures. April 14, 1894, the first silent movie was shown. April, 1923, the first sound movie was shown. However, it was not until about five years later, with the release of the highly popular "Jazz singer," that the sound track became the replacement for the piano or organ in movie theaters. About 40 films were produced each year. In 1914 at least one major theater had over 3,000 seats, and in about fifteen years the six major companies controlled 2,437 theaters. Another method of assessing the impact of the moving picture is the percentage of spectator amusement expenditures. In 1929 this figure was 78.86 percent, and during the 1930 s was around 84 percent. A decline began in the 1950s, with the advent of television (Aaronson, 1966; MacCann, 1987). 
Transportation Developments

Railroads. Records for railroad travel since 1890 show an increase in passengers and total passenger miles until 1923 and a decrease in both since that date. In 1920 the railroads carried $1,269,913,000$ passengers, but this aropped abruptly to $707,987,000$ in 1930 . The decline has continued until in 1970 the figure was 289,469,000 (Historical Statistics, 1975).

Automobiles. In 1910 there were 458,300 registered automobiles in the United States; one for every 25,000 persons. This figure had increased to $8,131,500$ by 1920 , or one car per 14 people. During the next ten years, until 1930, the registrations jumped 289 percent, to $23,034,700$ cars. Even during the depression years of 1930 to 1940 there was a more gradual increase of about four million registrations. Since 1930 the ratio of people to cars has decreased from 5.5 to 2 by 1970 (Historical statistics, 1975).

Aviation. According to Civil Aviation Authority records fewer than 50,000 passengers flew in 1928. This number had increased by 1940 to $2,686,000$ and by 1950 to 19,020,000 passengers. By 1960 this figure had more than tripled to $62,256,000$ passengers, and again increased to $169,668,000$ by 1970 (Historical Statistics, 1975). 
CHANGES FOR WOMEN

This section presents historical background more specifically related to women.

World War I and II Participation

Armed Services. As volunteers during World War I there were 23,400 nurses, and 12,800 clerical workers serving in the armed forces (Rogan, 1981).

The Red Cross provided recreational facilities for the armed services in both World War I and World War II. During World War II the United Services organizations (USO), supported by contributions and a million volunteer workers, enlarged the scope of morale building activities (Carson, 1946).

Public opinion was against women serving in the armed forces even after Pearl Harbor in 1941. The enlisted man did not want to work with women and many men refused to let their women volunteer for the services (Rustad, 1982).

Eventually women served in the Army, Marines, Navy (WAVES), Coast Guard (SPARS), and as Women Air Force Service Pilots (WASP). By 1945 enlistment in the services was at its peak. Personnel figures for the army give an indication of the women's participation. There were about 63,000 commissioned officers and 91,000 enlisted women. (Historical Statistics, 1975). 
War Production Industries. In 1940 only 25 percent of women in the United States earned their own money. Only 15 percent of married women worked. Their jobs were usually in the traditional nurse, secretary, teacher pattern, or light assembly or restaurant work for those with the average tenth grade education (Keil, 1979).

Seven factories in the United States in ordnance work in 1941 employed 143 women. By 1942 the number of women workers had risen to 65,000 . At the peak of the war effort there were around 18,000,000 women ordnance workers (WOWS), about 12 percent of the population, in munitions factories, shipyards, and airplane factories working all shifts. In spite of the manpower shortage they were subjected on the job to harassment and discrimination. Because of the manpower shortage they were subjected off the job to government propaganda to do more. But there was little help with the housework or child care (American Experience \#105, $1988)$.

As the war ended the wows were laid off first, followed by blacks, in order to provide employment for returning veterans. The propaganda then changed to the importance of the woman in the home so that children would not be neglected, so that husbands would not be unhappy, so that the woman could fulfill her natural role. One woman summed up the situation: During the war they were given recipes that took 20 minutes to prepare. After the 
war they were given recipes that took all day (American Experience \#105, 1988).

Employment Status

Labor Force Participation. A report of labor force distribution (ages $16-65+$ ) indicates that in 1890 females comprised 17 percent of the labor force. By 1970 females were 37.2 percent of the labor force. From another point of view, in 1890 the female labor force was 18.9 percent of the female population. By 193024.8 percent of the female population was employed. They constituted 21.9 percent of the total labor force. Ten years later women constituted 24.6 percent of the labor force and the proportion of women employed had increased by one percent to 25.8 percent. This proportion reached a peak of 35 percent in 1944 with wartime employment. Although there was a decline after 1944, by 1955 the rate was up to 33.5 percent and by 1987 the female labor force was 55.5 percent of the female population.

In 1890 only 13.9 percent of female workers were married. This proportion changed so that by 193028.9 percent of women workers were married. This figure increased to 35.9 percent by 1940 . The rate then increased so that by 1950 over 50 percent of female workers were married, and since the 1960s the rate has hovered around 60 percent (Historical Statistics, 1975; Statistical Abstract, $1988)$. 
Table XV presents changes in labor force participation rates by marital status, sex, and age for the years from 1960 to 1988. The age groups of 45-64 years and 65 years and over were selected as including the three cohorts from 1910 to 1924. The trend has been for married women and separated, widowed, or divorced women to remain in the labor market. Single women, in both the 45-64 and 65 years and over age groups, have shown a decline of around 10 percent in labor force participation from 1960 through 1988. For males, regardless of marital status, the figures indicate a steady pattern of declining labor force participation.

Occupational Fields. Another classification of labor force participation considers in which major occupation groups women have been employed. For example, in 1900 they comprised 18.5 percent of white collar workers and 71.8 percent of service workers. By 1970 these figures had changed to 48.6 and 60.5 percent respectively. A 1988 report indicated that women filled over 90 percent of the nursing, teaching, secretarial, medical assistant, private household and textile sewing machine operator positions.

\section{Family Conditions}

Birth Rates. Birth rates for the 1930s, the depression years, showed a drop from 21.3 to a low of 18.4 per thousand. By 1946 a high of 26.6 births per thousand was recorded. The yearly birth rate remained close to 25 per 
TABLE XV

LABOR FORCE PARTICIPATION RATES BY
MARITAL STATUS, SEX, AGE

Male

Eemale

$\begin{array}{llllllll}1960 & 1970 & 1980 & 1988 & 1960 & 1970 & 1980 & 1988\end{array}$

Married

$\begin{array}{lllllllll}45-64 & \text { years } 93.0 & 91.6 & 84.8 & 82.4 & 34.2 & 44.1 & 46.9 & 52.7\end{array}$

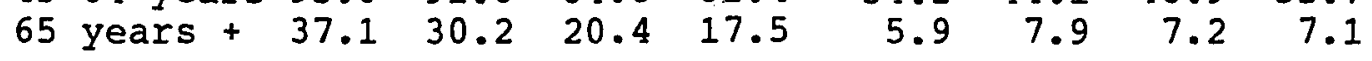

$\begin{array}{lllllllll}\text { Single } & & & & & & & \\ 45-64 \text { years } 74.4 & 66.6 & 65.2 & 65.9 & 75.1 & 67.8 & 62.8 & 65.2 \\ 65 \text { years }+24.3 & 21.0 & 20.0 & 20.7 & 21.6 & 17.6 & 12.0 & 10.9\end{array}$

Separated, Widowed, or Divorced

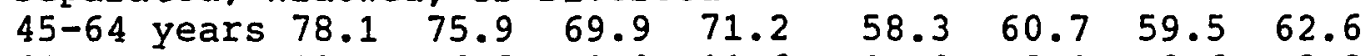
65 years $+18.2 \quad 16.5 \quad 13.0 \quad 11.6 \quad 11.0 \quad 9.9 \quad 8.6 \quad 8.2$

Adapted from Statistical Abstract, 1989, p. 385. 
thousand until 1960 when there was a decline to 23.7 per thousand. This declining birthrate continued until the mid-1970s (Bogue, 1985; Historical Statistics, 1975).

Table XVI presents the percent distribution of evermarried women by number of children ever born for women born betwwen 1910 and 1924 .

Divorce. One of the lifestyle changes of the midtwentieth century has been the increase in divorce rates. In $1986,8.9$ percent of all females were divorced. However, the divorced females aged 55-64 years (birth years 1922-31) were above average at 9 percent.

Education. At the time of World war II the educational average for females was ten years of schooling. Figures for high school graduation (Historical Statistics, 1975) show around a 25 percent increase from the 1910 through the 1920-1924 cohort. That is, taking age 17 as high school graduation year (and including males) in 192725.8 percent of the young people graduated from high school. In 1932 the figure was 35.5 percent; 1937, 44.2 percent, and 1942, 49 percent. A study in 1980 of educational attainment (Bogue, 1985) indicated that of those aged 60 and up about 10 percent had attended college and about 5 percent had completed four years.

\section{Constitutional Amendments}

Prohibition/Repeal. On January 16, 1919, the 18th amenament to the Constitution, the Volstead Act, became ef- 
TABLE XVI

PERCENT DISTRIBUTION OF EVER-MARRIED WOMEN BY NUMBER OF CHILDREN EVER BORN

Percent of Women by Number of Births

\begin{tabular}{llllllll}
$\begin{array}{l}\text { Year of } \\
\text { Birth }\end{array}$ & None & $1 \& 2$ & $3 \& 4$ & $5 \& 6$ & 7 to 9 & $10+$ \\
\hline $1910-14$ & 18.1 & 44.2 & 24.7 & 7.8 & 3.8 & 1.5 \\
$1915-19$ & 13.8 & 43.1 & 28.9 & 8.8 & 3.9 & 1.4 \\
$1920-24$ & 10.6 & 39.9 & 32.8 & 10.7 & 4.5 & 1.5
\end{tabular}

Adapted from Historical Statistics, 1975, p. 254. 
fective. This act prohibited the manufacture, export, or import of Iiquor in any state or territory of the United states. The act was ratified by all states except Rhode Island and Connecticut. Some fifteen years later, effective December 5, 1933, the 21st Amendment repealed the 18 th amendment. Regulation of liquor was returned to the individual states.

Nationwide Suffrage to Women. The 19th amendment to the Constitution granting nationwide suffrage to women went into effect on August 26, 1920. However, some states had enfranchised women many years before this Constitutional amendment. 
APPENDIX B

SAMPLE OF MEETING NOTICE 
SAMPLE OF MEETING NOTICE

(Original size: 8-1/2" by 11")

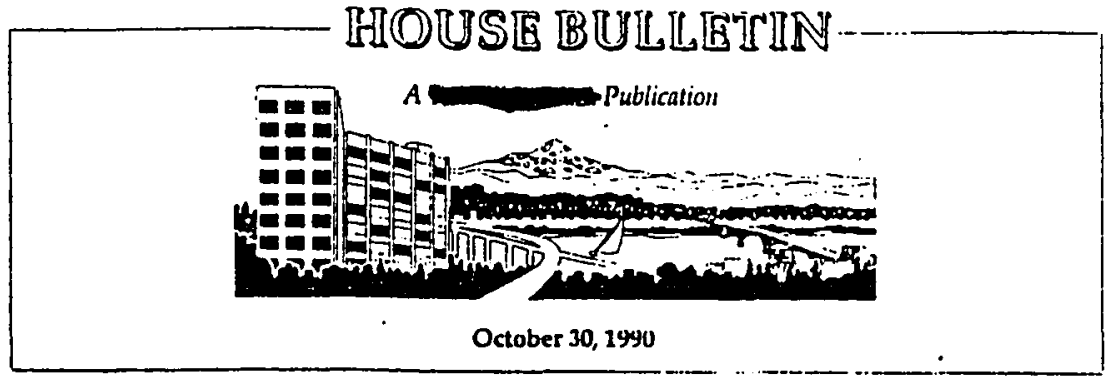

\section{Women's Story Group Meetings Planned}

Bette Ikehara, a graduate student at Portland State University, is doing a study project of older women in the community. We are interested in your life experiences and opinions on social issues.

Three group meetings, of 5 or 6 women each, are planned for : women, on the following dates:

Monday, Nov. 5, 10:30 a.m. for women born between 1910-14

Wednesday, Nov. 7, 10:30 a.m. for women borm between 1915-19

Thursday, Nov. 8, 10:30 a.m for women born between 1920-24.

Would you be able to meet for about and hour-and-a-half to tell us some of your opinions and experiences? We would like to tape record them. Refreshments will be served. $A$ donation will be made to the residents' fund.

If you are able to help with this women's story project, please contact win the Administration Office, at ext. Group size is limited, so please cal! as soon as possible to participate.

\section{Bulletin Board Clarification}

The last House Bulletin included a note about requesting approval from the Administration office before posting notices on the - bulletin board. Approval is needed only in the case of non-1 activities:

Bullelin board notices are to be typed un small cards and dated. The approval of the Administrator or his or her designee must be oblained for all notices other than those about activities. (General Rulcs, Articl: $\left.3.6^{\circ}\right)$

Pacificare Presentation ScheduledWednesday!

On Wednesday, October 31 at 10 a.m. in the Auditorium, a representative from the Secure Horizons senior health plan will talk on

Medicare Health Maintenance Organizations (HMOs), and will explain how their benefits differ from regular Medicare coverage. This informative meeting will enable you to make more informed shoices regarding your health insurance coverage.

Don't miss the Halloween Buffet Luncheon in the Dining Room - this Wednesday! 
APPENDIX C

INFORMED CONSENT 
I, AGREE TO TAKE PART IN THE STUDY, "A COMPARISON OF SOCIO-POLITICAL ATTITUDES OF OLDER URBAN WOMEN: THE 1910 THROUGH 1924 COHORTS," CONDUCTED BY ELIZABETH S. IKEHARA. IT HAS BEEN EXPLAINED TO ME THAT THE PURPOSE OF THE STUDY IS TO LEARN MORE ABOUT THE OPINIONS AND LIFE EXPERIENCES OF URBAN ELDERLY FEMALES.

ALTHOUGH I MAY NOT RECEIVE ANY DIRECT BENEFIT FROM TAKING PART IN THIS STUDY, MY PARTICIPATION MAY HELP TO INCREASE KNOWLEDGE WHICH MAY BENEFIT OTHERS.

I HAVE BEEN ASSURED THAT, ALTHOUGH THE SESSIONS WILL BE TAPE RECORDED, ALL INFORMATION I GIVE WILL BE CONFIDENTIAL. I UNDERSTAND THAT MY TAKING PART IS VOLUNTARY AND I AM FREE TO WITHDRAW FROM THIS STUDY AT ANY TIME.

THE RESEARCHER HAS OFFERED TO ANSWER ANY QUESTIONS I MAY HAVE ABOUT THE STUDY.

I HAVE READ AND UNDERSTAND THE ABOVE INFORMATION. DATE PARTICIPANT'S SIGNATURE

DATE RESEARCHER'S SIGNATURE

PLEASE SEND ME A REPORT ON THE RESULTS OF THE RESEARCH PROJECT. (Circle One.) YES NO

ADDRESS FOR THOSE REQUESTING RESEARCH REPORT:

IF YOU EXPERIENCE PROBLEMS THAT ARE THE RESULT OF YOUR TAKING PART IN THIS STUDY, PLEASE CONTACT THE SECRETARY OF THE HUMAN SUBJECTS RESEARCH AND REVIEW COMMITTEE, OFFICE OF GRANTS AND CONTRACTS, 303 CRAMER HALI, PORTLAND STATE UNIVERSITY, 725-3417. 
APPENDIX D

FOCUS GROUP QUESTIONNAIRE 
FOCUS GROUP QUESTIONNAIRE

Please answer these questions as completely as possible.

1. In what town, state, country were you living at age 16 ?

2. From what countries or part of the world did your ancestors come?

3. What kind of work did your father do?

4. Please circle the economic class that you would say you belong to: Lower Working Middle Upper

5. What is the highest grade in school you completed?

6. What is your religious preference?

7. Are you now Married Widowed Divorced Separated Never Married (please circle)

8. If married: Have you ever been: Divorced widowed (please circle)

9. How many children have you ever had?

10. What is/was your husband's job?

11. Are you: Working fulltime Working Parttime Unemployed Retired Keeping House Other

12, Did you ever work for as long as one year? Yes No

13. What kind of work do/did you do?

14. In which of these groups is your family income?

$$
\begin{array}{lcc}
\$ 1,000-4,999 & \$ 5,000-9,999 & \$ 10,000-14,999 \\
\$ 15,000-19,999 & \$ 20,000-24,999 & \$ 25,000 \text { or over }
\end{array}
$$

Thank you very much! 
APPENDIX E

TIME LINE FORM 


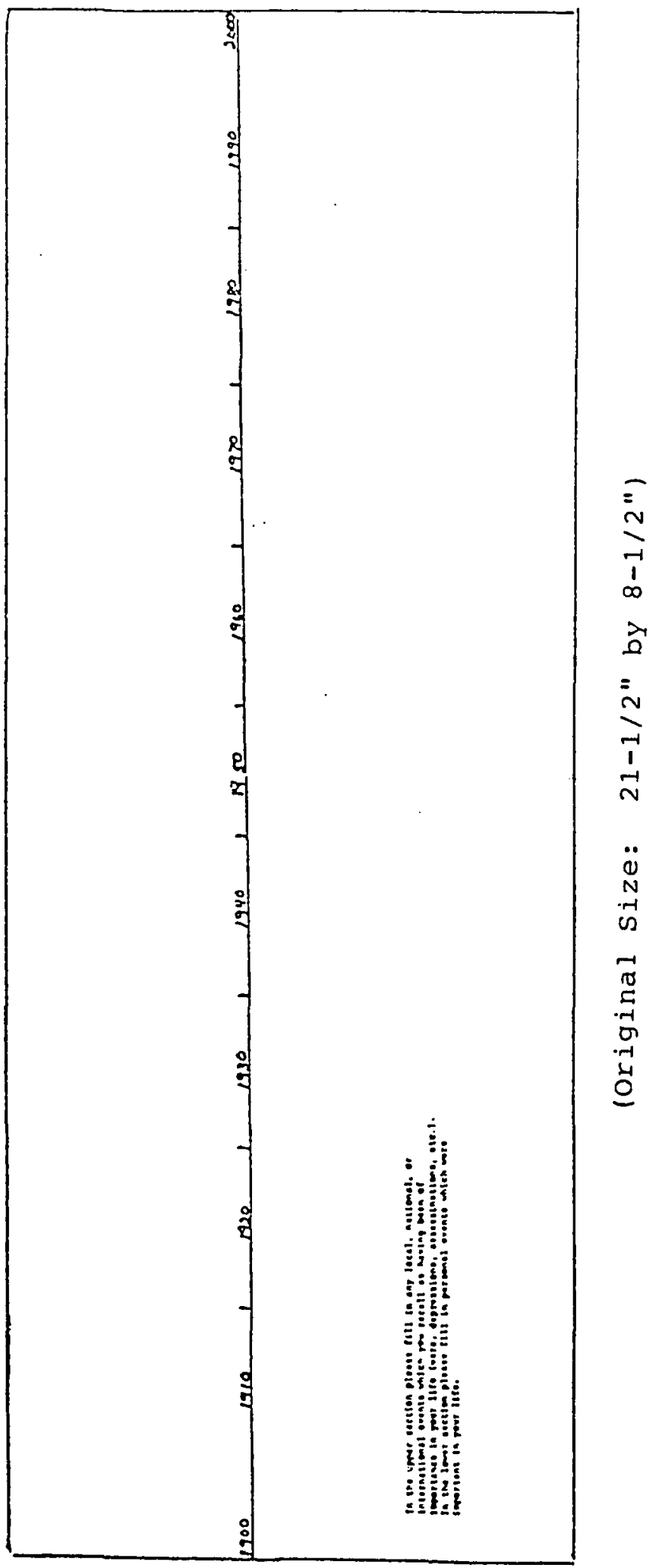


APPENDIX $F$

THANK YOU NOTE 
THANK YOU NOTE

(Original Size: $8-1 / 2^{\prime \prime}$ by $11 "$

Folded to: $4-1 / 4$ " by $5-1 / 2$ ")
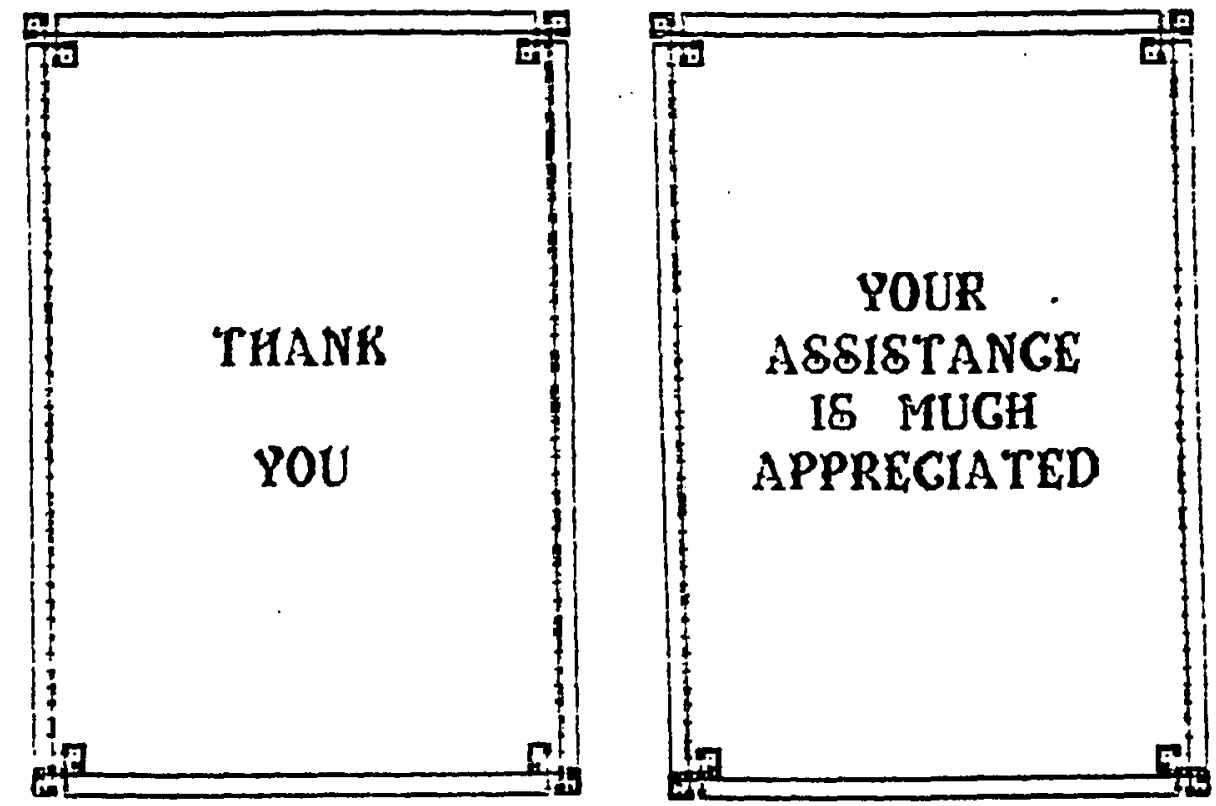
APPENDIX G

FOCUS GROUP DEMOGRAPHICS 
Focus Group Demographics

$$
\frac{1910-14}{\mathrm{~N}=13} \quad \frac{1915-19}{\mathrm{~N}=14} \quad \frac{1920-24}{\mathrm{~N}=14}
$$

Ethnic Background Europe/Canada America

Residence at Age 16

Same City

Same State

Different State

New England

Middle Atlantic

North Central

South Central

Pacific

$\begin{array}{lll}5 & 11 & 8\end{array}$

Highest Grade in School Completed 8 th grade

Some high school

High school

Some college

College

Post-graduate

\section{0}

1

4

0

8

$\begin{array}{ll}2 & 0 \\ 2 & 0 \\ 3 & 4 \\ 2 & 2 \\ 5 & 8\end{array}$

Father's Occupation

Professional, Technical

Sales and Clerical

Craftsmen, Operatives

Farmers and Laborers

Service Workers

0
0
5
5

0

1

1

2

7

0

3

2

4

0

0

4

2
8

Spouse's Occupation

Professional, Technical

Sales and Clerical

Craftsmen, Operatives

Farmers and Laborers

1

0
1
3
7
2
1

Participant's Occupation Professional, Technical Sales and Clerical Craftsmen, Operatives Service Workers

$\begin{array}{lll}4 & 6 & 2 \\ 3 & 5 & 5 \\ 6 & 3 & 5 \\ 0 & 0 & 2\end{array}$

$\begin{array}{lll}6 & 7 & 6 \\ 6 & 6 & 7 \\ 1 & 0 & 0 \\ 0 & 1 & 1\end{array}$


Focus Group Demographics

\begin{tabular}{|c|c|c|c|}
\hline & $\frac{1910-14}{N=13}$ & $\begin{array}{l}\text { Cohort } \\
\frac{1915-19}{\mathrm{~N}=14}\end{array}$ & $\frac{1920-24}{N=14}$ \\
\hline \multicolumn{4}{|l|}{ Economic Class } \\
\hline Lower & 1 & 0 & 1 \\
\hline Working & 3 & 5 & 7 \\
\hline Middle & 8 & 8 & 5 \\
\hline Upper & 1 & 1 & 0 \\
\hline \multicolumn{4}{|l|}{ Present Occupational Status } \\
\hline Working full time & 0 & 0 & 1 \\
\hline Working part time & 1 & 0 & 1 \\
\hline Retired & 10 & 12 & 12 \\
\hline Keeping house & 1 & 1 & 0 \\
\hline Other: Volunteer work & 1 & 1 & 0 \\
\hline \multicolumn{4}{|l|}{ Religious Preference } \\
\hline Catholic & 4 & 4 & 1 \\
\hline Jewish & 0 & 0 & 1 \\
\hline Protestant & 9 & 10 & $1 \overline{1}$ \\
\hline None & 0 & 0 & 1 \\
\hline \multicolumn{4}{|l|}{ Present Marital Status } \\
\hline Married & 3 & 3 & 4 \\
\hline Widowed & 9 & 6 & 4 \\
\hline Divorced & 1 & 3 & 5 \\
\hline Separated & 0 & 1 & 0 \\
\hline Never married & 0 & 1 & 1 \\
\hline \multicolumn{4}{|l|}{ Previously } \\
\hline Divorced & 2 & 0 & 3 \\
\hline Widowed & 1 & 2 & 1 \\
\hline \multicolumn{4}{|l|}{ Average number of children } \\
\hline to women ever married & 1.85 & 3.08 & 3.08 \\
\hline Children adopted & 2 & 3 & 0 \\
\hline \multicolumn{4}{|l|}{ Estimated Individual Income } \\
\hline$\$ 1,000-4,999$ & 2 & 0 & 1 \\
\hline $\begin{array}{r}5,000--9,999 \\
10,000--14,999\end{array}$ & $\begin{array}{l}3 \\
3\end{array}$ & $\begin{array}{l}7 \\
3\end{array}$ & $\begin{array}{l}2 \\
6\end{array}$ \\
\hline $15,000--19,999$ & 2 & 2 & 3 \\
\hline $20,000--24,999$ & 2 & 0 & 0 \\
\hline $25,000+$ & 1 & 2 & 1 \\
\hline No answer & 0 & 0 & 1 \\
\hline
\end{tabular}


APPENDIX $\mathrm{H}$

TALLY OF TIME LINE EVENTS 
Tally of Time Line Events

PUBLIC EVENTS

(Chronological order)

World War I

Estonian Revolution

Flu Epidemic

0

1

Lindbergh publicity

Flappers

Motion pictures

Radio

Depression

Roosevelt era

Spanish Civil war

World War II

Eisenhower president

TV beginning

Plane travel more common

Korean War

Cold War--McCarthyism

Kennedy era

Space voyages

Vietnam Conflict

King assassination

Drug scene

San Francisco earthquake

Berlin Wall down

Middle East crisis

Local Events

Celebrity Events

$$
\begin{array}{ll}
\text { Cohort } & \begin{array}{l}
\text { Co10-14 } \\
\mathrm{N}=13
\end{array} \\
\frac{1915-19}{\mathrm{~N}=14} & \frac{1920-24}{\mathrm{~N}=14}
\end{array}
$$


Tally of Time Line Events

$\begin{array}{ll}1910-14 & \begin{array}{l}\text { Cohort } \\ \mathrm{N}=13\end{array} \\ \frac{1915-19}{\mathrm{~N}=14} & \frac{1920-24}{\mathrm{~N}=14}\end{array}$

PERSONAL EVENTS

(Life stage order)

Schooling

11

11

10

Recreation

First radio

Movies

Electricity to town

0

0

Employment

Navy service

6

0

9

11

12

Children

Birth

Adoption

Education

Marriage

Raised 4 children alone

Grandchildren

$\begin{array}{ll}1 & 1 \\ 1 & 1 \\ 0 & 1\end{array}$

3

14

2

Deaths

Spouse

Children

Parents

Siblings

7

0

0

1

0

0

10

11

1

0

0

3

1

Divorce

3

1

0

0

1

1

1

Remarriage

0

Moved to different area

4

0

Homebuilding

0

\section{4}

1

6

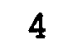

4

3

2

5

4

Travel

3

11

10

Retirement

4

4

Volunteer work

2

7

Il lnesses

3 
APPENDIX I

JOB DISCRIMINATION REPORTS 
JOB DISCRIMINATION REPORTS

Following is a transcript of a conversation among women of a 1920-24 cohort focus group on the subject of job discrimination because they were women.

B:

I can tell you about that! When I started at -- Bank and I already told you that I had had a number of years of banking experience, I took a man's job. I man had always had that job prior to me. They changed it just enough, just enough, and I can't support this, but I always had the feeling I was probably making about half as much money as he was making. At a later point, some 15 years later, there was a law-suit instituted by seven women based on similar things. So in order to fulfill the obligation of the lawsuit which -- Bank lost; but there was no money that changed hands, but one of the propositions of the loss of this lawsuit was they they had to institute a program to better realize the value of their women. They took all of us who had been hired prior to 1972, threw all this information into the computer; education, experience, whatever. out of this came 203 of us if we had been men would have been immediately hired for the management training program. At the time I was hired it never occurred to me to talk about the management training program. But today the women they think about it and they ask. We didn't even know to ask even though I had managed a S\&L office in CA. I didn't even ask to go on the management training program. We're not used to even asking for things. We just took what was handed to us.

E:

Years back the -- Telephone Company had a bad reputation. Women just-- What they actually said to your face was, "Why can't you think like a man?" And I remember it irked the very s--- out of me. I had the advantage of being married at that time and with a husband that could support me. So one day I rushed out and joined the union, which shocked my family to death. Because they didn't come from any labor ranks. I didn't know what I was doing. I just knew I didn't want that. So I went up in the ranks of the labor organization, to irritate the telephone company I guess. And I did a good job of it. Anyway I was elected officer and was sent back to Cleveland as chairman of the ---- delegation of the Communication Workers of America. Don't misunderstand me. I have no further ties with labor for a number of years. But there was a time and a place where labor was badly needed. I had no further trouble because in the end I opened my own business and was my own 
discriminator. Then, of course, in the nursing profession --no, nothing like that. Things have changed so much for the better in some ways, although I think that the labor unions ought to be cleaned up in some ways. We were pure motive people in those days. We had real goals and ideals. I met a lot of wonderful people. I should have mentioned that I took a management job (phone company) which was a true disaster because I was not trained that way and they were suspicious of me and when a work stoppage came along I was notified I would have to work. Turned out nobody stopped work. I was just in the wrong job so I resigned.

I :

Growing up in the same generation there was discrimination. As a photographer the women never went out with the camera. We were in the darkroom. Then when I worked for the optometrist he would have loved to have me go on to school and become an optometrist so I could work with him. This was something that came up about every month. "Don't you think you ought to go back to school?" There was no assistant because there was just the two of us. Then when I went to work for the Corps of Engineers, where I worked for over 30 years, I started out as a secretary and stayed secretary. But I had through the years always dealt with management so I had a lot of responsibility. But the girl that took my place immediately got a different title and two steps in grade because the change of time. There was a lot of discrimination because the Corps is 99 percent engineers and through the years each year there would be more women show up as engineers or trained in math. My own position, it wasn't really discriminatory because I didn't feel I had the background for it, so I didn't feel I was discriminated against.

$\mathrm{H}:$

I don't think I had the discrimination or maybe when I worked Ft. --- - because every buck private that came in thought he was better than the typist. While I worked they thought they were better and could order them around. Waitress in that it was mainly women, very few men--and the biggest discrimination was at the --- department store. I started out, at that time we started out $\$ 2$ an hour. The males that came in, regardless of what they knew or who they are, were put as head of departments. A man was put in the toy department as the manager, another man was put as head of the cosmetics department. It didn't matter where. A man was the manager. No women. There wasn't a woman manager in that store. The first year I worked there I was in men's wear, then transferred to a job called receiving department recording clerk, which was --I worked in that 15 years. During that time at separate times I had 
managed the area because the managers had quit from back there or been fired or was sick. But I was never asked to be the assistant manager until we had this one boss and then he offered it to me at $\$ 3$ an hour less than they paid a man to do it. So I refused it. Not too long after that he got fired. But that store was discriminatory.

$\mathrm{R}:$

I don't think I ran into much discrimination. I worked for the State of -.--- and this was pretty bad as far as I was corcerned. There were certain jobs that women were not allowed to do. And there was a time, I guess maybe the feminist movement had something to do with it, because all of a sudden the State had decided that women needed to be put into different positions, managerial positions. And they've gone the other way around where--this was after I retired, of course, but they were putting women now in managerial positions over a man who was more qualified than a woman now. So a lot of women doing a lot of jobs that they are not really qualified for simply because they are a woman. So it's more or less reverse discrimination now. Very much so. But I never really had any problems because I was a female, other than that. I did retire; I was glad to retire.

E:

Talking about discrimination, you know how there's something you kind of put in the back of your mind. There was something the telephone frowned on and did not want you to get--education. A man said to my friend, who later became way up in the company, "Why would you want to go to college? What for?" Now that was their attitude to young women in 1940 .

B:

It's because every firm had the idea that you came out of school and worked until you got married.

$R:$

You were supposed to get married.

B:

Yeah, that was the age for it.

E :

Do you remember even back then if you were married you were discriminated against for having been married and taking a single woman's job--you worthless person. 
$\mathrm{H}:$

I had a friend who was starting out, you know, and she got married, she was in advertising, and she had to go under Miss because it was so poorly thought of for you to take a job if you had a husband.

B:

Some firms were different from other firms. I had a friend that worked at the telephone company in (city name) who couldn't get married until after the war. The telephone company hired nobody but single women. If you got married you had to leave. Teaching school was the same thing, you had to be single. Even after the war, in the midwest women with children couldn't work.

I :

I had a friend who just recently died at 86 and in the services when they were talking about her life they mentioned that she was the one and only woman who they continued working, she got married in october, and they let her continue working the rest of the year. That was the first time in the history of that county that they had let a woman continue after she married. 